\title{
Upper Extremity Biomechanics and Gender: The Effects of Modern Computing Technologies
}

\section{Citation}

Coppola, Sarah Marie. 2019. Upper Extremity Biomechanics and Gender: The Effects of Modern Computing Technologies. Doctoral dissertation, Harvard T.H. Chan School of Public Health.

\section{Permanent link}

http://nrs.harvard.edu/urn-3:HUL.InstRepos:40976812

\section{Terms of Use}

This article was downloaded from Harvard University's DASH repository, and is made available under the terms and conditions applicable to Other Posted Material, as set forth at http:// nrs.harvard.edu/urn-3:HUL.InstRepos:dash.current.terms-of-use\#LAA

\section{Share Your Story}

The Harvard community has made this article openly available.

Please share how this access benefits you. Submit a story.

\section{Accessibility}


UPPER EXTREMITY BIOMECHANICS AND GENDER: THE EFFECTS OF MODERN COMPUTING TECHNOLOGIES

\title{
SARAH MARIE COPPOLA
}

\author{
A Dissertation Submitted to the Faculty of \\ The Harvard T.H. Chan School of Public Health \\ in Partial Fulfillment of the Requirements \\ for the Degree of Doctor of Science \\ in the Department of Environmental Health \\ Harvard University \\ Boston, Massachusetts.
}

May, 2019 


\title{
Upper extremity biomechanics and gender: the effects of modern computing technologies
}

\begin{abstract}
Statement of problem: Modern computing devices are often designed for a one size fits all approach, and consumers purchase devices based off of technical specifications rather than whether the devices fit them. These devices are often designed for men, and they require different postures, techniques, and levels of functional strength from women. Female sex/gender is associated with higher risks of upper extremity repetitive injury, which may be caused by both physiological and the psychosocial sex/gender differences as well as increased biomechanical exposure.
\end{abstract}

Methods: Short key travel mobile computers, touchscreen tablet computers, and traditional desktop workstations were investigated for sex/gender exposure bias. This dissertation utilized direct and indirect measures including electromyography, typing force, joint movement, and selfreported questionnaires to analyze modern technologies' effects on female and male participants. Small key travel mobile computers, touchscreen tablet computers, and traditional desktop workstations were investigated for sex/gender exposure bias.

Results: A typing study with four short travel keyboards showed that female participants are more affected by different key switch designs than male participants. A touchscreen thumb swiping study revealed that male and female participants were differently affected by tablet orientation but similarly affected by tablet size, swipe location, and swipe direction. An observational study with office workers showed that female participants used more significantly more forearm muscle activity and applied typing forces than male participants. 
Conclusion: The results from the three studies suggest that there is a sex/gender bias in biomechanical exposures when using modern technology. These results demonstrate the need to include both genders in usability testing for mobile technology and to consider individual differences when designing technologies. 


\section{Table of Contents}

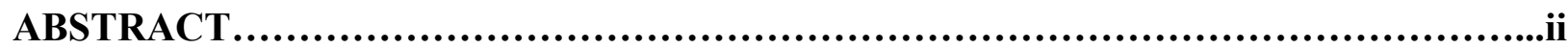

LIST OF FIGURES................................................................vi

LIST OF

TABLES..................................................................................vii

ACKNOWLEDGEMENTS..................................................................ix

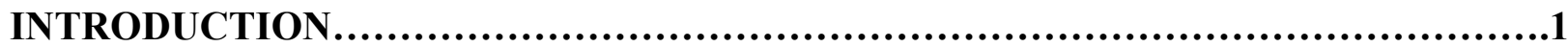

CHAPTER 1 Going short: the effects of short travel key switches on typing performance, typing force, forearm muscle activity, and user

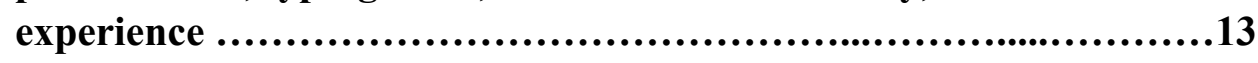

Abstract....................................................14

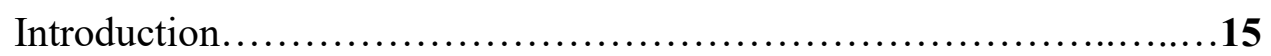

Methods.............................................................

Results....................................................23

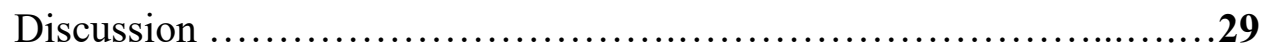

CHAPTER 2 Sex/Gender differences in thumb biomechanics and performance during two handed tablet use..........................................37

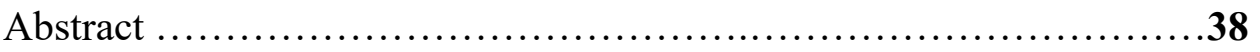

Introduction................................................

Methods..................................................42

Results.................................................47

Discussion ................................................61

CHAPTER 3 Sex/gender differences in upper extremity biomechanical exposures in office workers during an observational study $\ldots \ldots \ldots \ldots \ldots \ldots \ldots \ldots \ldots . . . . .70$

Abstract ...................................................

Introduction..................................................... 
Methods.

Results............................................................

Discussion..................................................93

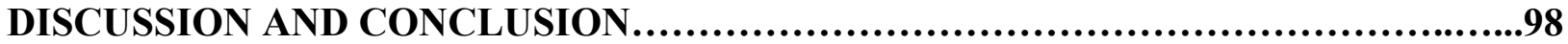




\section{List of Figures}

Figure 2.1 Portrait and landscape swipe locations on the screen. Thumb swipe lanes were indicated by a target bar $(10 \mathrm{~mm} \times 2 \mathrm{~mm})$ starting in the center edge of each of the four zones. Long vertical and horizontal swipes $(60 \mathrm{~mm})$ crossed zones and short horizontal swipes $(20 \mathrm{~mm})$ remained in one zone.

Figure 3.1 EMG plot for significant interactions $(\mathrm{p}<0.05)$ between task and sex/gender for extensor carpi radialis (ECR). Marginal means for \%MVC.

Figure 3.2 EMG plot for significant interactions $(\mathrm{p}<0.05)$ between task and sex/gender for left extensor carpi radialis (ECR). Marginal means for variation $\left(90^{\text {th }}-10^{\text {th }}\right) \% \mathrm{MVC}$. 


\section{List of Tables}

Table 1.1 Experimental Devices and Properties

Table 1.2 Across participant marginal means (and standard errors) for forearm electromyography $(\% \mathrm{MVC})$ and typing force.

Table 1.3 Performance: Across participant marginal means (and standard errors) during a 1 minute typing test.

Table 1.4 Self Report: Across participant marginal means (and standard errors) for selfreported discomfort and difficulty.

Table 1.5 Across participant marginal means (and standard errors) for electromyography (\%MVC) and typing force.

Table 1.6 Performance: Across participant marginal means (and standard errors) for adjusted speed (calculated as words typed minus errors) during a 1 minute typing test.

Table 1.7 Across participant marginal means (and standard errors) for self reported discomfort and difficulty.

Table 2.1 Anthropometric measures of means (standard deviations) across all participants

Table 2.2 a Combined Model Median Muscle Activity: Across participant marginal means (and standard errors) for surface electromyography (\%MVC).

Table 2.2 b Combined Model Median Muscle Activity: Across participant marginal means (and standard errors) for surface electromyography (\%MVC).

Table 2.2 c Combined Model Median Muscle Activity: Across participant marginal means (and standard errors) for surface electromyography (\%MVC).

Table 2.3 a Stratified Model Median Muscle Activity: Female across participant marginal means (and standard errors) for surface electromyography (\%MVC).

Table 2.3 b Stratified Model Median Muscle Activity: Female across participant marginal means (and standard errors) for surface electromyography (\%MVC).

Table 2.3 c Stratified Model Median Muscle Activity: Male across participant marginal means (and standard errors) for surface electromyography (\%MVC).

Table 2.3 d Stratified Model Median Muscle Activity: Male across participant marginal means (and standard errors) for surface electromyography (\%MVC).

Table 2.4 a Combined Model Average Performance: Across participant marginal means (and standard errors) for completion time.

Table 2.4 b Combined Model Average Performance: Across participant marginal means (and standard errors) for completion time. 
Table 2.4 c Combined Model Average Performance: Across participant marginal means (and standard errors) for completion time.

Table 2.5 a Stratified Model Median Performance: Across participant marginal means (and standard errors) for completion time

Table 2.5 b Stratified Model Median Performance: Across participant marginal means (and standard errors) for completion time

Table 2.6 Combined Model Self Report: Across participant marginal means (and standard errors) for discomfort and difficulty

Table 2.7 Stratified Model Self Report: Across participant marginal means (and standard errors) for discomfort and difficulty

Table 3.1 Participants' data

Table 3.2a Median Extensor Carpi Radialis and Trapezius Muscle Electromyography: Across participant marginal means (and standard errors) for $\% \mathrm{MVC}$.

Table 3.2b Median Wrist and Shoulder Posture: Across participant marginal means (and standard errors) for degrees.

Table 3.2c Median Head, Neck, and Torso Posture: Across participant marginal means (and standard errors) for degrees.

Table 3.3a Variability Extensor Carpi Radialis and Trapezius Muscle Electromyography: Across participant marginal means (and standard errors) for \%MVC.

Table 3.3b Variability Wrist and Shoulder Posture: Across participant marginal means (and standard errors) for degrees.

Table 3.3c Variability Head, Neck, and Torso Posture: Across participant marginal means (and standard errors) for degrees.

Table 3.4 Mean Wrist Velocity and Acceleration: Across participant marginal means (and standard errors).

Table 3.5 Applied Mouse and Keyboard Forces: Across participant marginal means (and standard errors) for \%maximum voluntary force. 


\section{Acknowledgments}

I would like to thank everyone who supported me in my graduate work. It is a strange problem to reflect on all the people who have so richly blessed my life and to realize that there are far too many to list.

Jack Dennerlein has been an important mentor since I was first considering ergonomics and he invited me to visit his lab to learn more about his work. Thank you for the opportunity to work in your lab and the encouragement to grow as a researcher.

I would also like to thank my committee members Paul Catalano and David Lombardi for their support and helpful statistical expertise on this dissertation.

Robert Herrick, Diana Ceballos Ochoa, and Emily Sparer were also helpful educators and mentors. Thank you for your encouragement and input.

The Northeastern Occupational Biomechanics and Ergonomics Laboratory has been a wonderful support over the last four years. I'd especially like to thank Phil Dixon and Boyi Hu for being amazing team members through a lot of challenges- truly this work would not have been possible without you. I'd also like to thank Michael Lin for his mentorship and collaboration and all of the rest of the biomechanics team for help with experiments. Thank you also to all those who have overlapped in lab over the years including Luz Marin, Lauren Murphy, Hao Trieu, Dan Weinstein, Whitney Huynh, Nick Green, John Schilkowsky, Calvin Liang, Julia Rhyins, Emily Man, Alice Loukianova, Alvin Liu, Mike Grant, Aubrie Sanchez, Don Meglio, Andrea Sheldon, Jamie Tessler, Ying Loo, Elisabetta Decillis, and Lauren Bigger for the coffee runs, photoshoots, awful music sing-alongs, dance parties, procrastination spirals, and ranting sessions. 
The Tufts Human Factors community first taught me how to be a researcher and how to take the risk to study something so personally meaningful. I'd especially like to thank Dan Hannon and the Center for Engineering Education and Outreach.

Wentworth Institute's Industrial Design department has been a great creative outlet to grow as an educator and learn insights into ergonomics from diverse creative perspectives. Thank you especially to Derek Cascio for being such a great teammate and colleague turned friend when I ended up with a cast on my foot and needed so much help getting around.

Thank you to my neighbors at the Regal. Living with you all has been one of the best decisions I've made. Thank you for the reminders about what really matters in life and for inviting me into your families. Life on crutches was so much easier with such amazing neighbors. I will miss our talks, walks, and commutes.

The best part about being a Harvard student is getting to meet such amazing scholars from all over the world. My classmates at HSPH have been amazing and supportive friends. Vy and Bora, thank you for all of the solidarity, homework help, and coffee rants these last 4 years. I can't imagine doing grad school without you. Christine, thank you for all that you do to serve our community, being a commuting buddy, and someone who just gets it. To the others who've overlapped during these last 4 years, including Sebastian, Sarah, Gabe, Feiby, Maria, Alex, Liz, Tiffany, Adrian, Mary, and Aisha, thank you for your friendship and support. Thank you also to the EPI cafeteria crew who adopted me into your cohort when I had none. I'd also like to thank my friends across Harvard from HGCF and the graduate student union for making this experience so rich and fulfilling. 
With graduate school years bookended by serious injuries and a few minor ones in between, I quite literally could not have survived without the support of my friends. Thank you to my friends near and far, for all of the late-night conversations, coffee breaks, prayers, pep talks, and for teaching me about community. Thank you Megan, for being my sartorial expert, singing partner, and the person who picks me up from urgent care- truly you have gone beyond the normal bounds of friendship. Kelsie, thank you for going through grad school first, and providing solidarity and perspective in the stresses of research and navigating academia. We may live on different coasts, but I will always consider you my roommate. Danielle, from elementary school poodle skirts to grad school mixers, I am so happy our paths intersected in Boston during these years. Thank you for your friendship through so many stages of life. Latoya, we've come so far from the days we were teaching high school and had no idea what we were doing. Thank you for being such a constant in my life. Thank you Marya, for the solidarity through these last 6 years of grad school. I've appreciated your input on research, teaching, and all the other life things all these years. Thank you to my Corvallis family, especially Dusty and Jody, who took care of me when I was first injured and helped me apply to grad school, move across the country, and who have provided helpful perspective about the world outside of graduate school. And to anyone not listed here, please know that your friendship has meant the world to me.

My dog Moose deserves a co-author credit for his faithful watch during my writing retreats.

Nothing I have ever achieved would have been possible without my family who taught me the importance of leaving the world better than I found it. Thank you for the support, guidance, and encouragement and for teaching me independence while also always being a safe place to return.

To whom much is given, much is expected. 
Introduction 
Technology use is prevalent among developed countries, and the proliferation of mobile computing technologies is increasing the amount of time people spend using it (Anderson, 2015). In the United States, $73 \%$ of the population owns a computer, $53 \%$ own a tablet, and $77 \%$ own a smart phone (Center, 2018). A first principle in the field of Human Factors and Ergonomics seeks to design safe and efficient tools and systems that fit humans; however, people often use keyboards, mice, and touchscreens without matching device design to personal anthropometry. This current one size fits all approach to design may expose some people to greater injury risk than others (Yamauchi, Seo, Jett, Parks, \& Casady, 2015).

Previous epidemiological studies have found an association between traditional desktop computer use and MSDs; however, less is known about population-level risks with modern devices such as laptops, tablets, and smartphones (Gerr et al., 2002; Hagberg, Vilhemsson, Tornqvist, \& Toomingas, 2007; Marcus et al., 2002; K Messing, Stock, \& Tissot, 2009). Technological device designs require repetitive motions, static muscle loads, and extreme postures, which are known risk factors for upper-limb musculoskeletal pain and injury (Cook, Burgess-Limerick, \& Chang, 2000). Musculoskeletal pain and disorders (MSDs) are prevalent among workers, accounting for up to one third of occupational injuries and $\$ 1.84$ billion in direct costs in the U.S (Liberty Mutual, 2018; OSHA). Unlike more traditional desktop computing devices, mobile technologies do not provide support for the upper limbs which may cause more awkward postures and injury risk (Toh, Coenen, Howie, \& Straker, 2017; Xie, Szeto, \& Dai, 2017).

The specific design characteristics of technology can influence musculoskeletal loads, and higher muscle activity and typing forces are associated with muscle fatigue, discomfort, and injury risk (Kim, Aulck, Bartha, Harper, \& Johnson, 2014; Marcus et al., 2002). Previous studies 
have shown that aspects of input devices such as key travel distance, activation force, key size, tactile feedback, and location can affect muscle activity and typing/mousing forces (Gerard, Armstrong, Franzblau, Martin, \& Rempel, 1999; F. J. Lee, Mcloone, Kotani, \& Dennerlein, 2007; Radwin \& Ruffalo, 1999). Newer computing devices have slim profiles and small travel distances that are outside the known range of travel distances in the literature. These microdistances need to be evaluated for upper limb muscle use, typing force, and typing performance.

Similarly, touchscreen devices such as tablets and smartphones have been previously studied for the impact of no key travel distance on typing and upper extremity posture and muscle use (D. L. Lee, Kuo, Jindrich, \& Dennerlein, 2009; Trudeau, Catalano, Jindrich, \& Dennerlein, 2013). Tablets are generally held, causing muscle loads (Gustafsson, Johnson, Lindegård, \& Hagberg, 2011; Trudeau, Asakawa, Jindrich, \& Dennerlein, 2016). Studies have shown associations between the type of gesture required and the impact on the thumb, wrist and forearm (Trudeau et al., 2013). Others have looked at the impact of anthropometry on ability to interact with parts of a screen (Odell \& Chandrasekaran, 2012; Pereira, Miller, Huang, Odell, \& Rempel, 2013).

Sex/Gender is an important risk factor for technology-related musculoskeletal pain (Coté, 2011). Studies of computer workers have found higher rates of upper extremity disorders and injury in women as compared to men (Gerr et al., 2002; Hagberg et al., 2007; Hooftman, van der Beek, Bongers, \& van Mechelen, 2009; Lassen, Mikkelsen, Kryger, \& Andersen, 2005; Paksaichol, Janwantanakul, Purepong, Pensri, \& van der Beek, 2012; Punnett \& Bergqvist, 1999; Treaster \& Burr, 2004; Wahlstedt, Norback, Wieslander, Skoglund, \& Runeson, 2010). However, the reasons behind these observed differences are complicated and involve the 
complex interaction between individual factors, harmful exposures, and women's multiple roles (Karen Messing, 2012).

Physical capabilities likely explain some of the increased injury risk for women. Women on average have less upper limb muscle strength and aerobic capacity (Faber, Hansen, \& Christensen, 2006) and have to use higher percentages of their maximum voluntary contractions to perform the same tasks as men(Haward \& Griffin, 2002; Meyland et al., 2014; Mogk \& Keir, 2003; Nordander et al., 2008). Other studies have shown that women activate more accessory muscles and fewer primary muscle groups than men in an isometric task at $50 \%$ maximum force (Anders, Bretschneider, Bernsdorf, Erler, \& Schneider, 2004). A study of the shoulder muscles during a repetitive mousing task showed sex/gender differences in movement and fatigue strategies, which might explain the difference in injury rates (Fedorowich, Emery, Gervasi, \& Coté, 2012). Similarly, other studies have shown that women use different biomechanical strategies and recruit muscles and connective tissues differently to accomplish physically demanding tasks (Gillespie, Herbert, \& Punnett, 2012). However, when controlling for body weight and fat composition, the sex/gender difference in static strength is reduced (Chatigny, Maria Seifert, \& Messing, 1995). In addition, while connective tissues do have sex hormone receptors, the influence of hormones on musculoskeletal injury risk is poorly understood (Gillespie et al., 2012).

Psychosocial factors may also explain some of the observed sex/gender differences in clinical outcomes. Work is gender segregated, and women are more likely to work in jobs that require repetitive upper extremity tasks (L. M. Anderson \& Stellman, 2012; Josephson et al., 1999; McDiarmid, Oliver, Ruser, \& Gucer, 2000). Even in jobs that are considered "gender neutral", specific tasks are often assigned by gender (Gillespie et al., 2012). Historically, 
women's work has been less studied because it was considered lower risk for acute injury and therefore injuries in women were attributed to their frailty (Habib \& Messing, 2012; K. Messing, 1997; Karen Messing, 2012). While men are more likely to sustain serious or fatal occupational injuries (Islam, Velilla, Doyle, \& Ducatman, 2001), the rates of occupational injury are underreported by workers' compensation claims, and women have many barriers to reporting and receiving workers' compensation claims (Cox \& Lippel, 2008). Women are also more likely to be engaged in precarious employment with poor job control and security and higher rates of workplace harassment, all of which are associated with upper extremity MSDs (Campos-Serna, Ronda-Perez, Artazcoz, Moen, \& Benavides, 2013; Lippel, Vézina, Bourbonnais, \& Funes, 2016; K Messing et al., 2009). Women are also more likely to perform physical domestic work around the home (Mannino \& Deutsch, 2007). Historically, "women's work" in the informal and domestic spheres was not considered real work, so safety intervention and compensation were limited (Lippel, 2003; Karen Messing, 2012; Stellman, Lucas, \& Anderson, 2012). For example, De Quervain's tenosynovitis was associated with housework and therefore considered "nonoccupational" (Moore, 1997). The psychosocial factors of work also vary with other individual characteristics such as race, age, and immigration status.

Tools, workstations, and ergonomic interventions have been primarily designed for men of European descent and are poorly adapted for women (Gillespie et al., 2012; Stellman et al., 2012). This causes different exposures because women use different postures, techniques, and functional strength to complete the same task, and these differences may be even greater for nonEuropean populations whose anthropometry is on average smaller than the European populations' anthropometry (Coté, 2011; K Messing \& Mager Stellman, 2006; Stellman et al., 2012) When using the same technological devices, women may be exposed to more 
biomechanical stress than men. For example, Won, Johnson, Punnett \& Dennerlein (2009) investigated gender differences in a study of 15 women and 15 men in a repeated-measures study with five standardized computer tasks, with multiple mouse locations for one of the tasks. Women had higher relative applied forces to the keyboard and mouse, as well as higher EMG readings in the extensor carpi radialis muscle (ECR) and flexor carpi radialis. They also had higher trapezius muscle activity, though this was not statistically significant. In addition, the female participants had more degrees of wrist flexion, external rotation, and wrist extension, which is consistent with the EMG readings.

The term sex/gender is used throughout this dissertation because while the two are different, they are intertwined in studies of ergonomics and biomechanics (Coté, 2011; K Messing \& Mager Stellman, 2006). The US Institute of Medicine defines sex as "the classification of living things generally as either male or female, according to their reproductive organs and functions assigned by the chromosomal complement" and gender as "a person's selfrepresentation as male or female, or how that person is responded to by social institutions on the basis of the individual's gender presentation"(Institute of Medicine . Committee on Understanding the Biology of Sex and Gender, 2001). Similarly, the World Health Organization defines sex as "genetic/physiological or biological characteristics of a person which indicates whether one is female or male" and gender as “women's and men's roles and responsibilities that are socially determined" (Health, 1998). People's physiology, biology, and experienced environments are intertwined, and have important synergistic effects on health (Fausto-Sterling, 2000). There are cultural gender norms around occupation, exercise, and eating patterns, which all interact with a person's individual characteristics. Thus, this dissertation follows the 
convention in the literature and uses sex/gender. A limitation of this dissertation is that while gender exists on a spectrum, this dissertation analyzes sex/gender as a binary.

\section{Dissertation goals}

The overall goal of this dissertation is to examine whether there is a sex/gender bias in the design of modern computing technologies that leads to different upper extremity exposures in women and men. Specifically, this dissertation aims to determine if different software and hardware designs affect women's and men's upper extremity biomechanics and self-reported experience differently. To accomplish this, three studies of modern computing technologies including mobile computers, desktop computers, and tablet devices were conducted in both laboratory and field settings. Knowing whether there is a sex/gender difference in upper extremity exposures will help to better explain the observed increased upper extremity injury and pain in women as compared to men. In addition, quantifying the sex/gender differences in technology exposures will allow for better design and usage guidelines.

\section{Chapter 1}

Chapter 1 determines ultra-thin mobile computers' effect on typing biomechanics in men and women. A repeated measures laboratory experiment analyzed four commercially available small key travel distance keyboard designs and sex/gender's effect on forearm muscle electromyography, typing force, and self-reported discomfort and difficulty. Twenty (10 female and 10 male) subjects performed typing tasks on each keyboard in a counterbalanced order. This is one of the first experiments to assess keyboards that are outside the recommended key travel range and can aid in developing guidelines for the design of future mobile computing devices. 


\section{Chapter 2}

Chapter 2 determines the sex/gender differences in thumb biomechanics during swiping tasks on a touchscreen tablet computer. A repeated measures laboratory experiment analyzed different tablet hardware and software designs' effects on upper extremity biomechanics, performance, and self-reported experience. Sixteen ( 8 female and 8 male) subjects performed swipes which varied in direction, orientation, and location on two different tablets. This study's results show the importance of including women in user testing during the design stage and the importance of considering different users in technological design.

\section{Chapter 3}

Chapter 3 determines sex/gender differences in an observational field study of 117 office workers at their own work desks. The study analyzed sex/gender differences in upper extremity muscle activity, postures, and movement during computing tasks. This chapter's results help to better explain the sex/gender differences in exposures to modern computing technology. 


\section{References}

Anders, C., Bretschneider, S., Bernsdorf, A., Erler, K., \& Schneider, W. (2004). Activation of shoulder muscles in healthy men and women under isometric conditions. Journal of Electromyography and Kinesiology, 699-707.

Anderson, L. M., \& Stellman, J. M. (2012). Working Women in the United States: A Statistical Profile. In M. B. Goldman, K. M. Rexrode, \& R. Troisi (Eds.), Women and Health: Elsevier Science \& Technology.

Anderson, M. (2015, October 29). Technology Device Ownership: 2015. Pew Research Center.

Campos-Serna, J., Ronda-Perez, E., Artazcoz, L., Moen, B., \& Benavides, F. (2013). Gender inequalities in occupational health related to the unequal distribution of working and employment conditions: a systematic review. Int. J. Equity Health, 12(1). doi:10.1186/1475-9276-12-57

Center, P. R. (2018). Mobile Fact Sheet. Retrieved from http://www.pewinternet.org/factsheet/mobile/

Chatigny, C., Maria Seifert, A., \& Messing, K. (1995). Repetitive Strain in Nonrepetitive Work: A Case Study. International Journal of Occupational Safety and Ergonomics, 1(1), 4251. doi:10.1080/10803548.1995.11076303

Cook, C., Burgess-Limerick, R., \& Chang, S. (2000). The prevalence of neck and upper extremity musculoskeletal symptoms in computer mouse users. Industrial Ergonomics, 347-356.

Coté, J. N. (2011). A critical review on physical factors and functional characteristics that explain a sex/gender difference in work-relatedneck/shoulder disorders. Ergonomics, 55:2, 173-182.

Cox, R., \& Lippel, K. (2008). Falling through the Legal Cracks: The Pitfalls of Using Workers Compensation Data as Indicators of Work-Related Injuries and Illnesses. Policy and Practice in Health and Safety, 6(2), 9-30. doi:10.1080/14774003.2008.11667721

Faber, A., Hansen, K., \& Christensen, H. (2006). Muscle strength and of aerobic capacity in a representative sample of employees with and without repetitive monotonous work. International Archives of Occupational and Environmental Health, 33-41.

Fausto-Sterling, A. (2000). Sexing the body gender politics and the construction of sexuality. In ProQuest (Ed.). New York, NY: New York, NY : Basic Books.

Fedorowich, L., Emery, K., Gervasi, B., \& Coté, J. N. (2012). Gender differences in neck/shoulder muscular patterns in response to repetitive motion induced fatigue. Journal of Electromyography and Kinesiology, 1183-1189.

Gerard, M. J., Armstrong, A., Franzblau, B. J., Martin, D. M., \& Rempel, D. M. (1999). The effect of keyswitch stiffness on typing force, finger electromyography, and subjective discomfort. American Industrial Hygiene Association Journal, 762-769.

Gerr, F., Marcus, M., Ensor, C., Kleinbaum, D., Cohen, S., Edwards, A., \& Monteilh, C. (2002). A prospective study of computer users: I. Study design and incidence of musculoskeletal symptoms in disorders. American Journal of Industrial Medicine, 41(4), 221-235.

Gillespie, R. M., Herbert, R., \& Punnett, L. (2012). Work-Related Musculoskeletal Disorders. In M. B. Goldman, K. M. Rexrode, \& R. Troisi (Eds.), Women and Health: Elsevier Science \& Technology. 
Gustafsson, E., Johnson, P. W., Lindegård, A., \& Hagberg, M. (2011). Technique, muscle activity and kinematic differences in young adults texting on mobile phones. Ergonomics, 54(5), 477-487. doi:10.1080/00140139.2011.568634

Habib, R. R., \& Messing, K. (2012). Gender, women's work and ergonomics. Ergonomics, 55, 129-132.

Hagberg, M., Vilhemsson, R., Tornqvist, E. W., \& Toomingas, A. (2007). Incidence of selfreported reduced productivity owing to musculoskeletal symptoms: association with workplace and individual factors among computer users. Ergonomics, 1820-1834.

Haward, B., \& Griffin, M. (2002). Repeatability of grip strength and dexterity tests and the effects of age and gender. International Archives of Occupational and Envirionmental Health, 111-119.

Health, W. H. O. D. o. F. a. R. (1998). Gender and health: technical paper. Geneva Retrieved from http://www.who.int/iris/handle/10665/63998

Hooftman, W. E., van der Beek, A. J., Bongers, P. M., \& van Mechelen, W. (2009). Is there gender difference in the effect of work related physical and psychosocial risk factors on musculoskeletal symptoms in related sickness absence. Scandinavian Journal of Work, Environment, and Health, 85-95.

Institute of Medicine . Committee on Understanding the Biology of Sex and Gender, D. (2001). Exploring the biological contributions to human health does sex matter? In T. M. Wizemann, M. L. Pardue, \& ProQuest (Eds.). Washington, D.C.: Washington, D.C. : National Academy Press.

Islam, S. S., Velilla, A. M., Doyle, E. J., \& Ducatman, A. M. (2001). Gender differences in work-related injury/illness: Analysis of workers compensation claims. American Journal of Industrial Medicine, 39(1), 84-91. doi:10.1002/1097-0274(200101)39:1<84::AIDAJIM8>3.0.CO;2-T

Josephson, M., Pernold, G., Ahlberg-Hultén, G., Härenstam, A., Theorell, T., Vingård, E., . . . Study Group, M.-N. (1999). Differences in the Association Between Psychosocial Work Conditions and Physical Work Load in Female- and Male-Dominated Occupations. American Industrial Hygiene Association Journal, 60(5), 673-678. doi:10.1080/00028899908984490

Kim, J. H., Aulck, L., Bartha, M. C., Harper, C. A., \& Johnson, P. W. (2014). Differences in typing forces, muscle activity, comfort, and typing performance among virtual, notebook, and desktop keyboards. Applied Ergonomics, 1406-1413.

Lassen, C. F., Mikkelsen, S., Kryger, A. I., \& Andersen, J. H. (2005). Risk factors for persistent elbow, forearm, and hand pain among computer workers. Scandinavian Journal of Work, 31(2), 122-131.

Lee, D. L., Kuo, P. L., Jindrich, D. L., \& Dennerlein, J. T. (2009). Computer keyswitch forcedisplacement characteristics affect muscle activity patterns during index finger tapping. Journal of Electromyography and Kinesiology, 810-820.

Lee, F. J., Mcloone, H. E., Kotani, K., \& Dennerlein, J. T. (2007). Alternative computer mouse design and testing to reduce finger extensor muscle activity during mouse use. Human Factors, 573-584.

Liberty Mutual Research Institute for Safety Releases 2014 Workplace Safety Index [press release]. (2015). Liberty Mutual Group. 
Lippel, K. (2003). Compensation for Musculoskeletal Disorders in Quebec: Systemic Discrimination against Women Workers? International Journal of Health Services, 33(2), 253-281. doi:10.2190/JPQD-RT1G-QKTK-JF2R

Lippel, K., Vézina, M., Bourbonnais, R., \& Funes, A. (2016). Workplace psychological harassment: Gendered exposures and implications for policy. International Journal of Law and Psychiatry, 46, 74-87. doi:10.1016/j.ijlp.2016.05.001

Mannino, C., \& Deutsch, F. (2007). Changing the Division of Household Labor: A Negotiated Process Between Partners. A Journal of Research, 56(5), 309-324. doi:10.1007/s11199006-9181-1

Marcus, M., Gerr, F., Monteilh, C., Ortiz, D. J., Gentry, E., Cohen, S., . . Kleinbaum, D. (2002). A prospectie study of computer users: II. Postural risk factors for musculoskeletal sympotms and disorders. American Journal of Industrial Medicine, 236-249.

McDiarmid, M., Oliver, M., Ruser, J., \& Gucer, P. (2000). Male and Female Rate Differences in Carpal Tunnel Syndrome Injuries: Personal Attributes or Job Tasks? Environmental Research, 83(1), 23-32. doi:10.1006/enrs.2000.4042

Messing, K. (1997). Women's occupational health: a critical review and discussion of current issues. Women \& health, 25(4), 39. doi:10.1300/J013v25n04 03

Messing, K. (2012). Multiple Roles and Complex Exposures. In M. B. Goldman, K. M. Rexrode, \& R. Troisi (Eds.), Women and Health: Elsevier Science \& Technology.

Messing, K., \& Mager Stellman, J. (2006). Sex, gender and women's occupational health: The importance of considering mechanism. Environmental Research, 101(2), 149-162.

Messing, K., Stock, S. R., \& Tissot, F. (2009). Should studies of risk factors for musculoskeletal disorders be stratified by gender? Lessons from the 1998 Quebec health and social survey. Scandinavian Journal of Work and Environmental Health, 96-112.

Meyland, J., Heilskov-Hansen, T., Alkjær, T., Koblauch, H., Mikkelsen, S., Svendsen, S., .. . Simonsen, E. (2014). Sex differences in muscular load among house painters performing identical work tasks. European Journal of Applied Physiology, 114(9), 1901-1911. doi:10.1007/s00421-014-2918-6

Mogk, J., \& Keir, P. (2003). The effects of posture on forearm muscle loading during gripping. Ergonomics, 956-975.

Moore, J. S. (1997). De Quervain's tenosynovitis. Stenosing tenosynovitis of the first dorsal compartment. Journal of occupational and environmental medicine, 39(10), 990. doi:10.1097/00043764-199710000-00011

Mutual, L. (2018). Workplace Safety Index. Retrieved from https://business.libertymutualgroup.com/businessinsurance/Documents/Services/Workplace\%20Safety\%20Index.pdf

Nordander, C., Ohlsson, K., Balogh, I., Hansson, G.-Å., Axmon, A., Persson, R., \& Skerfving, S. (2008). Gender differences in workers with identical repetitive industrial tasks: exposure and musculoskeletal disorders. International Archives of Occupational and Environmental Health, 81(8), 939-947. doi:10.1007/s00420-007-0286-9

Odell, D., \& Chandrasekaran, V. (2012). Enabling comfortable thumb interaction in tablet computers: a Windows 8 case study. Paper presented at the HFES, Boston.

OSHA. Ergonomics.

Paksaichol, A., Janwantanakul, P., Purepong, N., Pensri, P., \& van der Beek, A. J. (2012). Office workers' risk factors for the development of non-specific neck pain: a systematic review of prospective cohort studies. Occupational and Environmental Medicine, 610-618. 
Pereira, A., Miller, T., Huang, Y., Odell, D., \& Rempel, D. (2013). Holding a tablet computer with one hand: effect of tablet design features on biomechanics and subjective usability among users with small hands. Ergonomics.

Prevention of Musculoskeletal Disorders in the Workplace. Occupational Safety and Health Administration. Retrieved from https:/www.osha.gov/SLTC/ergonomics/

Punnett, L., \& Bergqvist, U. (1999). Musculoskeletal disorders in visual display unit work: gender and work demands. Occupational medicine (Philadelphia, Pa.), 14(1), 113.

Radwin, R. G., \& Ruffalo, B. A. (1999). Computer key switch force- displacement characteristics and short term effects on localized fatigue. Ergonomics, 160-170.

Stellman, J. M., Lucas, A., \& Anderson, L. M. (2012). International Perspectives: Women's Occupational Health. In M. B. Goldman, K. M. Rexrode, \& R. Troisi (Eds.): Elsevier Science \& Technology.

Toh, S., Coenen, P., Howie, E., \& Straker, L. (2017). The associations of mobile touch screen device use with musculoskeletal symptoms and exposures: A systematic review. PLoS One, 12(8). doi:10.1371/journal.pone.0181220

Treaster, D., \& Burr, D. (2004). Gender differences in prevalence of upper extremity musculoskeletal disorders. Ergonomics, 47(5), 495-526.

Trudeau, M., Asakawa, D. S., Jindrich, D., \& Dennerlein, J. T. (2016). Two-handed grip on a mobile phone affords greater thumb motor performance, decreased variability, and a more extended thumb posture than a one-handed grip. Applied Ergonomics.

Trudeau, M., Catalano, P., Jindrich, J., \& Dennerlein, J. (2013). Tablet Keyboard Configuration Affects Performance, Discomfort and Task Difficulty for Thumb Typing in a TwoHanded Grip. PLoS One.

Wahlstedt, K., Norback, D., Wieslander, G., Skoglund, L., \& Runeson, R. (2010). Psychosocial and ergonomics factors, and their relation to musculoskeletal complaints in the Swedish workforce. International Journal of Occupational Safety and Ergonomics, 311-321.

Won, E. J., Johnson, P. W., Punnett, L., \& Dennerlein, J. T. (2009). Upper extremity biomechanics in computer tasks differ by gender. Journal of Electromyography and Kinesiology, 19(3), 428-436.

Xie, Y., Szeto, G., \& Dai, J. (2017). Prevalence and risk factors associated with musculoskeletal complaints among users of mobile handheld devices: A systematic review. Applied Ergonomics, 59(Pt A), 132-142. doi:10.1016/j.apergo.2016.08.020

Yamauchi, T., Seo, J. H., Jett, N., Parks, G., \& Casady, B. (2015). Gender differences in mouse and cursor movements. International Journal of Human-Computer Interactions. 


\section{Chapter 1}

Going short: the effects of short travel key switches on typing performance, typing force, forearm muscle activity, and user experience

Published in Journal of Applied Biomechanics 35(2): 149-156 


\begin{abstract}
This study examined the effects of four micro-travel keyboards on forearm muscle activity, typing force, typing performance, and self-reported discomfort and difficulty. Twenty participants completed typing tasks on four commercially available devices with different key switch characteristics (dome, scissors, and butterfly) and key travels $(0.55,1.3$, and $1.6 \mathrm{~mm})$. The device with short travel $(0.55 \mathrm{~mm})$ and a dome type key switch mechanism was associated with higher muscle activities $(6-8 \%, \mathrm{p}<0.01)$, higher typing force $(12 \%, \mathrm{p}<0.001)$, slower typing speeds $(8 \%, p<0.01)$, and twice as much discomfort $(\mathrm{p}<0.05)$, compared to the three other devices: short travel $(0.55 \mathrm{~mm})$ and butterfly switch design and long travel $(1.3$ and $1.6 \mathrm{~mm})$ with scissor key switches. Participants rated the devices with larger travels (1.3 and $1.6 \mathrm{~mm})$ with least discomfort $(\mathrm{p}=0.015)$ and difficulty $(\mathrm{p}<0.001)$. When stratified by sex/gender, these observed associations were larger and more significant in the female participants compared to male participants. The devices with similar travel but different key switch designs had differences in outcomes but devices with different travel were not statistically different. These results suggest that key travel alone does not predict typing force or muscle activity.
\end{abstract}

\title{
Keywords
}

Mobile computing, biomechanics, tablet, notebook, keyboard 


\section{Introduction}

Today's lightweight notebook and tablet computers employ thinner keyboards than earlier models. These designs must sacrifice key travel distance as evidenced by new devices with key travel distances lying outside the current 1.5-6.0 mm standards(HFES, 2007). For example, the Microsoft Surface Pro 4's keyboard has $1.3 \mathrm{~mm}$ travel. Standards such as ISO-9241 (Ergonomics of Human-Computer Interaction) and ANSI/ HFES 100 (Human Factors Engineering of Computer Workstations) provide guidelines for the design and development of desktop and laptop computers but may not be relevant for modern devices. Studies comparing external tablet keyboard attachments to the no-travel, on-screen keyboards have demonstrated better performance with attached keyboard use (Chaparro, Phan, \& Jardina, 2013; Varcholik, LaViola, \& Hughes, 2012). However, the effects of these new short travel key designs on upper extremity muscle activity and typing force are unknown.

Keyboard design characteristics including key travel distance (Radwin \& Ruffalo, 1999), key size (Pereira, Hsieh, Laroche, \& Rempel, 2014), activation force(Armstrong, Foulke, Martin, Gerson, \& Rempel, 1994; Gerard, Armstrong, Franzblau, Martin, \& Rempel, 1999; Gerard, Armstrong, Foulke, \& Martin, 1996; Martin, Armstrong, Reed, Dennerlein, \& Rempel, 1994; Rempel et al., 1997), feedback (Chaparro, Phan, Siu, \& Jardina, 2014) key switch mechanism(Asundi \& Odell, 2011), and key location(Qin, Trudeau, Katz, Buchholz, \& Dennerlein, 2011) can affect muscle activity, typing force, and typing performance. However, most of these previous studies were conducted using regular desktop keyboards with travel distances within the recommended range of 1.5-6.0 $\mathrm{mm}$ and with dome or linear spring switches.

Key switch force-displacement is an important consideration for musculoskeletal symptoms. Ripat et al.(2006) randomly assigned symptomatic typists to use the same 
commercially available split keyboard (Ziba) in either its normal ( $0.36 \mathrm{~N}$ activation force, 2.8 $\mathrm{mm}$ travel) or modified ( $0.36 \mathrm{~N}$ activation force, $0.2 \mathrm{~mm}$ travel) design over 24 weeks and found similar improvements from baseline in clinical symptoms and satisfaction in both groups. In addition, symptomatic typists have been shown to type with higher typing forces than those without pain, though typing forces were measured after symptom onset which limits the ability to assign causality (Feuerstein, Armstrong, Hickey, \& Lincoln, 1997; Marcus et al., 2002; Pascarelli \& Kella, 1993). Higher activation force keyboards are generally associated with higher typing force (Bufton, Maklin, Nagurka, \& Simoneau, 2006; Gerard et al., 1996) and higher muscle activity (Gerard et al., 1999; Rempel et al., 1997).

The key switch mechanism has also been shown to affect upper extremity biomechanics, user experience, and forearm musculoskeletal symptoms (Chaparro et al., 2014; Gerard et al., 1996; Jindrich, Balakrishnan, \& Dennerlein, 2004; Rempel, Tittiranonda, Burastero, Hudes, \& So, 1999). Gerard et al.(1999) found that a buckle spring keyboard with $0.72 \mathrm{~N}$ activation force resulted in less typing force and muscle activity than $0.56 \mathrm{~N}$ and $0.83 \mathrm{~N}$ activation force elastomer dome keyboards, and similar typing force and muscle activity when compared to a $0.28 \mathrm{~N}$ activation force elastomer dome keyboard. Participants also preferred the buckle spring keyboard, though this was confounded because it was the keyboard they typically used. In contrast, Bufton et al.(2006) found higher typing forces were associated with a $0.86 \mathrm{~N}$ buckle spring keyboard compared to a $0.68 \mathrm{~N}$ elastomer dome keyboard. In order to achieve thinner designs, many mobile keyboards have abandoned spring and dome keyboards for scissor and butterfly switches (Comparing Mechanical, Membrane and Scissor-Switch Membrane Keyboards - Ergonomic Considerations of Keyswitch Type, 2013; Cunningham, 2016). 
A few studies with micro-travel keyboards (here defined as shorter than the recommended minimum 2.0 mm key travel) (Kia, Sisley, Johnson, \& Kim, 2019; Sisley, Kia, Johnson, \& Kim, 2017) have shown an association between shorter key travel and reduced muscle activity, typing force, performance, and self-reported typing user experience (Chaparro et al., 2014; Hoyle, Bartha, Harper, \& Peres, 2013; Hughes \& Johnson, 2014; Kim, Aulck, Bartha, Harper, \& Johnson, 2014). Chaparro et al. (2014) found that participants typed faster and preferred micro-travel mechanical keyboards over a pressure-sensing no-travel keyboard, but they did not measure any typing forces or muscle activity. Similarly, Hoyle et al. (2013) found better performance and user experience ratings were associated with moderate micro-travel (1.6 and $2.0 \mathrm{~mm}$ ) keyboards over very short $(0.4 \mathrm{~mm})$ and no-travel keyboards. Kim et al. (2014) measured upper extremity muscle activity, typing force, and performance for no-travel, microtravel $(1.8 \mathrm{~mm})$, and standard-travel $(4.0 \mathrm{~mm})$ keyboards, and found higher muscle activity and typing forces were associated with larger key travel. Kia et al. (2019) recently tested five commercially available micro-travel tablet, notebook, and desktop keyboards $(0.5-2.0 \mathrm{~mm})$, and found decreased flexor muscle activity, increased typing forces, decreased ulnar deviation, and increased typing performance was associated with increasing travel distance. However, these differences were relatively small and may be related to unmeasured keyboard factors as the devices did not share the same form factors.

Moreover, few of these studies have examined the effects on specific individual characteristics such as sex/gender, anthropometry, and strength. Past studies have demonstrated higher associations between typing biomechanics (Won, Johnson, Punnett, \& Dennerlein, 2009) and technology-related pain and injury (Coté, 2011) in women as compared to men. As such, the 
difference in the effects of mobile computing devices and micro-travel keyboards across sex/gender needs further investigation.

More investigation is necessary to understand micro-travel's effects on human health and performance in order to provide design guidance. The purpose of the current study was to investigate the effects of four different micro-travel keyboards on forearm muscle activity, typing force, typing performance, and self-reported discomfort and difficulty. In addition, the study sought to investigate if the effects of micro-travel distance keyboards differed between male and female participants. The study tested the null hypotheses that no significant differences will be observed in outcome measures across devices with different key-travel and key-force displacement characteristics and that the same trend will be observed in both male and female participants.

\section{Methods}

The study was a repeated measures laboratory experiment comparing four different commercially-available keyboards with small key travel distance with equal number of male and female participants to examine the effect on forearm muscle activity, typing force, typing performance, and self-reported discomfort and difficulty across all participants and within each sex/gender.

\section{Study Population}

Twenty participants, balanced for sex/gender, were recruited from the local community. Inclusion criteria for participants were: greater than 21 years of age, perfect or corrected vision, ability to touch type 30 words/minute, English language proficiency, and no history of upper extremity musculoskeletal pain or injury. Female participants ranged in age from 21 to 33 years 
(average \pm standard deviation: $27 \pm 3$ years), in stature from 153 to $180 \mathrm{~cm}(168 \pm 3 \mathrm{~cm})$, in grip strength from 177 to $314 \mathrm{~N}(245 \pm 39 \mathrm{~N})$. Male participants ranged in age from 21 to 32 years (average \pm standard deviation): $(27 \pm 4)$ years, in stature 169 to $186 \mathrm{~cm}:(179 \pm 5) \mathrm{cm}$, in grip strength 255 to $481 \mathrm{~N}(373 \pm 69 \mathrm{~N}))$. Of the 20 participants, 19 (10 female, 9 male) self-reported to be right-handed. Right hand grip strength was measured using a hand strength dynamometer (Stoelting, Inc., Wooddale, IL, USA) in supinated position with an extended elbow. Participants were coached to grip as hard as possible three times without breaks, and the highest measure was used. All protocols were approved by the local IRB and all participants provided written informed consent before participating.

\section{Experimental Tasks}

Participants completed two typing tasks for each of the four devices. The first typing task was a one minute typing test on an online typing test program (Typing Speed Test, TypingMaster, Inc.). For the second task, participants typed for three minutes to transcribe up to three news articles, depending on their typing pace, into a word processor. The chosen articles were on current events and written for an 11-14 year old audience. This was meant to simulate more average typing tasks such as writing an email without inducing fatigue, and participants were asked to type at their normal pace. During the typing tasks, participants sat upright on an armless, backed office task chair with their feet flat on the floor and their thighs parallel to the ground. The monitor was adjusted such that the top of the screen was aligned with the participant's eyes, and the center was aligned with his/her sternum, and the horizontal distance was the same for all participants. All participants used the same monitor, and brightness and light settings were kept constant for all participants. The devices were placed on a force platform on a desk such that they were centered with the monitor and the gap between the G and $\mathrm{H}$ keys was 
aligned with the participant's sternum. The desk's height was adjusted using visual inspection so that the keyboards were approximately at elbow height with approximately ninety-degree elbow flexion and neutral wrists.

Independent Variable: Device

Each participant typed on four commercially-available micro-travel devices (Table 1.1), each with a different combination of key-travel, short (S) or long (L), and mechanism (dome, butterfly, or scissor). The devices were Tablet S $(0.55 \mathrm{~mm})$ : Apple iPad Pro (Apple Inc, Cupertino, CA), Notebook S (0.55mm): Apple MacBook Pro (Apple Inc, Cupertino, CA), Tablet L (1.3 mm): Surface Pro 4 (Microsoft Corporation, Redmond, WA), and Notebook L (1.6 mm): Microsoft SurfaceBook (Microsoft Corporation, Redmond, WA). These were chosen for their different key travel distances and mechanisms as well as their current commercial availability. The order of the devices tested was randomized and counterbalanced within sex/gender across the 20 participants. Participants typed on each keyboard for five minutes before the trials in order to become comfortable and acclimated to the devices.

Table 1.1: Experimental Devices and Properties

\begin{tabular}{|l|c|c|c|c|}
\hline Brand & $\begin{array}{c}\text { Tablet S } \\
\text { (short) }\end{array}$ & $\begin{array}{c}\text { Notebook S } \\
\text { (short) }\end{array}$ & $\begin{array}{c}\text { Tablet L } \\
\text { (long) }\end{array}$ & $\begin{array}{c}\text { Notebook L } \\
\text { (long) }\end{array}$ \\
\hline Model & Apple Inc. & Apple Inc. & $\begin{array}{c}\text { Microsoft } \\
\text { Corporation }\end{array}$ & $\begin{array}{c}\text { Microsoft } \\
\text { Corporation }\end{array}$ \\
\hline Year & iPad® Pro & Macbook $®$ Pro & Surface® Pro 4 & $\begin{array}{c}\text { Surface } \\
\text { Book }\end{array}$ \\
\hline Travel & 2016 & 2016 & 2015 & 2016 \\
\hline Switch Mechanism & $0.55 \mathrm{~mm}$ & $0.55 \mathrm{~mm}$ & $1.30 \mathrm{~mm}$ & $1.60 \mathrm{~mm}$ \\
\hline Force & Dome & Butterfly & Scissor & Scissor \\
\hline Key Length x Width & $1.5 \times 1.83 \mathrm{~g}$ & $60-70 \mathrm{~g}$ & $60-70 \mathrm{~g}$ & $60-70 \mathrm{~g}$ \\
\hline Space between keys & $0.4 \mathrm{~cm}$ & $1.7 \times 1.6 \mathrm{~cm}$ & $1.6 \times 1.5 \mathrm{~cm}$ & $1.5 \times 1.5 \mathrm{~cm}$ \\
\hline
\end{tabular}




\section{Dependent Variables: Muscle Activity}

Study outcomes included the normalized median amplitude of electromyography signals of six (6) right forearm muscles: the extensor carpi radialis (ECR), extensor carpi ulnaris (ECU), extensor digitorum (ED), flexor carpi radialis (FCR), flexor carpi ulnaris (FCU), and flexor digitorum superficialis (FDS). Only the right-side was tested because previous research has shown no significant differences in muscle activities between the right and left arm during typing (Bruno Garza et al., 2012). After cleaning each participant's right forearm with alcohol and abrading with an exfoliating sponge to reduce impedance, bipolar electromyography sensors were mounted on the muscle bellies as identified through palpation and asking the participant to do demonstrative movements while the researcher provided resistance (Lin, Young, \& Dennerlein, 2015; Perotto, 1994). Delsys 8 Bagnoli system (Delsys, Natick, USA) measured, filtered, and amplified the EMG signals prior to their recording on a personal computer at 2000 samples per second using a USB A-to-D backplanes (NI cDAQ-9172; National Instruments, Austin, USA). Post-processing of the signals in Matlab (The Mathworks, Inc., Natick, MA, USA) included rectifying the signal and then second-order low pass filtering at $3 \mathrm{HZ}$ (single pole) (Dixon, Loh, Michaud-Paquette, \& Pearsall, 2017; Hoozemans \& van Dieën, 2005; Lin et al., 2015).

Prior to the typing tasks protocols and data collection, participants performed maximum voluntary contractions (MVC) for each muscle resisted by trained experimenters in order to normalize the amplitude of the electromyographic signals. For each contraction, participants were instructed to ramp up to their maximum muscle output, and each MVC was collected for 3 seconds, 3 times with at least 2 minutes of rest between trials. The highest 1-second average amplitude of the processed EMG signal during the three 3-second trials provided the MVC value for each 
muscle. The median value for each muscle's EMG signal was calculated for the middle 30 seconds of the typing test and the middle two minutes for the long form typing task to avoid discrepancies caused at the beginning or end of the task.

\section{Dependent Variable: Typing Force}

The median typing force was measured by custom force platform under each keyboard (Won, 2009; Dixon, 2017). The platform had three miniature compression load cells (ELFF-B410L; Measurement Specialties, Hampton, VA, $9.55 \mathrm{mV}^{*} \mathrm{~N}^{-1}, 44.48 \mathrm{~N}$ max) mounted underneath it in a triangular pattern. A USB backplane (NI cDAQ-9172; National Instruments, Austin, USA) powered, amplified, and sampled the signal from each of the three load cells at 2,000 samples per second. Post processing of the data included band-pass filtering (1-20 Hz, 6th order Butterworth filter) to remove noise and wrist contact using the biomechZoo toolbox in Matlab (The Mathworks, Inc., Natick, MA,USA) and custom Matlab code. When unloaded the root mean square value of sensor noise was $0.0063 \mathrm{~N}$. Normalized force was calculated as typing

force divided by grip strength. The median value for each signal was calculated for the middle 30 seconds of the typing test and the middle two minutes for the long form typing task to capture sustained typing and avoid discrepancies caused at the beginning or end of the task.

\section{Dependent Variable: Typing Performance}

For the timed typing test task, typing performance was measured in words per minute (WPM). The computer software provided a measure of typing performance in words per minute. An adjusted typing score was also calculated by the software by subtracting the number of errors from the total words typed. 
Dependent Variable: Perceived Experience

Participants self-reported discomfort and difficulty with each keyboard after each trial. After each new device, participants received 2 paper $10 \mathrm{~cm}$ visual analog scales which asked them to mark between 0 and 10 where 0 was "no discomfort" and 10 was "a lot of discomfort", and 0 for "no difficulty" and 10 for "a lot of difficulty".

Statistical Analysis

A repeated measures ANOVA for each dependent study outcome tested the null hypothesis followed by Tukey's post-hoc comparison for each keyboard design. Individual ANOVA models estimated the 6 muscles' median \%MVC, median typing force, median normalized force, typing speed, adjusted typing speed, discomfort, and difficulty. The muscle activity and typing force models included participants as a random effect, and device and typing task as fixed effects, while the performance and experience models did not include typing task. In addition to the models for all participants, separate models were stratified across the two sex/gender groups to examine the effects of device within sex/gender (Härenstam, 2009; Messing \& Mager Stellman, 2006; Messing, Stock, \& Tissot, 2009). Significance criteria for the F statistic (alpha value) was set at 0.05 . When a significant effect was found, a post-hoc analysis with Tukey HSD provided between group comparisons.

\section{Results}

Forearm extensor (ECR, ED, ECU) muscle activity did vary significantly across the devices with less median muscle activity $(\mathrm{p}<0.01)$ on Notebook S, Tablet L, and Notebook L compared to Tablet $\mathrm{S}$ (Table 1.2). No significant differences were observed for the forearm flexor muscles (FDS, FCU, FCR). The timed typing test was associated with significantly higher 
muscle activity across all of the muscles tested than the long form transcription task $(\mathrm{p}<0.001)$. No significant two-way interaction effects were observed between device and task.

Typing force varied significantly across devices (Table 1.2) with Tablet $\mathrm{S}$ associated with significantly higher median typing force compared to the other devices $(\mathrm{p}<0.001)$. The timed typing test was associated with significantly higher typing force than the long form transcription task $(\mathrm{p}<0.001)$. No significant two-way interaction effects were observed between device and task.

Typing speed also varied significantly across devices with slower typing speeds for Tablet $\mathrm{S}$ compared to Notebook L and Notebook $\mathrm{S}(\mathrm{p}=0.004)$ (Table 1.3). After adjusting for typing errors, the significant difference remained $(p=0.004)$. Notebook $L$ was also associated with a faster average adjusted typing speed (72 WPM) compared to Tablet S (64 WPM) tablet device $(\mathrm{p}=0.004)$. Adjusted speeds on Tablet $\mathrm{L}$ and Notebook $\mathrm{S}$ were not significantly different from adjusted speeds on Tablet S and Notebook L. 
Table 1.2: Across participant marginal means (and standard errors) for forearm electromyography $(\% M V C)$ and typing force.

\begin{tabular}{|c|c|c|c|c|c|}
\hline \multicolumn{6}{|c|}{ Keyboard Device } \\
\hline & $\begin{array}{l}\text { P } \\
\text { Value }^{1,2}\end{array}$ & Tablet S & Notebook S & Tablet L & Notebook L \\
\hline \multicolumn{6}{|l|}{$\begin{array}{l}\text { Median EMG } \\
\% M V C\end{array}$} \\
\hline ECR & 0.001 & $4.5^{\mathrm{A}}(0.49)$ & $4.2^{\mathrm{B}}(0.49)$ & $4.2^{\mathrm{B}}(0.49)$ & $4.4^{\mathrm{AB}}(0.5)$ \\
\hline ED & $<0.001$ & $8.1^{\mathrm{A}}(0.77)$ & $7.3^{\mathrm{B}}(0.77)$ & $7.5^{\mathrm{B}}(0.77)$ & $7.7^{\mathrm{B}}(0.8)$ \\
\hline $\mathbf{E C U}$ & 0.006 & $7.8^{\mathrm{A}}(0.84)$ & $7.2^{\mathrm{B}}(0.84)$ & $7.2^{\mathrm{B} 0}(.84)$ & $7.3^{\mathrm{B}}(0.8)$ \\
\hline FDS & 0.105 & $3.0(0.36)$ & $2.7(0.36)$ & $3.0(0.36)$ & $2.8(0.4)$ \\
\hline FCU & 0.607 & $2.6(0.53)$ & $2.6(0.53)$ & $2.7(0.53)$ & $2.6(0.5)$ \\
\hline FCR & 0.116 & $2.3(0.32)$ & $2.1(0.32)$ & $2.3(0.32)$ & $2.3(0.3)$ \\
\hline \multicolumn{6}{|l|}{$\begin{array}{l}\text { Median Typing } \\
\text { Force }\end{array}$} \\
\hline Newtons & $<0.001$ & $0.47^{\mathrm{A}}(0.02)$ & $0.42^{\mathrm{B}}(0.02)$ & $0.42^{\mathrm{B}}(0.02)$ & $0.42^{\mathrm{B}}(0.02)$ \\
\hline Normalized (\%) & $<0.001$ & $3.5^{\mathrm{A}}(0.3)$ & $3.2^{\mathrm{B}}(0.3)$ & $3.1^{\mathrm{B}}(0.3)$ & $3.2^{\mathrm{B}}(0.3)$ \\
\hline
\end{tabular}

${ }^{1}$ Repeated Measures ANOVA with participant as a random variable, Keyboard Device (4 levels), Typing Task (2 levels). Bold values indicate a significant effect $(p<0.05)$.

${ }^{2}$ For significant main effects, Tukey's Post-Hoc groupings are ranked such that $A>B>C>D$.

Values with the same superscript letters indicate no significant difference

Table 1.3: Performance: Across participant marginal means (and standard errors) during a 1 minute typing test.

\begin{tabular}{|lccccc|}
\hline \multicolumn{7}{|c|}{ Keyboard Devices } \\
\hline & P Value $^{1,2}$ & Tablet S & Notebook S & Tablet L & Notebook L \\
$\begin{array}{l}\text { Total Speed (WPM) } \\
\begin{array}{l}\text { Adjusted Speed } \\
\text { (WPM) }\end{array}\end{array}$ & $\mathbf{0 . 0 0 4}$ & $67^{\mathrm{B}}(4)$ & $73^{\mathrm{A}}(4)$ & $72^{\mathrm{AB}}(4)$ & $75^{\mathrm{A}}(4)$ \\
& $\mathbf{0 . 0 0 4}$ & $64^{\mathrm{B}}(4)$ & $70^{\mathrm{AB}}(4)$ & $69^{\mathrm{AB}}(4)$ & $72^{\mathrm{A}}(4)$ \\
\hline
\end{tabular}

${ }^{1}$ Repeated Measures ANOVA with participant as a random variable and keyboard device (4 levels). Bold values indicate a significant effect $(p<0.05)$.

${ }^{2}$ For significant main effects, Tukey's Post-Hoc groupings are ranked such that $\mathrm{A}>\mathrm{B}>\mathrm{C}>\mathrm{D}$. Values with the same superscript letters indicate no significant difference.

${ }^{3}$ Adjusted speed calculated as Total Speed- Errors.

The self-reported questionnaire revealed significant differences in perceived discomfort and difficulty across the devices (Table 1.4). Participants rated Notebook L with least discomfort, however this was only significantly different $(\mathrm{p}=0.0148)$ from Tablet $\mathrm{S}$. For 
difficulty, participants rated Notebook L least difficult, followed by Tablet L. These difficulty ratings were significantly lower $(\mathrm{p}<0.001)$ than Tablet $\mathrm{S}$.

Table 1.4: Self Report: Across participant marginal means (and standard errors) for selfreported discomfort and difficulty.

\begin{tabular}{|lccccc|}
\hline \multicolumn{5}{c|}{ Keyboard Devices } \\
\hline & P Value $^{1,2}$ & Tablet S & Notebook S & Tablet L & Notebook L \\
Discomfort & $\mathbf{0 . 0 1 5}$ & $3.05^{\mathrm{A}}$ & $1.53^{\mathrm{AB}}$ & $1.44^{\mathrm{AB}}(0.45)$ & $1.07^{\mathrm{B}}(0.45)$ \\
$\mathbf{( c m )}$ & & $(0.45)$ & $(0.45)$ & & \\
Difficulty & $<\mathbf{0 . 0 0 1}$ & $4.80^{\mathrm{A}}$ & $3.17^{\mathrm{AB}}$ & $2.05^{\mathrm{B}}(0.48)$ & $1.99^{\mathrm{B}}(0.48)$ \\
$(\mathbf{c m})$ & $(0.48)$ & $(0.48)$ & & \\
\hline
\end{tabular}

${ }^{1}$ Repeated Measures ANOVA with participant as a random variable and keyboard device (4 levels). Bold values indicate a significant effect $(p<0.05)$.

${ }^{2}$ For significant main effects, Tukey's Post-Hoc groupings are ranked such that $A>B>C>D$. Values with the same superscript letters indicate no significant difference.

The effects of device on forearm muscle activity showed similar trends with both sex/gender groups; however, statistical significance was present for almost all of the muscles in the female participants and for only one muscle in the male participants (Table 1.5). Five (ECR, ED, ECU, FDS, FCR) of the six muscles tested showed significant differences $(p<0.05)$ across the four devices in female participants compared to only one $(\mathrm{ED})(\mathrm{p}=0.009)$ in male participants (Table 5). Tablet S induced greater forearm muscle activity than the other three devices for both female and male participants.

The devices' effects on typing force showed similar trends and significance in both groups (Table 1.5). Tablet $\mathrm{S}$ was associated with more absolute and normalized typing force than the other devices in both female and male participants, though a more significant result was observed for female normalized force than male normalized force $(p<0.001$ vs. $p=0.019)$. 
Table 1.5: Across participant marginal means (and standard errors) for electromyography $(\% M V C)$ and typing force.

\begin{tabular}{|c|c|c|c|c|c|}
\hline \multicolumn{6}{|c|}{ Keyboard Device } \\
\hline & $\begin{array}{c}\text { P- } \\
\text { Value }\end{array}$ & Tablet S & Notebook S & Tablet L & Notebook L \\
\hline \multicolumn{6}{|l|}{$\begin{array}{l}\text { Median EMG } \\
\% \text { MVC }\end{array}$} \\
\hline \multicolumn{6}{|l|}{ Females } \\
\hline ECR & 0.003 & $4.7^{\mathrm{A}}(0.76)$ & $4.3^{\mathrm{B}}(0.76)$ & $4.4^{\mathrm{B}}(0.76)$ & $4.5^{\mathrm{AB}}(0.76)$ \\
\hline ED & $<0.001$ & $7.6^{\mathrm{A}}(1.0)$ & $6.7^{\mathrm{B}}(1.0)$ & $6.8^{\mathrm{B}}(1.0)$ & $6.9^{\mathrm{B}}(1.0)$ \\
\hline $\mathbf{E C U}$ & 0.009 & $8.4^{\mathrm{A}}(1.4)$ & $7.3^{\mathrm{B}}(1.4)$ & $7.4^{\mathrm{B}}(1.4)$ & $7.5^{\mathrm{AB}}(1.4)$ \\
\hline FDS & 0.033 & $3.9(0.61)$ & $3.2(0.61)$ & $3.8(0.61)$ & $3.4(0.61)$ \\
\hline FCU & 0.388 & $3.4(0.90)$ & $3.2(0.90)$ & $3.6(0.90)$ & $3.3(0.90)$ \\
\hline FCR & 0.005 & $2.8^{\mathrm{A}}(0.40)$ & $2.4^{\mathrm{B}}(0.40)$ & $2.6^{\mathrm{AB}}(0.40)$ & $2.6^{\mathrm{AB}}(0.40)$ \\
\hline \multicolumn{6}{|l|}{ Males } \\
\hline ECR & 0.179 & $4.3(0.66)$ & $4.2(0.66)$ & $4.1(0.66)$ & $4.2(0.66)$ \\
\hline ED & 0.009 & $8.7^{\mathrm{A}}(1.14)$ & $7.9^{\mathrm{B}}(1.14)$ & $8.1^{\mathrm{AB}}(1.14)$ & $8.5^{\mathrm{AB}}(1.14)$ \\
\hline $\mathbf{E C U}$ & 0.588 & $7.3(0.97)$ & $7.1(0.97)$ & $7.1(0.97)$ & $7.0(0.97)$ \\
\hline FDS & 0.853 & $2.1(0.27)$ & $2.1(0.27)$ & $2.1(0.27)$ & $2.2(0.27)$ \\
\hline FCU & 0.991 & $1.9(0.51)$ & $1.9(0.51)$ & $1.9(0.51)$ & $1.9(0.51)$ \\
\hline FCR & 0.419 & $1.8(0.49)$ & $1.9(0.49)$ & $1.9(0.49)$ & $1.9(0.49)$ \\
\hline $\begin{array}{l}\text { Median Typing } \\
\text { Force }\end{array}$ & & & & & \\
\hline Females & & & & & \\
\hline \multirow{2}{*}{$\begin{array}{r}\text { Newtons } \\
\text { Normalized } \\
(\%)\end{array}$} & $<0.001$ & $0.46^{\mathrm{A}}(0.03)$ & $0.41^{\mathrm{B}}(0.03)$ & $0.39^{\mathrm{B}}(0.03)$ & $0.41^{\mathrm{B}}(0.03)$ \\
\hline & $<0.001$ & $4.2^{\mathrm{A}}(0.35)$ & $3.7^{\mathrm{B}}(0.35)$ & $3.7^{\mathrm{B}}(0.35)$ & $3.5^{\mathrm{B}}(0.35)$ \\
\hline \multicolumn{6}{|l|}{ Males } \\
\hline Newtons & 0.003 & $0.48^{\mathrm{A}}(0.03)$ & $0.43^{\mathrm{B}}(0.03)$ & $0.46^{\mathrm{AB}}(0.03)$ & $0.44^{\mathrm{B}}(0.03)$ \\
\hline $\begin{array}{r}\text { Normalized } \\
(\%)\end{array}$ & 0.019 & $2.9^{\mathrm{A}}(0.35)$ & $2.7^{\mathrm{B}}(0.35)$ & $2.7^{\mathrm{AB}}(0.35)$ & $2.8^{\mathrm{AB}}(0.35)$ \\
\hline
\end{tabular}

${ }^{1}$ Repeated Measures ANOVA with participant as a random variable, Keyboard Device (4 levels), Typing Task (2 levels). Bold values indicate a significant effect $(p<0.05)$.

${ }^{2}$ For significant main effects, Tukey's Post-Hoc groupings are ranked such that $A>B>C>D$. Values with the same superscript letters indicate no significant difference

Both groups performed similarly across the four devices with slowest performance achieved on Tablet $\mathrm{S}(\mathrm{p}<0.05)$ (Table 1.6). Female participants typed fastest on Notebook L in terms of both total speed $(\mathrm{p}=0.021)$ and adjusted speed $(\mathrm{p}=0.034)$, whereas male participants typed fastest on Notebook $\mathrm{S}$ for total speed $(\mathrm{p}=0.023)$ and adjusted speed $(\mathrm{p}=0.013)$.

After stratifying by sex/gender, fewer differences across devices were observed for selfreported discomfort and difficulty (Table 1.7). Only difficulty in male participants showed 
significant differences $(p=0.01)$ with Tablet $\mathrm{S}$ rated significantly more difficult than Tablet $\mathrm{L}$ and Notebook L. 
Table 1.6: Performance: Across participant marginal means (and standard errors) for adjusted speed (calculated as words typed minus errors) during a 1 minute typing test.

\begin{tabular}{|c|c|c|c|c|c|}
\hline \multicolumn{6}{|c|}{ Keyboard Devices } \\
\hline & $\begin{array}{c}\mathrm{P} \\
\text { Value }^{1,2}\end{array}$ & Tablet S & Notebook S & Tablet L & Notebook L \\
\hline \multicolumn{6}{|l|}{ Total Speed (WPM) } \\
\hline Females & 0.021 & $68^{\mathrm{B}}(6)$ & $70^{\mathrm{AB}}(6)$ & $69^{\mathrm{AB}}(6)$ & $76^{\mathrm{A}}(6)$ \\
\hline Males & 0.023 & $67^{\mathrm{B}}(7)$ & $76^{\mathrm{A}}(7)$ & $75^{\mathrm{AB}}(7)$ & $74^{\mathrm{AB}}(7)$ \\
\hline \multicolumn{6}{|l|}{$\begin{array}{l}\text { Adjusted Speed } \\
\text { (WPM) }\end{array}$} \\
\hline Females & 0.034 & $66^{\mathrm{A}}(6)$ & $67^{\mathrm{A}}(6)$ & $66^{\mathrm{A}}(6)$ & $73^{A}(6)$ \\
\hline Males & 0.013 & $62^{\mathrm{B}}(6)$ & $72^{\mathrm{A}}(6)$ & $72^{\mathrm{A}}(6)$ & $72^{\mathrm{A}}(6)$ \\
\hline
\end{tabular}

${ }^{1}$ Repeated Measures ANOVA with participant as a random variable and keyboard device (4 levels). Bold values indicate a significant effect $(p<0.05)$.

${ }^{2}$ For significant main effects, Tukey's Post-Hoc groupings are ranked such that $\mathrm{A}>\mathrm{B}>\mathrm{C}>\mathrm{D}$. Values with the same superscript letters indicate no significant difference

Table 1.7: Across participant marginal means (and standard errors) for self reported discomfort and difficulty.

\begin{tabular}{|cccccc|}
\hline \multicolumn{6}{|c|}{ Keyboard Devices } \\
\hline & $\begin{array}{c}\text { P Value } \\
\text { Female }\end{array}$ & Tablet S & Notebook S & Tablet L & Notebook L \\
Discomfort & 0.143 & $2.88(0.64)$ & $1.09(0.64)$ & $1.03(0.64)$ & $1.16(0.64)$ \\
Difficulty & 0.054 & $5.08(0.75)$ & $3.54(0.75)$ & $2.58(0.75)$ & $2.24(0.75)$ \\
Male & & & & & \\
Discomfort & 0.288 & $3.17(0.63)$ & $1.82(0.63)$ & $1.71(0.63)$ & $1.01(0.63)$ \\
Difficulty & $\mathbf{0 . 0 0 9}$ & $4.61^{\mathrm{A}}(0.65)$ & $2.93^{\mathrm{AB}}(0.65)$ & $1.70^{\mathrm{B}}(0.65)$ & $1.82^{\mathrm{B}}(0.65)$ \\
\hline
\end{tabular}

${ }^{1}$ Repeated Measures ANOVA with participant as a random variable and keyboard device (4 levels). Bold values indicate a significant effect $(p<0.05)$.

${ }^{2}$ For significant main effects, Tukey's Post-Hoc groupings are ranked such that $A>B>C>D$. Values with the same superscript letters indicate no significant difference.

\section{Discussion}

In response to the widespread availability and use of thinner keyboards, the goal of this study was to examine the effects of different key travels and key switch mechanisms currently available in thinner keyboards on forearm muscle activity, typing force, typing performance, and 
self-reported discomfort and difficulty. Device significantly affected biomechanical outcomes, and the differences across devices were similar for all four outcomes: Tablet S with short travel and a dome type key switch mechanism was associated with higher muscle activity, higher typing force, slower typing speeds, and worse self-reported discomfort and difficulty.

Overall the results show that given similar activation force, larger key travel distances were associated with better performance and experience. The fastest typing speed and least discomfort and difficulty were observed for the device with the largest travel distance. Participants' self-reported more discomfort and difficulty with the devices with the shortest travel distance. These results are consistent with most previous research (Hoyle et al., 2013; Kim et al., 2014). Kia et al. (2019) also found better typing speed and accuracy was associated with larger key travel.

The present results suggest that key travel alone does not predict biomechanical outcomes and that key mechanism and activation force are also important factors in key-switch design. Specifically, the two devices with the same short travel $(0.55 \mathrm{~mm})$ had the largest differences across most muscles, though this difference was relatively small $(<1.0 \% \mathrm{MVC})$. These two devices differed in activation force and mechanism: Tablet $\mathrm{S}$ had a dome switch mechanism and a higher activation force than Notebook $\mathrm{S}$ which had a butterfly switch mechanism. Similarly, this study found that key travel distance was not strictly associated with typing force, typing performance, or perceived experience, as Tablet $\mathrm{S}$ was associated with the worst results across these measures compared to the other three devices. These results align with studies that have tested different activation forces (Gerard et al., 1996; Hughes \& Johnson, 2014; Kim et al., 2014; Rempel et al., 1999) and mechanisms(Asundi \& Odell, 2011; Bufton et al., 2006; Gerard et al., 1999). 
In terms of trends observed within sex/gender stratified groups, the results suggest that the effect of the 4 devices was different in female and male participants similar to what has been observed in general occupational health and safety studies (Habib \& Messing, 2012; Messing \& Mager Stellman, 2006; Messing et al., 2003). More statistically significant differences across devices were observed in female participants compared to male participants. This result suggests that women may be more affected by micro-travel keyboard designs than men, similar to Won et al (2009) which suggested differences in anthropometry increased the awkward postures and higher muscle activity for female participants. Though the differences observed were small, it is possible that over prolonged use, these differences could correspond to increased risk (Cook, Ludewig, Rosecrance, Zimmermann, \& Gerleman, 1999; Pereira et al., 2013). Moreover, the kinematics of the users was not measured as it is suspected that the differences in posture would be small across these devices; however, perhaps reaching some of the non-home row keys magnified the effects of the different devices. In this study, differences in strength probably played a role as all the metrics were normalized by strength or maximum voluntary contractions, meaning that female participants exerted more of their maximum effort than male participants.

As the demand for thinner keyboards and devices increases, it is important for mobile technology designers to consider both the user's experience and sex/gender when deciding on key force-displacement tradeoffs. Others before have made these recommendations for general concepts surrounding occupational ergonomics concerning sex/gender in both practice and research (Messing \& Mager Stellman, 2006; Messing et al., 2003). These results support the importance of considering gender in usability testing to ensure that the designs mitigate differences observed within different populations. 
This study investigated the effect of four commercially available devices, and as such it is not possible to disentangle the various travel, force-displacement, and mechanism characteristics in a full factorial designed study. The comparisons made above were done so within this context; however, they are supported by other studies that have shown similar patterns. The study did not collect wrist posture which could account for the increased muscle activity in Tablet 1, which did not have any wrist supports; however, participants were set up to maintain similar wrist postures across devices, and the other dependent variables corresponded with the EMG results.

Furthermore, the study was conducted in a laboratory setting, and the short duration of typing may not accurately reflect real-world, long term device use, and it is possible that computing has changed so much that long form transcription is also not reflective of the modern typing experience. In addition, the self-reported experience measures were collected after only a short experience with each device and may not be valid measures of long term discomfort and difficulty. However, consumers would likely only type on devices for a short period in the store, and thus these results may be important to manufacturers. The electromyography effect sizes were relatively small $(<1.0 \% \mathrm{MVC})$ across all devices and may not corresponded to an increased risk clinically; however these subtle differences could matter over long term exposure. We were unable to blind the device brands, and participants' prior experiences with them could have affected their self-reported results and behavior. Gender is a proxy for multiple biological and psycho-social characteristics, and stratifying by a male/female binary may not explain the root cause of the differences observed.

Key travel is only one design feature which may not fully account for the differences in typing force, muscle activity, typing performance, and participant experience. Future studies should explore key spacing, over-travel, and activation force in addition to key travel. In 
addition, future studies should account for individual differences such as anthropometry, strength, and sex/gender.

This study found differences in upper extremity biomechanics, typing performance, and self-reported experience across 4 micro-travel keyboard devices with $0.5 \mathrm{~mm}$ (Tablet $\mathrm{S} \&$ Notebook S), $1.3 \mathrm{~mm}$ (Tablet L), and $1.6 \mathrm{~mm}$ (Notebook L) travel distances during short laboratory-based typing tasks. The results further support the importance of other design features such as activation force and mechanism, as well as keyboard form factors. These considerations will be important as the market continues to demand thinner mobile devices.

\section{Acknowledgements}

This study was supported in part by National Institute for Occupational Safety and Health (T42 OH008416) and a gift from the Microsoft Corporation. Phil Dizon, Boyi Hu, and Michael Lin were collaborators on this project. 


\section{References}

Armstrong, T. J., Foulke, J. A., Martin, B. J., Gerson, J., \& Rempel, D. M. (1994). Investigation of Applied Forces in Alphanumeric Keyboard Work. American Industrial Hygiene Association Journal, 55(1), 30-35. doi:10.1080/15428119491019230

Asundi, K., \& Odell, D. (2011). Effects of keyboard keyswitch design: A review of the current literature. Work, 39, 151-159.

Bruno Garza, J., Eijckelhof, B., Johnson, P., Raina, S., Rynell, P., Huysmans, M., . . . Dennerlein, J. (2012). Observed differences in upper extremity forces, muscle efforts, postures, velocities and accelerations across computer activities in a field study of office workers. Ergonomics.

Bufton, M. J., Maklin, R. W., Nagurka, M. L., \& Simoneau, G. G. (2006). Effect of keyswitch design of desktop and notebook keyboards related to key stiffness and typing force. Ergonomics, 49(10), 996-1012.

Chaparro, B. S., Phan, M. H., \& Jardina, J. R. (2013). Usability and performance of tablet keyboards: Microsoft Surface vs. Apple iPad. Paper presented at the Proceedings of the Human Factors and Ergonomics Society 57th Annual Meeting, San Diego.

Chaparro, B. S., Phan, M. H., Siu, C., \& Jardina, J. R. (2014). User performance and satisfaction of tablet physical keyboards. Journal of Usability Studies, 9(2), 70-80.

Comparing Mechanical, Membrane and Scissor-Switch Membrane Keyboards - Ergonomic Considerations of Keyswitch Type. (2013). Ergopedia. Retrieved from http://www.ergopedia.ca/ergonomic_concepts/Mechanical_Keyswitches_Membrane_Key switches_and_Scissor_Switch_Membrane_Keyswitches_Ergonomic_Considerations.htm 1

Cook, T. M., Ludewig, P. M., Rosecrance, J. C., Zimmermann, C. L., \& Gerleman, D. G. (1999). Electromyographic effects of ergonomic modifications in selected meatpacking tasks. Applied Ergonomics, 30(3), 229-233. doi:10.1016/S0003-6870(98)00024-6

Cote, J. N. (2011). A critical review on physical factors and functional characteristics that explain a sex/gender difference in work-relatedneck/shoulder disorders. Ergonomics, $55: 2,173-182$.

Cunningham, A. (Producer). (2016, October 27). Hands-on with the new MacBook Pros, their keyboard, and the Touch Bar. arsTechnica. Retrieved from https://arstechnica.com/gadgets/2016/10/hands-on-with-the-new-macbook-pros-theirkeyboard-and-the-touch-bar/

Dixon, P. C., Loh, J. J., Michaud-Paquette, Y., \& Pearsall, D. J. (2017). biomechZoo: An opensource toolbox for the processing, analysis, and visualization of biomechanical movement data. Computer Methods and Programs in Biomedicine, 140, 1-10.

Feuerstein, M., Armstrong, T., Hickey, P., \& Lincoln, A. (1997). Computer keyboard force and upper extremity symptoms. JOEM, 39(12), 1144-1153.

Gerard, M. J., Armstrong, A., Franzblau, B. J., Martin, D. M., \& Rempel, D. M. (1999). The effect of keyswitch stiffness on typing force, finger electromyography, and subjective discomfort. American Industrial Hygiene Association Journal, 762-769.

Gerard, M. J., Armstrong, M. J., Foulke, T., \& Martin, A. (1996). Effects of key stiffness on force and the development of fatigue while typing. American Industrial Hygiene Association Journal, 57(9), 849-854.

Habib, R. R., \& Messing, K. (2012). Gender, women's work and ergonomics. Ergonomics, 55, 129-132. 
HFES 100 Committee. (2007) ANSI/HFES 100-2007 Human Factors Engineering of Computer Workstations. Santa Monica, CA:

Hoozemans, M. J. M., \& van Dieën, J. H. (2005). Prediction of handgrip forces using surface EMG of forearm muscles. Journal of Electromyography and Kinesiology, 15(4), 358366. doi:10.1016/j.jelekin.2004.09.001

Hoyle, W. S., Bartha, M. C., Harper, C. A., \& Peres, S. C. (2013). Low profile keyboard design: the effect of physical key characteristics on typing productivity and user preference. Paper presented at the Proceedings of the human factors and ergonomics society.

Hughes, M., \& Johnson, P. W. (2014). Differences in the three dimensional typing forces between short and long travel keyboards'. Paper presented at the Proceedings of the human factors and ergonomics society annual meeting.

Härenstam, A. (2009). Exploring gender, work and living conditions, and health - suggestions for contextual and comprehensive approaches. Scandinavian Journal of Work, Environment \& Health, 35(2), 127-133. doi:10.5271/sjweh.1308

Jindrich, D. L., Balakrishnan, A. D., \& Dennerlein, J. T. (2004). Effects of keyswitch design and finger posture on finger joint kinematics and dynamics during tapping on computer keyswitches. Clinical Biomechanics, 19(6), 600-608.

Kia, K., Sisley, J., Johnson, P. W., \& Kim, J. H. (2019). Differences i typing forces, muscle activity, wrist posture, typing performance, ad self-reported comfort among conventional and ultra-low travel keyboards. Applied Ergonomics, 74, 10-16.

Kim, J. H., Aulck, L., Bartha, M. C., Harper, C. A., \& Johnson, P. W. (2014). Differences in typing forces, muscle activity, comfort, and typing performance among virtual, notebook, and desktop keyboards. Applied Ergonomics, 1406-1413.

Lin, M., Young, J., \& Dennerlein, J. (2015). Evaluating the effect of four different pointing device designs on upper extremity posture and muscle activity during mousing tasks. Applied Ergonomics, 47, 259-264.

Marcus, M., Gerr, F., Monteilh, C., Ortiz, D. J., Gentry, E., Cohen, S., . . Kleinbaum, D. (2002). A prospective study of computer users: II. Postural risk factors for musculoskeletal sympotms and disorders. American Journal of Industrial Medicine, 236-249.

Martin, B. J., Armstrong, T. J., Reed, M., Dennerlein, J., \& Rempel, D. (1994). Investigation of techniques designed to evaluate finger forces in alphanumeric keyboard work. In (Vol. 27, pp. 765-765).

Messing, K., \& Mager Stellman, J. (2006). Sex, gender and women's occupational health: The importance of considering mechanism. Environmental Research, 101(2), 149-162.

Messing, K., Punnett, L., Bond, M., Alexanderson, K., Pyle, J., Zahm, S., . . de Grosbois, S. (2003). Be the fairest of them all: challenges and recommendations for the treatment of gender in occupational health research. American Journal of Industrial Medicine, 43(6), 618-629.

Messing, K., Stock, S. R., \& Tissot, F. (2009). Should studies of risk factors for musculoskeletal disorders be stratified by gender? Lessons from the 1998 Québec Health and Social Survey. Scandinavian journal of work, environment \& health, 35(2), 96. doi:10.5271/sjweh.1310

Pascarelli, E. F., \& Kella, J. J. (1993). Soft-tissue injuries related to use of the computer keyboard. A clinical study of 53 severely injured persons. Journal of Occupational Medicine, 35(5), 522-532. 
Pereira, A., Hsieh, C. M., Laroche, C., \& Rempel, D. (2014). The effect of keyboard key spacing on typing speed, error, usability, and biomechanics, Part 2: Vertical Spacing. Human Factors, 752-759.

Pereira, A., Lee, D. L., Sadeeshkumar, H., Laroche, C., Odell, D., \& Rempel, D. (2013). The Effect of Keyboard Key Spacing on Typing Speed, Error, Usability, and Biomechanics: Part 1. Human Factors: The Journal of Human Factors and Ergonomics Society, 55(3), 557-566. doi:10.1177/0018720812465005

Perotto, A. (1994). Anatomical Guide for the Electromyographer: The Limbs and Trunk. Springfield, IL: Charles C Thomas.

Qin, J., Trudeau, M., Katz, J. N., Buchholz, B., \& Dennerlein, J. T. (2011). Biomechanical loading on the upper extremity increases from single key tapping to directional tapping. Journal of Electromyography and Kinesiology, 21, 587-594.

Radwin, R. G., \& Ruffalo, B. A. (1999). Computer key switch force- displacement characteristics and short term effects on localized fatigue. Ergonomics, 160-170.

Rempel, D., Serina, E., Klinenberg, E., Martin, B., Armstrong, T., Foulke, J., \& Natarajan, S. (1997). The effect of keyboard keyswitch make force on applied force and finger flexor muscle activity. Ergonomics, 40, 800-808.

Rempel, D., Tittiranonda, P., Burastero, S., Hudes, M., \& So, Y. (1999). Effect of Keyboard Keyswitch Design on Hand Pain. Journal of Occupational and Environmental Medicine, 41(2), 111-119.

Ripat, J., Scatliff, T., Giesbrecht, E., Quanbury, A., Friesen, M., \& Kelso, S. (2006). The effect of alternative keyboards on severity of symptoms and functional status of individuals with work related upper extremity disorders. Journal of Occupational Rehabilitation, 16, 707-718.

Sisley, J., Kia, K., Johnson, P. W., \& Kim, J. H. (2017). Effects of Key Travel Distances on Biomechanical Exposures and Typing Performance During UltraLow Key Travel Keyboards. Proceedings of the Human Factors and Ergonomics Society Annual Meeting, 61(1), 981-985. doi:10.1177/1541931213601727

Varcholik, P. D., LaViola, J. J., \& Hughes, C. E. (2012). Establishing a baseline for text entry for a multi-touch virtual keyboard. International Journal of Human-Computer Studies, 70, 657-672.

Won, E. J., Johnson, P. W., Punnett, L., \& Dennerlein, J. T. (2009). Upper extremity biomechanics in computer tasks differ by gender. Journal of Electromyography and Kinesiology, 19(3), 428-436.

Ziba. Can Ergonomics find a place in the home? Retrieved from https://web.archive.org/web/20140330211941/http://www.ziba.com/work/microsoftnatural-keyboard 


\section{Chapter 2}

Sex/Gender differences in thumb biomechanics and performance during two-handed tablet use 


\begin{abstract}
Touchscreen devices affect upper extremity muscle activity and may have risk for upperextremity pain and disorders. These devices' designs may affect men and women differently. This study investigated the hypothesis that sex/gender and tablet hardware and software factors affect forearm muscle activity, performance, and self-reported user perception. Sixteen adult (8 female, 8 male) participants completed 320 tablet gestures across four swipe locations, with various tablet sizes ( 8 " and 10"), tablet orientations (portrait and landscape), swipe orientations (vertical and horizontal), and swipe directions (medial and radial). Compared to male participants, female participants used significantly more muscle activity $(p<0.05)$ in extensor carpi ulnaris, extensor digitorum, flexor digitorum, abductor pollicis longus, and extensor pollicis brevis. Sex/Gender stratified results revealed that tablet orientation and swipe location affected each group differently. The study results demonstrate the importance of swipe locations and suggest that the tablet interface design can be improved. In addition, these results demonstrate the importance of including men and women in usability testing.
\end{abstract}




\section{Introduction}

Mobile touchscreen devices have become ubiquitous, and usage rates continue to increase in both developed and developing countries (Poushter, 2016). In the US, 53\% of adults own a tablet and 77\% own a smartphone ("Mobile Fact Sheet," 2018). The mobility of these devices

allows near constant use, and prolonged exposure is associated with musculoskeletal symptoms (Kim \& Kim, 2015). Thumb pain is so common that "texting thumb" has become a common complaint for users (Ali et al., 2014; Eapen, Kumar, Bhat, \& Venugopal, 2014; Redmayne, Smith, \& Abramson, 2013). Unlike more traditional desktop computing devices, mobile technologies do not provide support for the upper limbs which may cause more awkward postures and injury risk (Toh, Coenen, Howie, \& Straker, 2017; Xie, Szeto, \& Dai, 2017).

Different aspects of touchscreen hardware designs have been explored in previous studies (Orphanides \& Nam, 2017). Larger screens are associated with more upper limb muscle activity and fatigue (Kietrys, Gerg, Dropkin, \& Gold, 2015; Pereira, Miller , Huang, Odell, \& Rempel, 2013). Different grip styles have been investigated, and two-handed holds generally require lower muscle activity and wrist extension when compared to one-handed holds (Ko, Hwang, \& Liang, 2016; Trudeau, Asakawa, Jindrich, \& Dennerlein, 2016; Trudeau, Young, Jindrich, \& Dennerlein, 2012; Xie, Szeto, Dai, \& Madeleine, 2015; Young, Trudeau, Odell, Marinelli, \& Dennerlein, 2013). In addition, device orientation affects biomechanics and usability. Trudeau et al. (2013) found that portrait orientation was associated with less discomfort and wrist adduction than landscape orientation, while Pereira et al. (2013) found that portrait orientation was associated with less wrist extension.

User interface designs also affect usability and upper limb biomechanics. A few studies have explored thumb functional reach on touch screen devices (Bergstrom-Lehtovirta \& 
Oulasvirta, 2014; Odell \& Chandrasekaran, 2012; Xiong \& Muraki, 2016). The size, shape, and location of on-screen targets have been shown to affect performance and biomechanics (Kim, Aulck, Bartha, Harper, \& Johnson, 2014; Park \& Han, 2010; Xiong \& Muraki, 2014). Trudeau et al. (2012) found that thumb tapping targets farthest and closest to the palm required the most flexion and extension and decreased motor performance. Another study found that tapping between the top right and bottom left of a smartphone screen was faster and used less finger flexor and more thumb abductor muscle activity than typing between the top left and bottom right (Xiong \& Muraki, 2014). In addition, Jeong \& Liu (2017) found horizontal swipes using the index finger had better self-reported performance and lower physical demands than vertical swipes.

Some studies have investigated individual differences and mobile technology. Multiple studies have explored how different age groups are affected by mobile touchscreen technology (Chang, Tsai, Chang, \& Chang, 2014; Gao \& Sun, 2015; Mihajlov, Law, \& Springett, 2015). Previous research has explored tablet usability and biomechanics for people with disabilities (Irwin \& Sesto, 2012; Sesto, Irwin, Chen, Chourasia, \& Wiegmann, 2012), people with upper limb musculoskeletal symptoms (Xie et al., 2015), and different hand and thumb sizes (Ahn, Kwon, Bahn, Yun, \& Yu, 2016; Kim, Choe, Choi, \& Park, 2017; Xiong \& Muraki, 2016). A few studies have measured sex/gender differences in self-reported cellphone related pain (Gustafsson, Thomée, Grimby-Ekman, \& Hagberg, 2017; Korpinen, Pääkkönen, \& Gobba, 2013; Shan et al., 2013); however, it is unknown if participants used touchscreen or keypad phones. Surveys have found an association between female sex/gender and self-reported tablet-related pain among high school students (Shan et al., 2013) and university populations (Lee, Cha, Hwangbo, Mo, \& Ji, 2018). Laboratory studies have found more neck flexion in male 
participants compared to female participants when using mobile phones (Guan et al., 2016). Zhang et al. (2015) found that male participants performed better during one-handed thumb tapping tasks on a large touchscreen phone. Moreover, in a study with keypad mobile phones, female participants used significantly higher thumb abductor and finger extensor muscles while texting (Gustafsson, Johnson, \& Hagberg, 2010).

Sex/Gender is an important risk factor for technology-related musculoskeletal pain (Coté, 2011). Studies of computer workers have found higher rates of upper extremity disorders and injury in women as compared to men (Gerr et al., 2002; Punnett \& Bergqvist, 1999). Women on average have less upper limb muscle strength and aerobic capacity (Faber, Hansen, \& Christensen, 2006) and need to use higher percentages of their maximum voluntary contractions to perform the same tasks as men (Haward \& Griffin, 2002; Mogk \& Keir, 2003; Nordander et al., 2008). Other studies have shown that women activate more accessory muscles and fewer primary muscle groups than men in isometric tasks at 50\% maximum force (Anders, Bretschneider, Bernsdorf, Erler, \& Schneider, 2004).

To our knowledge, no studies have investigated the sex/gender differences in thumb swiping tasks on touchscreen devices. Therefore, the purpose of this study was to use the data previously reported in Coppola et al. (2018) to explore the effect of sex/gender during thumb swiping tasks with different tablet hardware and software characteristics on forearm muscle activity, performance, and usability. Specifically, we hypothesize that female participants will use more muscle activity across tasks, perform worse on farther reach swipe targets, and report higher discomfort and difficulty for larger tablets. 


\section{Methods}

This paper builds upon the study methods previously reported in Coppola et al. (2018).

\section{Study Population}

Eight female and eight male healthy right-handed participants were recruited for the study (Table 2.1). Participants were between the ages of 21 and 33 years with no history of upper-extremity MSDs or uncorrected vision problems. The local institutional review boards approved all protocols, and all participants provided written consent.

Table 2.1: Anthropometric measures of means (standard deviations) across all participants

\begin{tabular}{|c|c|c|c|}
\hline & Female $\mathrm{n}=8$ & Male $\mathrm{n}=8$ & P-value $^{1}$ \\
\hline Age (years) & $24.3(2)$ & $24.8(3)$ & 1.0 \\
\hline Height (cm) & $167.1(7)$ & $179.8(7)$ & $<\mathbf{0 . 0 0 1}$ \\
\hline $\begin{array}{c}\text { Hand Length } \\
(\mathrm{cm})\end{array}$ & $18.1(1)$ & $19.8(1)$ & $<\mathbf{0 . 0 0 1}$ \\
\hline $\begin{array}{c}\text { Thumb Length } \\
(\mathrm{cm})\end{array}$ & $9.7(1)$ & $10.4(1)$ & $<\mathbf{0 . 0 0 1}$ \\
\hline $\begin{array}{c}\text { Index Finger } \\
\text { Length (cm) }\end{array}$ & $8.5(1)$ & $9.5(1)$ & $<\mathbf{0 . 0 0 1}$ \\
\hline
\end{tabular}

${ }^{1} \mathrm{~T}$-tests tested between group differences. Bold values indicate a significant effect $(p<0.05)$.

\section{Tablet Instrumentation and Experimental Tasks}

Participants performed 16 thumb swiping gestures with the thumb of their right hand, repeating each gesture 5 times in four different tablet configurations for a total of 320 swipes. The independent variables were: tablet size (small vs. large), tablet orientation (portrait vs. landscape), swipe direction (outward vs. inward), swipe orientation (horizontal vs. vertical), swipe location (4 swipe zones), and swipe length (short vs. long). As defined in Trudeau(2012), "outward" movements of the thumb were defined as consisting primarily in 
carpometacarpal (CMC) joint flexion or abduction movements with extension of the interphalangeal (IP) and metacarpal (MCP) joints and include the following directions: South(S) $\rightarrow$ North $(\mathrm{N}) \& \operatorname{East}(\mathrm{E}) \rightarrow$ West $(\mathrm{W})$. "Inward" movements of the thumb were defined as consisting primarily in $\mathrm{CMC}$ extension or adduction movements with flexion of the IP and MCP joints and include the following directions: $\mathrm{N} \rightarrow \mathrm{S}, \mathrm{NW} \rightarrow \mathrm{SE}, \mathrm{W} \rightarrow \mathrm{E}$, and $\mathrm{SW} \rightarrow \mathrm{NE}$.

Each gesture required the user to touch the screen activating a target bar (10 $\mathrm{mm} \times 2 \mathrm{~mm})$ in the center edge of one of the four zones (Figure $2.1 \mathrm{a \& b}$ ) and then steer the bar along and within a lane between two lines a specified distance apart $(10 \mathrm{~mm})$ for a specified distance (short $20 \mathrm{~mm}$ or long $60 \mathrm{~mm}$ ) (Accot \& Zhai, 1997; Dennerlein, Martin, \& Hasser, 2000). The gesture was completed when the thumb reached and passed the end of these lines. Each gesture was performed 5 times in the same direction as shown on the screen. The subjects were instructed to swipe as accurately and quickly as possible each time and to naturally bring their thumb back to their starting position without swiping backwards on the screen. Each 5 trial task typically took around 1 minute. A custom native application was created for an Android program to collect completion time data and provide visual guidance for users.

The two tablet computers selected in the study were a Samsung Galaxy III with a 10" display (Samsung Electronics Co., Ltd., South Korea) and a Samsung Galaxy Note III with an 8" display (Samsung Electronics Co., Ltd., South Korea). Device, device orientation, and each thumb swipe task were presented to the participant in a balanced randomized fashion (Figure 1). Participants sat on a height adjustable office task chair without arm supports. The height of the chair was adjusted while their feet were flat on the floor and their thighs were horizontal with their knees at a ninety-degree angle. Participants were instructed to hold the tablet with two hands and interact with the tablet using only their right thumbs without dropping the tablet. 
Participants sat upright and were allowed to use their laps (thighs) to help support their hands/wrists/distal forearms while using the device. All nearby light sources were indirect, and there was no glare on the tablet's screen. The entire experiment including set-up took approximately two hours.

\section{Dependent Variables: Muscle Activity}

Surface electromyography (EMG) electrodes (DE-2.1 Single Differential Electrode; Delsys, Boston, Massachusetts, USA) measured 8 muscle groups of the right forearm including Extensor Carpi Radialis (ECR), Extensor Carpi Ulnaris (ECU), Extensor Digitorum (ED), Extensor Pollicis Brevis (EPB), Abductor Pollicis Longus (APL), Flexor Carpi Radialis (FCR), Flexor Carpi Ulnaris (FCU), Flexor Digitorum Superficialis (FDS). Participants' skin was cleaned and exfoliated before electrode placement. Electrode placement on the muscles was achieved through palpation and validated through EMG signal response to corresponding muscle contraction exercises (Lin, Young, \& Dennerlein, 2015; Perotto, 1994). EMG signals were sampled at $1000 \mathrm{~Hz}$. Upon amplification, EMG signals were rectified and smoothed using a $3 \mathrm{~Hz}$ low pass filter. Three isometric maximum voluntary contractions (MVC) were collected for each muscle to normalize EMG signals within participants. Participants were coached to gradually ramp up to reach their maximal exertions for 3 seconds while the experimenter resisted. The highest value of the 3 exertions was designated as the $100 \%$ MVC. A minimum break of at least two minutes was taken between MVC tests of each muscle group. Normalization of EMG was calculated as percent MVC of each muscle. The median $\left(50^{\text {th }}\right.$ percentile $)$ muscle activity levels in percent MVC were used to compare across participants. 

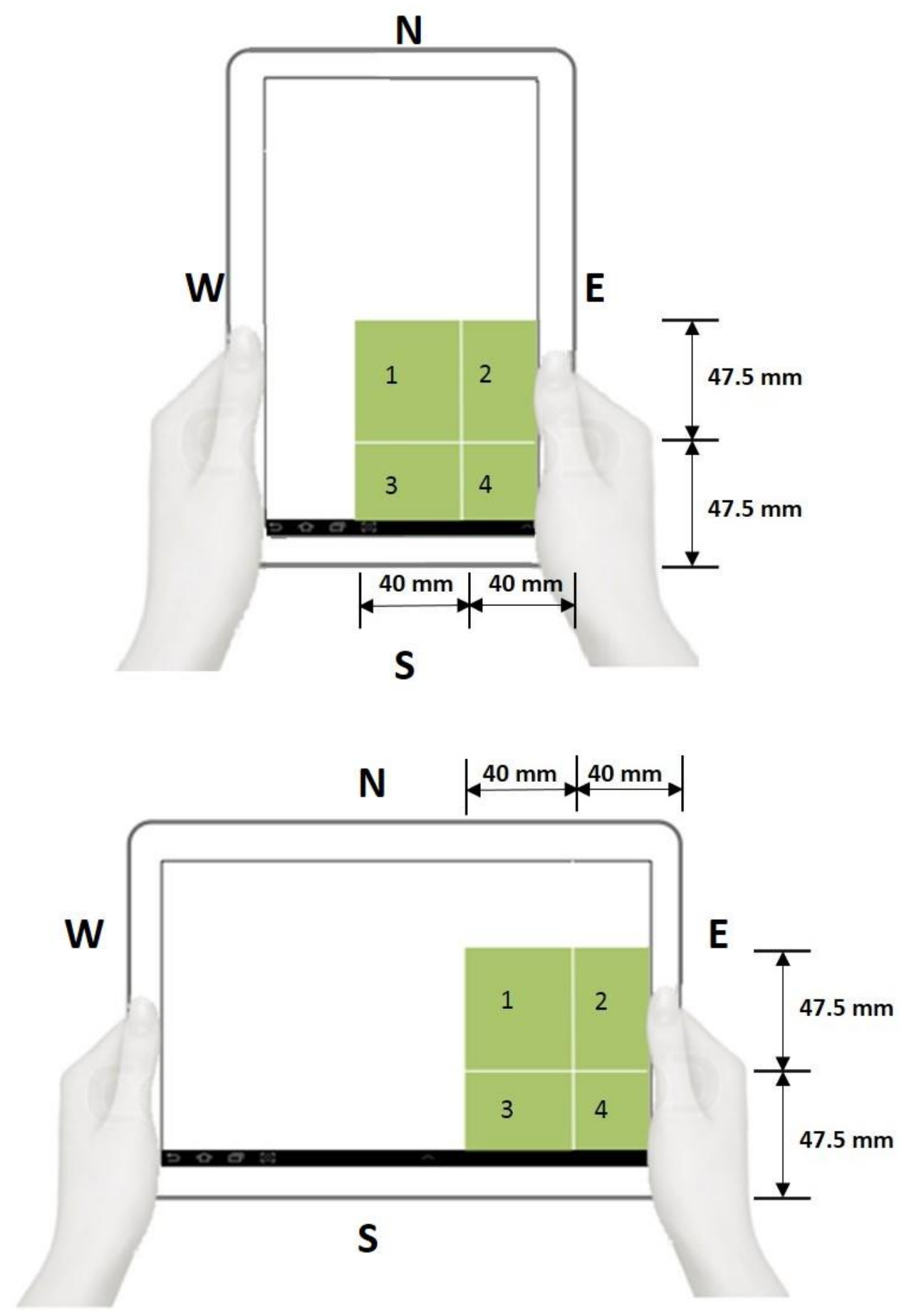

Figure 2.1a and 2.1b. Portrait and landscape orientations showing swipe locations on the screen. Thumb swipe lanes were indicated by a target bar $(10 \mathrm{~mm} \times 2 \mathrm{~mm})$ starting in the center edge of each of the four zones. Long vertical and horizontal swipes $(60 \mathrm{~mm})$ crossed zones and short horizontal swipes $(20 \mathrm{~mm})$ remained in one zone. 
Dependent Variables: Performance

The custom native Android program collected completion time data for the five swipes in each of the configurations.

Dependent Variables: Self-reported Discomfort

All participants responded to eight survey questions about overall hand and wrist discomfort after completing each condition with each tablet. For each combination of tablet size (large \& small) and orientation (portrait \& landscape), participants were asked to rate how much discomfort/difficulty they felt on the hand/wrist while: swiping up, swiping down, swiping to the left, swiping to the right, swiping close to the edge of the screen, and swiping farther away from the edge of the screen. The responses were marked on a $10-\mathrm{cm}$ visual analogue scale (VAS) with $0 \mathrm{~cm}$ being the lowest level of perceived-discomfort and $10 \mathrm{~cm}$ being the highest.

\section{Data and Statistical Analysis}

A repeated measures ANOVA (RMANOVA) evaluated the effect of sex/gender and each tablet/swipe characteristic. A single RMANOVA model was run for each of the 16 dependent variables, including muscle activity (6, in percent MVC), performance (1, in milliseconds) and user perception (2, VAS scale from 0 to 10). For each muscle activity and performance RMANOVA model, we included participant as a random effect and all six independent variables (sex/gender (1 df), tablet size (1df), tablet orientation (1df), swipe direction (1 df), swipe location (3 df), swipe orientation (1df)) as fixed effects, as well as the interactions between sex/gender and the tablet/swipe factors. Separate user perception RMANOVA models were run for the different swipe factors with participant included as a random effect and tablet size and orientation as fixed effects. Anthropometric factors were also tested as potential confounders, but 
none were significant. To explore significant interaction effects and the effect of the tablet/swipe factors observed within each sex/gender, the RMANOVA models were stratified on sex/gender. The significance criterion (alpha value) was set at 0.05 . When a significant effect was found, a post-hoc analysis with Tukey's honest significance test for variables with more than two levels. Statistical analysis was performed using JMP Pro 11 (SAS) linear mixed model software.

\section{Results}

\section{Dependent Variables: Muscle Activity}

Sex/Gender was a significant main effect for 5 of the 8 tested forearm muscles (Table 2.2 a,b\&c). Female participants had higher marginal means for their median \%MVC than male participants for extensor carpi ulnaris $(p=0.0025)$, extensor digitorum $(p=0.0293)$, flexor digitorum $(\mathrm{p}=0.0240)$, abductor pollicis longus $(\mathrm{p}=0.0245)$, and extensor pollicis brevis $(\mathrm{p}=$ $0.0039)$.

There were several significant interaction effects found between sex/gender and the other independent variables. Sex/Gender x size was marginally significant $(p=0.0465)$ for extensor pollicis brevis. Sex/Gender x orientation was significant for extensor carpi radialis $(p=0.0012)$, flexor carpi ulnaris $(p=0.001)$, extensor digitorum $(p=0.0045)$, flexor digitorum $(p=0.0002)$, abductor pollicis longus $(\mathrm{p}=0.0081)$, and extensor pollicis brevis $(\mathrm{p}=0.0033)$. Sex/Gender $\mathrm{x}$ zone was significant for extensor carpi ulnaris $(p=0.0152)$, extensor carpi radialis $(p=0.0105)$, flexor carpi ulnaris $(\mathrm{p}<0.0001)$, extensor digitorum $(\mathrm{p}=0.0001)$, flexor digitorum $(\mathrm{p}=0.001)$, and extensor pollicis brevis $(\mathrm{p}<0.0001)$. Sex/Gender $\mathrm{x}$ swipe orientation was only significant for extensor pollicis brevis $(\mathrm{p}=0.0277)$. Sex/Gender $\mathrm{x}$ direction was significant for flexor 
digitorum $(\mathrm{p}=0.0015)$, abductor pollicis longus $(\mathrm{p}=0.0291)$, and extensor pollicis brevis $(\mathrm{p}=$ $0.0278)$. 
Table 2.2 a,b\&c: Combined Model Median Muscle Activity: Across participant marginal means (and standard errors) for surface electromyography (\%MVC).

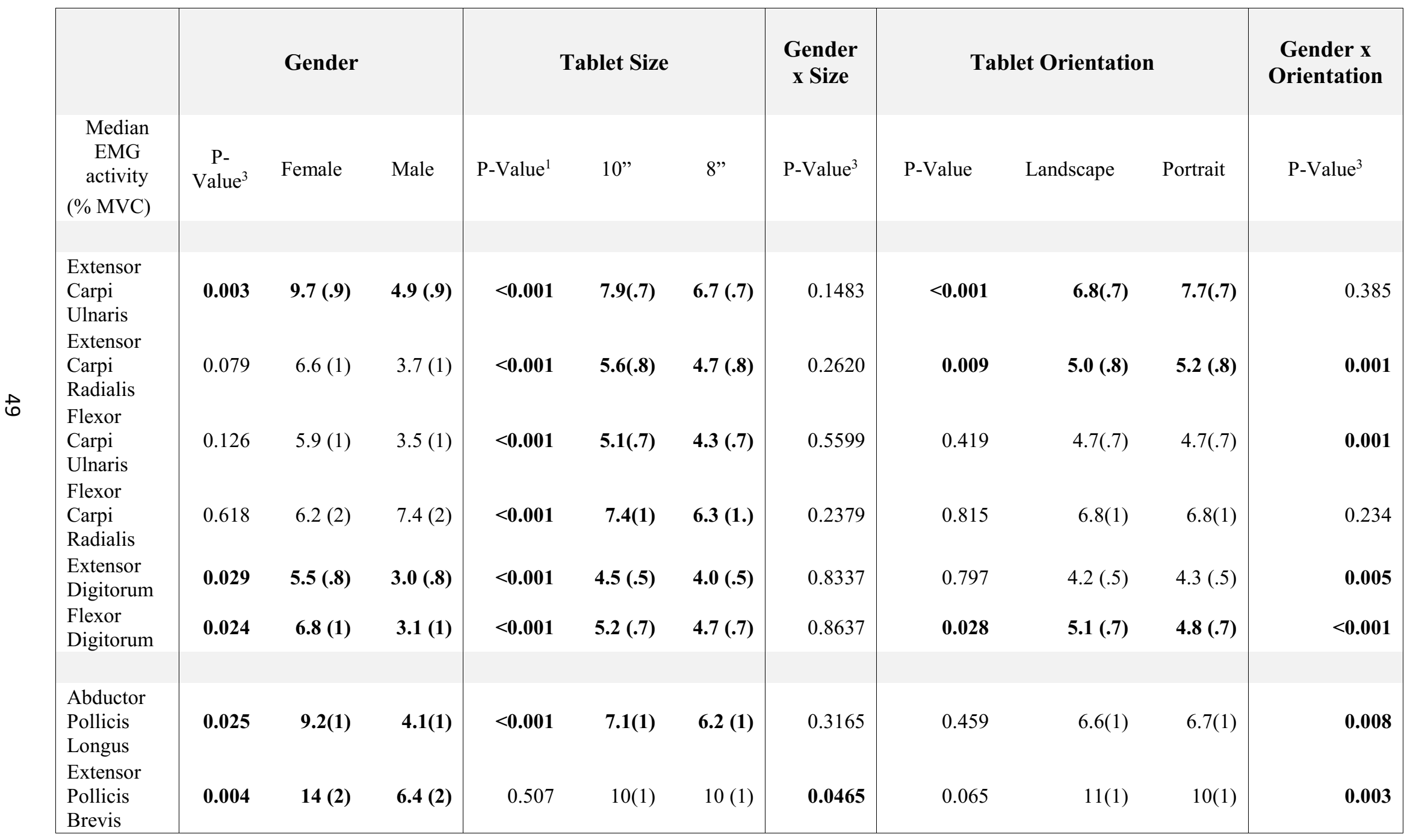


Figure 2.2 (Continued)

\begin{tabular}{|c|c|c|c|c|c|c|}
\hline & \multicolumn{5}{|c|}{ Swipe Zone $^{2}$} & Gender $x$ \\
\hline $\begin{array}{l}\text { EMG } \\
\text { activity } \\
\text { (\% MVC) }\end{array}$ & $\begin{array}{c}\text { P- } \\
\text { Value }^{3}\end{array}$ & TL & TR & BL & BR & P-Value \\
\hline $\begin{array}{l}\text { Extensor } \\
\text { Carpi } \\
\text { Ulnaris }\end{array}$ & $<0.001$ & $10(.7)^{A}$ & $7.2(.7)^{\mathrm{B}}$ & $7.0(.7)^{\mathrm{B}}$ & $4.7(.7)^{\mathrm{C}}$ & 0.015 \\
\hline $\begin{array}{l}\text { Extensor } \\
\text { Carpi } \\
\text { Radialis }\end{array}$ & $<0.001$ & $5.7(.8)^{\mathrm{A}}$ & $4.9(.8)^{\mathrm{C}}$ & $5.3(.8)^{B}$ & $4.6(.8)^{\mathrm{D}}$ & 0.011 \\
\hline $\begin{array}{l}\text { Flexor } \\
\text { Carpi } \\
\text { Ulnaris }\end{array}$ & $<0.001$ & $5.3(.7)^{\mathrm{A}}$ & $4.3(.7)^{\mathrm{C}}$ & $4.9(.7)^{B}$ & $4.3(.7)^{C}$ & $<0.001$ \\
\hline $\begin{array}{l}\text { Flexor } \\
\text { Carpi } \\
\text { Radialis }\end{array}$ & 0.0716 & $6.6(1)$ & $6.8(1)$ & $6.9(1)$ & $7.0(1)$ & 0.573 \\
\hline $\begin{array}{l}\text { Extensor } \\
\text { Digitorum }\end{array}$ & $<0.001$ & $6.2(.6)^{A}$ & $3.8(.6)^{\mathrm{B}}$ & $4.2(.6)^{\mathrm{B}}$ & $2.9(.6)^{C}$ & $<0.001$ \\
\hline $\begin{array}{l}\text { Flexor } \\
\text { Digitorum }\end{array}$ & $<0.001$ & $5.8(.7)^{A}$ & $4.4(.7)^{\mathrm{C}}$ & $5.1(.7)^{B}$ & $4.4(.7)^{C}$ & $<0.001$ \\
\hline $\begin{array}{l}\text { Abductor } \\
\text { Pollicis } \\
\text { Longus }\end{array}$ & $<0.001$ & $8.4(1)^{A}$ & $6.1(1)^{C}$ & $6.7(1)^{B}$ & $5.4(1)^{\mathrm{D}}$ & 0.364 \\
\hline $\begin{array}{l}\text { Extensor } \\
\text { Pollicis } \\
\text { Brevis }\end{array}$ & $<0.001$ & $12(1)^{A}$ & $10(1) C$ & $11(1)^{B}$ & $9.0(1)^{C}$ & $<0.001$ \\
\hline
\end{tabular}


Figure 2.2 (Continued)

\begin{tabular}{|c|c|c|c|c|c|c|c|c|}
\hline & \multicolumn{3}{|c|}{ Swipe Orientation } & $\begin{array}{l}\text { Gender x } \\
\text { Swipe }\end{array}$ & \multicolumn{3}{|c|}{ Swipe Direction } & \multirow{2}{*}{$\begin{array}{l}\text { Gender } x \\
\text { Direction }\end{array}$} \\
\hline $\begin{array}{l}\text { Median EMG } \\
\text { activity } \\
\text { (\% MVC) }\end{array}$ & P-Value & Horizontal & Vertical & P-Value & P-Value & Normal-in & Reverse-out & \\
\hline $\begin{array}{l}\text { Extensor Carpi } \\
\text { Ulnaris }\end{array}$ & 0.120 & $7.5(.7)$ & 7.1(.7) & 0.442 & $<0.001$ & 6.3(.7) & $8.3(.7)$ & 0.069 \\
\hline $\begin{array}{l}\text { Extensor Carpi } \\
\text { Radialis }\end{array}$ & 0.406 & $5.2(.8)$ & $5.1(.8)$ & 0.095 & $<0.001$ & $4.9(.8)$ & $5.3(.8)$ & 0.183 \\
\hline $\begin{array}{l}\text { Flexor Carpi } \\
\text { Ulnaris }\end{array}$ & 0.662 & $4.7(.7)$ & $4.7(.8)$ & 0.811 & $<0.001$ & $4.5(.7)$ & $5.0(.7)$ & 0.288 \\
\hline $\begin{array}{l}\text { Flexor Carpi } \\
\text { Radialis }\end{array}$ & 0.658 & $6.9(1)$ & $6.8(1)$ & 0.146 & 0.436 & $6.9(1)$ & $6.8(1)$ & 0.398 \\
\hline $\begin{array}{l}\text { Extensor } \\
\text { Digitorum }\end{array}$ & 0.037 & $4.4(.5)$ & $4.1(.5)$ & 0.671 & $<0.001$ & $3.7(.5)$ & $4.8(.5)$ & 0.068 \\
\hline $\begin{array}{l}\text { Flexor } \\
\text { Digitorum }\end{array}$ & 0.356 & $5.0(.7)$ & $4.9(.7)$ & 0.109 & $<0.001$ & $4.5(.7)$ & $5.4(.7)$ & 0.002 \\
\hline $\begin{array}{l}\text { Abductor } \\
\text { Pollicis Longus }\end{array}$ & 0.379 & $6.7(1)$ & $6.6(1)$ & 0.317 & $<0.001$ & $6.2(1)$ & $7.1(1)$ & 0.029 \\
\hline $\begin{array}{l}\text { Extensor } \\
\text { Pollicis Brevis }\end{array}$ & 0.008 & 11(1) & $10(1)$ & 0.028 & $<0.001$ & $9.9(1)$ & 11(1) & 0.028 \\
\hline
\end{tabular}

${ }^{1}$ Repeated Measures ANOVA with participant as a random variable, Gender (2 levels), Tablet Size (2 levels), Tablet Orientation (2 levels), Swipe Location (4 levels), Swipe Orientation (2 levels), and 2-way interactions with gender. Bold values indicate a significant effect $(p<0.05)$.

${ }^{2} \mathrm{TL}=$ top left, $\mathrm{TR}=$ top right, $\mathrm{BL}=$ bottom left, $\mathrm{BR}=$ bottom right

${ }^{3}$ For significant main effects, Tukey's Post-Hoc groupings are ranked such that $\mathrm{A}>\mathrm{B}>\mathrm{C}>\mathrm{D}$. Values with the same superscript letters indicate no significant difference. 
To explore the interactions and different effects within each Sex/gender group, the RMANOVA model was stratified on sex/gender (Table 2.3a,b,c\&d). Male participants were more significantly affected by hardware factors than female participants. For female participants, the larger tablet induced significantly more muscle activity in 6 muscles, whereas the difference was significant for all 8 muscles in the male group. Tablet orientation had opposite effects in each group. Female participants used significantly more muscle activity in landscape compared to portrait for flexor carpi ulnaris, flexor digitorum, and extensor pollicis brevis. Though not significant, this trend existed for all of the other muscles except extensor carpi ulnaris. In male participants, portrait orientation was associated with increased muscle activity in extensor carpi ulnaris, extensor carpi radialis, flexor carpi ulnaris, extensor digitorum, and abductor pollicis longus, and though not significant, the same trend was observed in the other three muscles.

Swipe zone was significant $(<0.05)$ for all muscles except flexor carpi ulnaris in both groups. The post-hoc tests revealed the effect of each of the swipe zones was similar in both groups with the top left generally requiring the most muscle activity and the bottom right generally requiring the least muscle activity. Horizontal swipes were associated with more muscle activity in extensor pollicis brevis in female participants and in extensor digitorum, flexor digitorum, and abductor pollicis longus in male participants. Outward swipes were associated with more muscle activity than inward swipes $(\mathrm{p}<0.0001)$ for all but flexor carpi ulnaris in both groups. 
Table 2.3 a\&b: Stratified Model Median Muscle Activity: Female across participant marginal means (and standard errors) for surface electromyography (\%MVC).

\begin{tabular}{|c|c|c|c|c|c|c|}
\hline Female & \multicolumn{3}{|c|}{ Tablet Size } & \multicolumn{3}{|c|}{ Tablet Orientation } \\
\hline $\begin{array}{c}\text { Median EMG } \\
\text { activity } \\
\text { (\% MVC) }\end{array}$ & P-Value ${ }^{1}$ & $10 "$ & $8 "$ & P-Value & Landscape & Portrait \\
\hline $\begin{array}{c}\text { Extensor Carpi } \\
\text { Ulnaris }\end{array}$ & $<0.001$ & $10(.9)$ & 8.9(.9) & 0.054 & $9.3(.9)$ & $10(.9)$ \\
\hline $\begin{array}{c}\text { Extensor Carpi } \\
\text { Radialis }\end{array}$ & $<0.001$ & 7.1(1) & $6.0(1)$ & 0.684 & $6.6(1)$ & $6.5(1)$ \\
\hline $\begin{array}{l}\text { Flexor Carpi } \\
\text { Ulnaris }\end{array}$ & $<0.001$ & $6.3(1)$ & $5.4(1)$ & 0.019 & $6.1(1)$ & $5.6(1)$ \\
\hline $\begin{array}{c}\text { Flexor Carpi } \\
\text { Radialis }\end{array}$ & $<0.001$ & $6.7(.9)$ & $5.7(.9)$ & 0.139 & $6.3(.9)$ & $6.1(.9)$ \\
\hline $\begin{array}{l}\text { Extensor } \\
\text { Digitorum }\end{array}$ & 0.055 & $5.8(.7)$ & $5.3(.7)$ & 0.133 & $5.7(.7)$ & $5.3(.7)$ \\
\hline $\begin{array}{c}\text { Flexor } \\
\text { Digitorum }\end{array}$ & 0.009 & $7.0(1)$ & $6.5(1)$ & $<0.001$ & $7.1(1)$ & $6.4(1)$ \\
\hline $\begin{array}{c}\text { Abductor } \\
\text { Pollicis Longus }\end{array}$ & $<0.001$ & $9.7(2)$ & $8.7(2)$ & 0.284 & $9.3(2)$ & $9.0(2)$ \\
\hline $\begin{array}{c}\text { Extensor } \\
\text { Pollicis Brevis }\end{array}$ & 0.471 & $14(2)$ & $14(2)$ & 0.009 & $15(2)$ & $14(2)$ \\
\hline
\end{tabular}


Figure 2.3 (Continued)

\begin{tabular}{|c|c|c|c|c|c|c|c|c|c|c|c|}
\hline Female & \multicolumn{5}{|c|}{ Swipe Zone ${ }^{2}$} & \multicolumn{3}{|c|}{ Swipe Orientation } & \multicolumn{3}{|c|}{ Swipe Direction } \\
\hline $\begin{array}{c}\text { EMG } \\
\text { activity } \\
(\% \text { MVC) }\end{array}$ & $\begin{array}{c}\text { P- } \\
\text { Value }^{3}\end{array}$ & $\mathrm{TL}$ & TR & $\mathrm{BL}$ & BR & $\begin{array}{c}\text { P- } \\
\text { Value }\end{array}$ & Horizontal & Vertical & $\begin{array}{c}\text { P- } \\
\text { Value }\end{array}$ & Normal-in & Reverse-out \\
\hline $\begin{array}{c}\text { Extensor } \\
\text { Carpi } \\
\text { Ulnaris }\end{array}$ & $<0.001$ & $13(.9)^{A}$ & $9.5(.9)^{B}$ & $9.3(.9)^{\mathrm{B}}$ & $6.6(.9)^{\mathrm{C}}$ & 0.641 & $9.8(.9)$ & $9.5(.9)$ & $<0.001$ & $8.4(.9)$ & $11(.9)$ \\
\hline $\begin{array}{c}\text { Extensor } \\
\text { Carpi } \\
\text { Radialis }\end{array}$ & $<0.001$ & $7.3(1)^{A}$ & $6.3(1)^{B}$ & $6.9(1)^{A}$ & $5.8(1)^{\mathrm{C}}$ & 0.609 & $6.5(1)$ & $6.6(1)$ & $<\mathbf{0 . 0 0 1}$ & $6.3(1)$ & $6.8(1)$ \\
\hline $\begin{array}{c}\text { Flexor } \\
\text { Carpi } \\
\text { Ulnaris }\end{array}$ & $<0.001$ & $6.9(1)^{A}$ & $5.5(1)^{B}$ & $5.9(1)^{B}$ & $5.2(1)^{B}$ & 0.698 & $5.8(1)$ & $5.9(1)$ & 0.003 & $5.5(1)$ & $6.2(1)$ \\
\hline $\begin{array}{l}\text { Extensor } \\
\text { Digitorum }\end{array}$ & $<0.001$ & $8.1(.7)^{A}$ & $4.9(.7)^{B}$ & $5.4(.7)^{B}$ & $3.8(.7)^{\mathrm{C}}$ & 0.332 & $5.7(.7)$ & $5.4(.7)$ & $<\mathbf{0 . 0 0 1}$ & $4.9(.7)$ & $6.2(.7)$ \\
\hline $\begin{array}{c}\text { Flexor } \\
\text { Digitorum }\end{array}$ & $<0.001$ & $8.1(1)^{A}$ & $6.1(1)^{C}$ & $7.1(1)^{B}$ & $5.9(1)^{\mathrm{C}}$ & 0.690 & $6.7(1)$ & $6.8(1)$ & $<0.001$ & $6.1(1)$ & $7.4(1)$ \\
\hline $\begin{array}{l}\text { Abductor } \\
\text { Pollicis } \\
\text { Longus }\end{array}$ & $<0.001$ & $12(2)^{A}$ & $8.5(2)^{B}$ & $9.3(2)^{\mathrm{B}}$ & $7.3(2)^{C}$ & 0.988 & $9.2(2)$ & $9.2(2)$ & $<0.001$ & $8.6(2)$ & $9.8(2)$ \\
\hline $\begin{array}{c}\text { Extensor } \\
\text { Pollicis } \\
\text { Brevis }\end{array}$ & $<0.001$ & $16(2)^{A}$ & $14(2)^{B}$ & $15(2)^{B}$ & $12(2)^{C}$ & 0.008 & $15(2)$ & $14(2)$ & $<\mathbf{0 . 0 0 1}$ & $14(2)$ & $15(2)$ \\
\hline
\end{tabular}

${ }^{1}$ Repeated Measures ANOVA with participant as a random variable, Gender (2 levels), Tablet Size (2 levels), Tablet Orientation (2 levels), Swipe Location (4 levels), Swipe Orientation (2 levels). Bold values indicate a significant effect $(p<0.05)$.

${ }^{2} \mathrm{TL}=$ top left, $\mathrm{TR}=$ top right, $\mathrm{BL}=$ bottom left, $\mathrm{BR}=$ bottom right

${ }^{3}$ For significant main effects, Tukey's Post-Hoc groupings are ranked such that $\mathrm{A}>\mathrm{B}>\mathrm{C}>\mathrm{D}$. Values with the same superscript letters indicate no significant difference 
Table 2.3 c\&d: Stratified Model Median Muscle Activity: Male across participant marginal means (and standard errors) for surface electromyography (\%MVC).

\begin{tabular}{|c|c|c|c|c|c|c|}
\hline Male & \multicolumn{3}{|c|}{ Tablet Size } & \multicolumn{3}{|c|}{ Tablet Orientation } \\
\hline $\begin{array}{l}\text { activity } \\
\text { (\% MVC) }\end{array}$ & P-Value ${ }^{1}$ & $10 "$ & $8 "$ & P-Value & Landscape & Portrait \\
\hline $\begin{array}{l}\text { Extensor Carpi } \\
\text { Ulnaris }\end{array}$ & $<0.001$ & 5.3(1) & 4.4(1) & $<0.001$ & 4.3(1) & $5.5(1)$ \\
\hline $\begin{array}{l}\text { Extensor Carpi } \\
\text { Radialis }\end{array}$ & $<0.001$ & $4.1(.8)$ & $3.3(.8)$ & $<\mathbf{0 . 0 0 1}$ & $3.5(.8)$ & $3.9(.8)$ \\
\hline $\begin{array}{l}\text { Flexor Carpi } \\
\text { Ulnaris }\end{array}$ & $<0.001$ & 3.9(.6) & $3.2(.6)$ & 0.011 & 3.4(.6) & 3.7(.6) \\
\hline $\begin{array}{l}\text { Flexor Carpi } \\
\text { Radialis }\end{array}$ & $<0.001$ & 8.1(2) & $6.8(2)$ & 0.586 & 7.4(2) & $7.5(2)$ \\
\hline $\begin{array}{l}\text { Extensor } \\
\text { Digitorum }\end{array}$ & $<0.001$ & $3.3(.8)$ & $2.7(.8)$ & 0.003 & $2.7(.8)$ & $3.2(.8)$ \\
\hline $\begin{array}{l}\text { Flexor } \\
\text { Digitorum }\end{array}$ & $<\mathbf{0 . 0 0 1}$ & 3.4(.7) & $2.8(.7)$ & 0.138 & $3.0(.7)$ & $3.2(.7)$ \\
\hline $\begin{array}{c}\text { Abductor } \\
\text { Pollicis Longus }\end{array}$ & $<0.001$ & 4.5(1) & 3.7(1) & 0.002 & 3.8(1) & 4.4(1) \\
\hline $\begin{array}{c}\text { Extensor Pollicis } \\
\text { Brevis }\end{array}$ & $<0.001$ & 6.6(1) & $6.2(1)$ & 0.159 & $6.3(1)$ & $6.5(1)$ \\
\hline
\end{tabular}


Figure 2.3 (Continued)

\begin{tabular}{|c|c|c|c|c|c|c|c|c|c|c|c|}
\hline Male & \multicolumn{5}{|c|}{ Swipe Zone $^{2}$} & \multicolumn{3}{|c|}{ Swipe Orientation } & \multicolumn{3}{|c|}{ Swipe Direction } \\
\hline $\begin{array}{c}\text { EMG } \\
\text { activity } \\
(\% \mathrm{MVC})\end{array}$ & $\begin{array}{c}\text { P- } \\
\text { Value }^{3}\end{array}$ & $\mathrm{TL}$ & $\mathrm{TR}$ & $\mathrm{BL}$ & $\mathrm{BR}$ & $\begin{array}{c}\text { P- } \\
\text { Value }\end{array}$ & Horizontal & Vertical & $\begin{array}{c}\text { P- } \\
\text { Value }\end{array}$ & Normal-in & $\begin{array}{c}\text { Reverse- } \\
\text { out }\end{array}$ \\
\hline $\begin{array}{c}\text { Extensor } \\
\text { Carpi } \\
\text { Ulnaris }\end{array}$ & $<0.001$ & $7.3(1)^{A}$ & $4.9(1)^{B}$ & $4.6(1)^{B}$ & $2.7(1)^{\mathrm{C}}$ & 0.032 & $5.2(1)$ & 4.6(1) & $<0.001$ & $4.1(1)$ & $5.7(1)$ \\
\hline $\begin{array}{c}\text { Extensor } \\
\text { Carpi } \\
\text { Radialis }\end{array}$ & $<0.001$ & $4.1(.8)^{A}$ & $3.5(.8)^{\mathrm{BC}}$ & $3.8(.8)^{A B}$ & $3.3(.8)^{\mathrm{C}}$ & 0.031 & $3.8(.8)$ & $3.6(.8)$ & 0.002 & $3.5(.8)$ & $3.9(.8)$ \\
\hline $\begin{array}{l}\text { Flexor Carpi } \\
\text { Ulnaris }\end{array}$ & $<0.001$ & $3.7(.6)^{A B}$ & 3.1(.6) ${ }^{\mathrm{C}}$ & 3.9(.6) & $3.4(.6)^{\mathrm{BC}}$ & 0.839 & $3.5(.6)$ & $3.6(.6)$ & 0.001 & $3.4(.6)$ & $3.7(.6)$ \\
\hline $\begin{array}{c}\text { Flexor Carpi } \\
\text { Radialis }\end{array}$ & 0.1737 & $7.1(2)$ & $7.3(2)$ & $7.6(2)$ & $7.7(2)$ & 0.279 & $7.6(2)$ & $7.3(2)$ & 0.355 & $7.5(2)$ & $7.3(2)$ \\
\hline $\begin{array}{l}\text { Extensor } \\
\text { Digitorum }\end{array}$ & $<0.001$ & $4.2(.8)^{A}$ & $2.7(.8)^{\mathrm{B}}$ & $2.9(.8)^{\mathrm{B}}$ & $1.9(.8)^{\mathrm{C}}$ & 0.014 & $3.2(.8)$ & $2.7(.8)$ & $<0.001$ & $2.6(.8)$ & $3.3(.8)$ \\
\hline $\begin{array}{c}\text { Flexor } \\
\text { Digitorum }\end{array}$ & $<0.001$ & $3.5(.7)^{\mathrm{A}}$ & $2.7(.7)^{\mathrm{C}}$ & $3.2(.7)^{\mathrm{AB}}$ & $2.9(.7)^{\mathrm{BC}}$ & 0.016 & $3.2(.7)$ & $2.9(.7)$ & $<0.001$ & $2.8(.7)$ & $3.3(.7)$ \\
\hline $\begin{array}{l}\text { Abductor } \\
\text { Pollicis } \\
\text { Longus }\end{array}$ & $<0.001$ & $5.1(1)^{A}$ & $3.8(1)^{\mathrm{BC}}$ & $4.2(1)^{B}$ & $3.4(1)^{C}$ & 0.048 & $4.3(1)$ & 3.9(1) & $<0.001$ & 3.8(1) & $4.4(1)$ \\
\hline $\begin{array}{c}\text { Extensor } \\
\text { Pollicis } \\
\text { Brevis }\end{array}$ & $<\mathbf{0 . 0 0 1}$ & $7.1(1)^{A}$ & $5.9(1)^{B}$ & $7.0(1)^{A}$ & $5.6(1)^{B}$ & 0.554 & $6.4(1)$ & $6.4(1)$ & $<0.001$ & $6.1(1)$ & $6.8(1)$ \\
\hline
\end{tabular}

${ }^{1}$ Repeated Measures ANOVA with participant as a random variable, Gender (2 levels), Tablet Size (2 levels), Tablet Orientation (2 levels), Swipe Location (4 levels), Swipe Orientation (2 levels). Bold values indicate a significant effect $(p<0.05)$.

$$
{ }^{2} \mathrm{TL}=\text { top left, } \mathrm{TR}=\text { top right, } \mathrm{BL}=\text { bottom left, } \mathrm{BR}=\text { bottom right }
$$

${ }^{3}$ For significant main effects, Tukey's Post-Hoc groupings are ranked such that $\mathrm{A}>\mathrm{B}>\mathrm{C}>\mathrm{D}$. Values with the same superscript letters indicate no significant difference. 
Table 2.4 a,b\&c: Combined Model Average Performance: Across participant marginal means (and standard errors) for completion time

\begin{tabular}{|c|c|c|c|c|c|c|c|c|c|c|c|}
\hline & \multicolumn{3}{|c|}{ Gender } & \multicolumn{3}{|c|}{ Tablet Size } & Gender & \multicolumn{3}{|c|}{ Tablet Orientation } & $\underset{\text { Grientation }}{\text { Gender }}$ \\
\hline & P-Value ${ }^{3}$ & Female & Male & P-Value ${ }^{1}$ & $10 "$ & $8 "$ & P-Value ${ }^{3}$ & P-Value & Landscape & Portrait & P-Value ${ }^{3}$ \\
\hline $\begin{array}{l}\text { Time } \\
(\mathrm{ms})\end{array}$ & 0.743 & $\begin{array}{l}1112 \\
(114)\end{array}$ & $\begin{array}{l}1058 \\
(114)\end{array}$ & 0.939 & $\begin{array}{r}1083 \\
(83)\end{array}$ & $\begin{array}{r}1086 \\
(83)\end{array}$ & 0.684 & 0.073 & $1121(83)$ & $1048(83)$ & 0.116 \\
\hline
\end{tabular}

\begin{tabular}{|c|c|c|c|c|c|c|}
\hline & \multicolumn{5}{|c|}{ Swipe Zone ${ }^{2}$} & $\begin{array}{c}\text { Gender x } \\
\text { Zone }\end{array}$ \\
\hline & P-Value ${ }^{3}$ & TL & TR & BL & BR & P-Value ${ }^{3}$ \\
\hline Time (ms) & $<0.001$ & $1444(88)^{A}$ & $1007(87)^{B}$ & $990(87)^{B}$ & $899(89)^{\mathrm{B}}$ & 0.036 \\
\hline
\end{tabular}


Figure 2.4 (Continued)

\begin{tabular}{|c|c|c|c|c|c|c|c|c|}
\hline & \multicolumn{3}{|c|}{ Swipe Orientation } & $\begin{array}{c}\text { Gender x Swipe } \\
\text { orientation }\end{array}$ & \multicolumn{3}{|c|}{ Swipe Direction } & $\begin{array}{l}\text { Gender } \mathbf{x} \\
\text { Direction }\end{array}$ \\
\hline & P-Value & Horizontal & Vertical & P-Value ${ }^{3}$ & P-Value & Normal-in & Reverse-out & P-Value ${ }^{3}$ \\
\hline Time (ms) & 0.589 & $1072(80)$ & 1097 (87) & 0.461 & $<0.001$ & $992(83)$ & $1177(83)$ & 0.966 \\
\hline
\end{tabular}

${ }^{1}$ Repeated Measures ANOVA with participant as a random variable, Gender (2 levels), Tablet Size (2 levels), Tablet Orientation (2 levels), Swipe Location (4 levels), Swipe Orientation (2 levels), and 2-way interactions with gender. Bold values indicate a significant effect $(p<0.05)$

$$
{ }^{2} \mathrm{TL}=\text { top left, } \mathrm{TR}=\text { top right, } \mathrm{BL}=\text { bottom left, } \mathrm{BR}=\text { bottom right }
$$

${ }^{3}$ For significant main effects, Tukey's Post-Hoc groupings are ranked such that $\mathrm{A}>\mathrm{B}>\mathrm{C}>\mathrm{D}$. Values with the same superscript letters indicate no significant difference 
Table 2.5 a\&b: Stratified Model Median Performance: Across participant marginal means (and standard errors) for completion time

\begin{tabular}{|c|ccc|ccc|}
\hline & \multicolumn{3}{|c|}{ Tablet Size } & \multicolumn{3}{c|}{ Tablet Orientation } \\
Time (ms) & P-Value ${ }^{1}$ & $10 "$ & $8 ”$ & P-Value & Landscape & Portrait \\
$(\%$ MVC) & & & & & & \\
Female & 0.789 & $1118(119)$ & $1105(119)$ & $\mathbf{0 . 0 0 5}$ & $\mathbf{1 1 7 9}(\mathbf{1 1 9})$ & $\mathbf{1 0 4 4}(\mathbf{1 1 9})$ \\
Male & 0.761 & $1048(115)$ & $1068(115)$ & 0.889 & $1063(115)$ & $1054(115)$ \\
\hline
\end{tabular}

\begin{tabular}{|c|c|c|c|c|c|c|c|c|c|c|c|}
\hline \multirow[b]{2}{*}{$\begin{array}{l}\text { Time }(\mathrm{ms}) \\
(\% \mathrm{MVC})\end{array}$} & \multicolumn{5}{|c|}{ Swipe Zone ${ }^{2}$} & \multicolumn{3}{|c|}{ Swipe Orientation } & \multicolumn{3}{|c|}{ Swipe Direction } \\
\hline & P-Value ${ }^{3}$ & $\mathrm{TL}$ & TR & $\mathrm{BL}$ & BR & $\begin{array}{c}\mathrm{P}- \\
\text { Value }\end{array}$ & Horizontal & Vertical & $\begin{array}{c}\mathrm{P}- \\
\text { Value }\end{array}$ & $\begin{array}{l}\text { Normal- } \\
\text { in }\end{array}$ & $\begin{array}{c}\text { Reverse- } \\
\text { out }\end{array}$ \\
\hline Female & $<0.001$ & $\begin{array}{c}1552 \\
(124)^{A}\end{array}$ & $\begin{array}{c}971 \\
(\mathbf{1 2 4})^{\mathrm{BC}}\end{array}$ & $\begin{array}{c}1052 \\
(124)^{\mathrm{B}}\end{array}$ & $\begin{array}{c}873 \\
(125)^{\mathrm{C}}\end{array}$ & 0.872 & $1116(117)$ & 1107 (123) & $<0.001$ & $\begin{array}{l}1018 \\
(120)\end{array}$ & $\begin{array}{l}1205 \\
(120)\end{array}$ \\
\hline Male & $<0.001$ & $\begin{array}{c}1336 \\
(124)^{\AA}\end{array}$ & $\begin{array}{c}1043 \\
(123)^{\mathrm{B}}\end{array}$ & $\begin{array}{c}928 \\
(123)^{\mathrm{B}}\end{array}$ & $\begin{array}{c}926 \\
(126)^{\mathrm{B}}\end{array}$ & 0.427 & $1029(110)$ & $1088(122)$ & 0.007 & 966 (116) & $\begin{array}{l}1150 \\
(116)\end{array}$ \\
\hline
\end{tabular}

${ }^{1}$ Repeated Measures ANOVA with participant as a random variable, Tablet Size (2 levels), Tablet Orientation (2 levels), Swipe Location (4 levels), Swipe Orientation (2 levels). Bold values indicate a significant effect $(p<0.05)$

${ }^{2} \mathrm{TL}=$ top left, $\mathrm{TR}=$ top right, $\mathrm{BL}=$ bottom left, $\mathrm{BR}=$ bottom right

${ }^{3}$ For significant main effects, Tukey's Post-Hoc groupings are ranked such that $\mathrm{A}>\mathrm{B}>\mathrm{C}>\mathrm{D}$. Values with the same superscript letters indicate no significant difference 
Table 2.6: Combined Model Self Report: Across participant marginal means (and standard errors) for discomfort and difficulty

\begin{tabular}{|c|c|c|c|c|c|c|c|c|c|c|c|c|}
\hline \multirow[b]{2}{*}{ VAS (cm) } & \multicolumn{3}{|c|}{ Gender } & \multicolumn{3}{|c|}{ Tablet Size } & \multicolumn{3}{|c|}{ Tablet Orientation } & \multicolumn{3}{|c|}{ Zone } \\
\hline & $\begin{array}{c}\text { P- } \\
\text { Value }^{1}\end{array}$ & $\mathrm{~F}$ & M & $\begin{array}{c}\text { P- } \\
\text { Value }^{1}\end{array}$ & $10 "$ & $8 "$ & P-Value & Landscape & Portrait & P-Value & Left & Right \\
\hline Discomfort & 0.106 & $1.3(.4)$ & $2.3(.4)$ & 0.645 & $1.8(.3)$ & $1.7(.3)$ & 0.985 & $1.8(.3)$ & $1.8(.3)$ & $<0.001$ & $2.6(.3)$ & $1.0(.3)$ \\
\hline Difficulty & 0.233 & $1.7(.5)$ & $2.5(.5)$ & 0.934 & $2.1(.4)$ & $2.1(.4)$ & 0.469 & $2.2(.4)$ & $2.0(.4)$ & $<0.001$ & $3.1(.4)$ & $1.1(.4)$ \\
\hline
\end{tabular}

${ }^{1}$ Repeated Measures ANOVA with participant as a random variable, Gender (2 levels) Tablet Size (2 levels), Tablet Orientation (2 levels), Zone (2 levels). Bold values indicate a significant effect $(p<0.05)$.

Table 2.7: Stratified Model Self Report: Across participant marginal means (and standard errors) for discomfort and difficulty

\begin{tabular}{|c|c|c|c|c|c|c|c|c|c|}
\hline & \multicolumn{3}{|c|}{ Tablet Size } & \multicolumn{3}{|c|}{ Tablet Orientation } & \multicolumn{3}{|c|}{ Zone } \\
\hline $\begin{array}{l}\text { VAS }(\mathrm{cm}) \\
(\% \mathrm{MVC})\end{array}$ & P-Value ${ }^{1}$ & 10 " & $8 "$ & P-Value & Landscape & Portrait & P-Value & Left & Right \\
\hline \multicolumn{10}{|l|}{ Female } \\
\hline Discomfort & 0.888 & $1.3(.4)$ & $1.3(.4)$ & 0.655 & $1.3(.4)$ & $1.2(.4)$ & $<0.001$ & $2.0(.4)$ & $0.6(.4)$ \\
\hline Difficulty & 0.372 & $1.6(.5)$ & $1.8(.5)$ & 0.361 & $1.8(.5)$ & $1.6(.5)$ & $<0.001$ & $2.8(.5)$ & $0.6(.5)$ \\
\hline \multicolumn{10}{|l|}{ Male } \\
\hline Discomfort & 0.654 & $2.4(.5)$ & $2.2(.5)$ & 0.804 & $2.3(.5)$ & $2.4(.5)$ & $<0.001$ & $3.2(.5)$ & $1.0(.5)$ \\
\hline Difficulty & 0.627 & $2.7(.5)$ & $2.4(.5)$ & 0.796 & $2.6(.5)$ & $2.5(.5)$ & 0.001 & $3.5(.5)$ & $1.6(.5)$ \\
\hline
\end{tabular}

${ }^{1}$ Repeated Measures ANOVA with participant as a random variable, Tablet Size (2 levels), Tablet Orientation (2 levels), Zone (2 levels) as fixed effects. Bold values indicate a significant effect $(p<0.05)$. 
Dependent Variables: Performance

Sex/Gender was not a significant main effect for performance (Table 2.4). Sex/Gender x swipe zone was significant $(\mathrm{p}=0.0363)$. In the sex/gender stratified model (Table 2.5), tablet orientation had a significant effect $(\mathrm{p}=0.005)$ in female participants only with shorter average completion times observed in the portrait orientation compared to landscape orientation. Swipe zone and swipe direction were significant main effects for both groups, though post hoc testing revealed significant differences between the bottom left and bottom right locations for female participants.

Dependent Variables: Self-reported discomfort

Only swipe zone (two levels) was a significant $(\mathrm{p}<0.0001)$ main effect for self reported discomfort and difficulty (Table 2.6). Participants indicated that swipes farther from the hand towards the center of the screen had more discomfort and difficulty than swipes on the right edge of the screen. Female participants rated lower average discomfort and difficulty, but there was not a statistically significant difference. No significant interaction effects were observed. Similarly, swipe zone was observed as a significant main effect for both male and female selfreported discomfort and difficulty in the sex/gender stratified model (Table 2.7).

\section{Discussion}

The aim of this study was to build upon a previous thumb swiping study to determine the effect of sex/gender for participants' thumb swiping performance, forearm muscle activity, and self-reported discomfort during thumb swiping tasks (Coppola et al., 2018). Overall, there was a significant effect of sex/gender in addition to the other independent variables (tablet size, tablet 
orientation, gesture location, gesture direction, and gesture orientation) on many forearm muscles. Sex/Gender did not have a significant effect on performance or user perception.

Consistent with our hypothesis, female sex/gender was associated with higher muscle activity for the thumb muscles involved in swipes and wrist muscles involved in holding the tablet. Similarly, the stratified results revealed that female participants used more of their maximum voluntary contractions across most muscles to complete the swiping tasks compared to male participants which corresponds to previous research (Nordander et al., 2008). The differences observed in the wrist extensors and flexors were probably due to the differences in male and female grip strength (Angst et al., 2010; Fain \& Weatherford, 2016; Macdermid, Fehr, \& Lindsay, 2002).

The significant interactions between sex/gender and tablet orientation and swipe zone revealed that male and female participants were affected differently by the different tablet factors. The opposite effects of tablet orientation in each group suggest different grip strategies were utilized by male and female participants. Landscape mode induced larger muscle activity in female participants than portrait mode, whereas portrait mode induced more muscle activity in male participants. In addition, female participants had longer completion times in landscape mode compared to portrait mode. Changing the orientation of the tablet changes the location of the tablet's center of mass and the grip strategies necessary to support its weight (Eardley, Roudaut, Gill, \& Thompson, 2017; Pereira et al., 2013; Trudeau et al., 2013). The width of the gripping area is larger in landscape mode. This is similar to the findings in Xiong \& Muraki (2016) which found that participants with smaller hands have more difficulty maintaining grip and utilizing the thumb on wider touchscreens. Interestingly, while tablet size was a significant main effect for muscle activity, no difference was found between the two sex/gender groups. The 
different aspects of tablet size, tablet orientation, and grip strategies should be explored in future studies.

Swipe zone was a significant main effect across both wrist and thumb muscles, suggesting that reaching different parts of the touchscreen is associated with changes in both grip and thumb efforts. The top left location farthest from the base of the thumb was consistently associated with the most muscle activity and longest completion times in both sexes/genders. For the two thumb muscles, no significant difference was found for the two right locations closer to the palm in male participants, while the top right was associated with significantly more muscle activity than the bottom right in female participants. In EPB, no difference was observed between the two left zones in male participants and the bottom left was significantly higher than the top right and bottom right, whereas in the female participants, the bottom left location was significantly less than the top left and not significantly different from the top right. This suggests that the female participants were more affected by reach and that targets closer to the palm and base of the thumb are easier for female participants to achieve. This is consistent with previous research that has shown that people with smaller hands and thumbs have more difficulty reaching and have to alter hand grips in order to reach farther targets and that people with larger hands and thumbs have difficulty reaching targets close to the base of the thumb (Xiong \& Muraki, 2016; Zhang et al., 2015).Swipes farther from the palm also took the longest to complete and were rated as having more discomfort and difficulty than swipes closer to the palm.

Consistent with previous thumb tapping studies, swiping inward towards the palm was associated with less muscle activity and shorter completion times (Trudeau, Young, et al., 2012; Xiong \& Muraki, 2014). In addition, male participants were affected by swipe direction and used 
more muscle activity to complete horizontal swipes. Horizontal swipes require $\mathrm{CMC}$ joint extension/flexion, which may be more awkward to achieve for people with larger hands.

This study's results suggest that male and female users' forearm muscles are affected differently by tablet hardware and software factors. Manufacturers should consider creating and marketing different sized tablets for different people. The farthest location tested in this study was consistently associated with the worst outcomes in this study and in previous research, suggesting that user interface designers should avoid target locations in the center of tablet touchscreens. In addition to the many accessibility options available on the interface to improve the user experience for people with visual and hearing disabilities, the screen could be adapted to move the target location based on the user's individual comfort zone.

The current study has several limitations. First, we only considered the two-handed grip support condition with only the right thumb used for swipes. Sex/Gender is a proxy for many biological and psychosocial variables and thus may not fully explain the between group differences that were observed. The low sample size limited the ability to explore other potential covariates such as anthropometry. Another limitation is that this was a laboratory study with a short duration of swiping tasks, and the relatively small differences in muscle activity may not have clinical significance. Future studies should include fingers on both hands in longer tasks and explore different tablet sizes and grip strategies.

\section{Conclusion}

The study results demonstrated significant sex/gender differences in forearm muscle activity for thumb swiping tasks during a two-handed grip on a tablet. In addition, tablet size, tablet orientation, swipe location, swipe orientation, and swipe direction significantly affected 
forearm muscle activity, performance, and user experience. These results should inform tablet hardware and software design to provide improved performance and usability while inducing a more neutral thumb and wrist posture with smaller muscle load demands. Tablet manufacturers should recruit diverse users for testing and ensure that groups of people are not more negatively affected by design than others.

\section{Acknowledgements}

This research was supported in part by the National Science Foundation (0964220), The Office Ergonomics Research Committee, and the National Institute for Occupational Safety and Health (T42 OH008416). We would like to thank Mark Janelli and John Schilkowsky for contributions to study design, experiment preparation, data collection and compilation and Julia Rhyins for help reviewing the manuscript. 


\section{References}

Accot, J., \& Zhai, S. (1997). Beyond Fitts' law: models for trajectory-based HCI tasks. Paper presented at the CHI EA '97 CHI '97 Extended Abstracts on Human Factors in Computing Systems, Atlanta.

Ahn, S. H., Kwon, S., Bahn, S., Yun, M. H., \& Yu, W. (2016). Effects of Grip Curvature and Hand Anthropometry for the Unimanual Operation of Touchscreen Handheld Devices. Human Factors and Ergonomics in Manufacturing \& Service Industries, 26(3), 367-380. doi:10.1002/hfm.20662

Ali, M., Asim, M., Danish, S. H., Ahmad, F., Iqbal, A., \& Hasan, S. D. (2014). Frequency of De Quervain's tenosynovitis and its association with SMS texting. Muscles, ligaments and tendons journal, 4(1), 74.

Anders, C., Bretschneider, S., Bernsdorf, A., Erler, K., \& Schneider, W. (2004). Activation of shoulder muscles in healthy men and women under isometric conditions. Journal of Electromyography and Kinesiology, 699-707.

Angst, F., Drerup, S., Werle, S., Herren, D. B., Simmen, B. R., \& Goldhahn, J. (2010). Prediction of grip and key pinch strength in 978 healthy subjects. BMC Musculoskeletal Disorders, 11, 94-94. doi:10.1186/1471-2474-11-94

Bergstrom-Lehtovirta, J., \& Oulasvirta, A. (2014). Modeling the functional area of the thumb on mobile touchscreen surfaces. Paper presented at the CHI '14 Proceedings of the SIGCHI Conference on Human Factors in Computing Systems, Toronto.

Chang, H.-T., Tsai, T.-H., Chang, Y.-C., \& Chang, Y.-M. (2014). Touch panel usability of elderly and children. Computers in Human Behavior, 37(C), 258-269. doi:10.1016/j.chb.2014.04.050

Coppola, S. M., Lin, M. Y., Schilkowsky, J., Arezes, P. M., \& Dennerlein, J. T. (2018). Tablet form factors and swipe gesture designs affect thumb biomechanics and performance during two-handed use. Applied Ergonomics, 69, 40-46.

Coté, J. N. (2011). A critical review on physical factors and functional characteristics that explain a sex/gender difference in work-relatedneck/shoulder disorders. Ergonomics, $55: 2,173-182$.

Dennerlein, J. T., Martin, D. B., \& Hasser, C. (2000). Force-feedback improves performance for steering and combined steering-targeting tasks. Paper presented at the CHI '00: Proceedings of the SIGCHI conference on Human Factors in Computing Systems, Th Hague.

Eapen, C., Kumar, B., Bhat, A. K., \& Venugopal, A. (2014). Extensor Pollicis Longus Injury in Addition to De Quervain's with Text Messaging on Mobile Phones. Journal of clinical and diagnostic research : JCDR, 8(11), LC01. doi:10.7860/JCDR/2014/8304.5094

Eardley, R., Roudaut, A., Gill, S., \& Thompson, S. (2017). Understanding Grip Shifts: How Form Factors Impact Hand Movements on Mobile Phones. In (Vol. 2017-, pp. 46804691).

Faber, A., Hansen, K., \& Christensen, H. (2006). Muscle strength and of aerobic capacity in a representative sample of employees with and without repetitive monotonous work. International Archives of Occupational and Environmental Health, 33-41. 
Fain, E., \& Weatherford, C. (2016). Comparative study of millennials' (age 20-34 years) grip and lateral pinch with the norms. Journal of Hand Therapy, 29(4), 483.

doi:10.1016/j.jht.2015.12.006

Gao, Q., \& Sun, Q. (2015). Examining the Usability of Touch Screen Gestures for Older and Younger Adults. Human Factors: The Journal of Human Factors and Ergonomics Society, 57(5), 835-863. doi:10.1177/0018720815581293

Gerr, F., Marcus, M., Ensor, C., Kleinbaum, D., Cohen, S., Edwards, A., . . Monteilh, C. (2002). A Prospective Study of Computer Users: I. Study Design, and Incidence of Musculoskeletal Symptoms and Disorders. American Journal of Industrial Medicine.

Guan, X., Fan, G., Chen, Z., Zeng, Y., Zhang, H., Hu, A., . . He, S. (2016). Gender difference in mobile phone use and the impact of digital device exposure on neck posture. Ergonomics, 59(11), 1453-1461. doi:10.1080/00140139.2016.1147614

Gustafsson, E., Johnson, P. W., \& Hagberg, M. (2010). Thumb postures and physical loads during mobile phone use - A comparison of young adults with and without musculoskeletal symptoms. Journal of Electromyography and Kinesiology, 20(1), 127135. doi:10.1016/j.jelekin.2008.11.010

Gustafsson, E., Thomée, S., Grimby-Ekman, A., \& Hagberg, M. (2017). Texting on mobile phones and musculoskeletal disorders in young adults: A five-year cohort study. Applied Ergonomics, 58, 208-214. doi:10.1016/j.apergo.2016.06.012

Haward, B., \& Griffin, M. (2002). Repeatability of grip strength and dexterity tests and the effects of age and gender. International Archives of Occupational and Envirionmental Health, 111-119.

Irwin, C. B., \& Sesto, M. E. (2012). Performance and touch characteristics of disabled and nondisabled participants during a reciprocal tapping task using touch screen technology. Applied Ergonomics, 43(6), 1038-1043. doi:10.1016/j.apergo.2012.03.003

Kietrys, D. M., Gerg, M. J., Dropkin, J., \& Gold, J. E. (2015). Mobile input device type, texting style and screen size influence upper extremity and trapezius muscle activity, and cervical posture while texting. Applied Ergonomics, 50, 98-104.

Kim, H.-J., \& Kim, J.-S. (2015). The relationship between smartphone use and subjective musculoskeletal symptoms and university students. Journal of Physical Therapy Science, 27, 575-579.

Kim, H. K., Choe, M., Choi, Y., \& Park, J. (2017). Does the Hand Anthropometric Dimension Influence Touch Interaction? Journal of Computer Information Systems, 1-12. doi:10.1080/08874417.2017.1305876

Kim, J. H., Aulck, L., Bartha, M. C., Harper, C. A., \& Johnson, P. W. (2014). Differences in typing forces, muscle activity, comfort, and typing performance among virtual, notebook, and desktop keyboards. Applied Ergonomics, 1406-1413.

Ko, P. H., Hwang, Y. H., \& Liang, H. W. (2016). Influence of smartphone use styles on typing performance and biomechanical exposure. Ergonomics, 59(6), 821-828.

Korpinen, L., Pääkkönen, R., \& Gobba, F. (2013). Self-reported neck symptoms and use of personal computers, laptops and cell phones among Finns aged 18-65. Ergonomics, 56(7), 1134-1146. doi:10.1080/00140139.2013.802018

Lee, S. C., Cha, M. C., Hwangbo, H., Mo, S., \& Ji, Y. G. (2018). Smartphone form factors: Effects of width and bottom bezel on touch performance, workload, and physical demand. Applied Ergonomics, 67, 142-150. doi:10.1016/j.apergo.2017.10.002 
Macdermid, J. C., Fehr, L., \& Lindsay, K. (2002). The Effect of Physical Factors on Grip Strength and Dexterity. Hand Therapy, 7(4), 112-118. doi:10.1177/175899830200700401

Mihajlov, M., Law, E. L.-C., \& Springett, M. (2015). Intuitive Learnability of Touch Gestures for Technology-Naïve Older Adults. Interacting with Computers, 27(3), 344-356. doi:10.1093/iwc/iwu044

Mobile Fact Sheet. (2018, February 5).

Mogk, J., \& Keir, P. (2003). The effects of posture on forearm muscle loading during gripping. Ergonomics, 956-975.

Nordander, C., Ohlsson, K., Balogh, I., Hansson, G., Axmon, A., Persson, R., \& Skerfving, S. (2008). Gender differences in workers with identical repetitive industrial tasks: exposure and musculoskeletal disorders. International Archives of Occupational and Environmental Health, 939-947.

Odell, D., \& Chandrasekaran, V. (2012). Enabling comfortable thumb interaction in tablet computers: a Windows 8 case study. Paper presented at the Proceedings of the Human Factors and Ergonomics Society Annual Meeting.

Orphanides, A. K., \& Nam, C. S. (2017). Touchscreen interfaces in context: A systematic review of research into touchscreens across settings, populations, and implementations. Applied Ergonomics, 61, 116-143. doi:10.1016/j.apergo.2017.01.013

Park, Y. S., \& Han, S. H. (2010). One-handed thumb interaction of mobile devices from the input accuracy perspective. International Journal of Industrial Ergonomics, 40(6), 746756.

Pereira, A., Miller, T., Huang, Y., Odell, D., \& Rempel, D. (2013). Holding a tablet computer with one hand: effect of tablet design features on biomechanics and subjective usability among users with small hads. Ergonomics, 56(9), 163-175.

Poushter, J. (2016, February 22). Smartphone Ownership and Internet Usage Continues to Climb in Emerging Economies.

Punnett, L., \& Bergqvist, U. (1999). Musculoskeletal disorders in visual display unit work: gender and work demands. Occupational medicine (Philadelphia, Pa.), 14(1), 113.

Redmayne, M., Smith, E., \& Abramson, M. J. (2013). The relationship between adolescents' well-being and their wireless phone use: a cross-sectional study.(Report). Environmental Health: A Global Access Science Source, 12(1). doi:10.1186/1476-069X-12-90

Sesto, M. E., Irwin, C. B., Chen, K. B., Chourasia, A. O., \& Wiegmann, D. A. (2012). Effect of Touch Screen Button Size and Spacing on Touch Characteristics of Users With and Without Disabilities. Human Factors: The Journal of Human Factors and Ergonomics Society, 54(3), 425-436. doi:10.1177/0018720811433831

Shan, Z., Deng, G., Li, J., Li, Y., Zhang, Y., \& Zhao, Q. (2013). Correlational Analysis of neck/shoulder Pain and Low Back Pain with the Use of Digital Products, Physical Activity and Psychological Status among Adolescents in Shanghai (Neck/Shoulder and Low Back Pain among Students). 8(10), e78109. doi:10.1371/journal.pone.0078109

Toh, S. H., Coenen, P., Howie, E. K., \& Straker, L. M. (2017). The associations of mobile touch screen device use with musculoskeletal symptoms and exposures: A systematic review. PLoS ONE, 12(8).

Trudeau, M., Asakawa, D. S., Jindrich, D., \& Dennerlein, J. T. (2016). Two-handed grip on a mobile phone affords greater thumb motor performance, decreased variability, and a more extended thumb posture than a one-handed grip. Applied Ergonomics. 
Trudeau, M., Catalano, P., Jindrich, J., \& Dennerlein, J. (2013). Tablet Keyboard Configuration Affects Performance, Discomfort and Task Difficulty for Thumb Typing in a TwoHanded Grip. PLoS One.

Trudeau, M., Udtamadilok, T., Karlson, A., \& Dennerlein, J. (2012). Thumb motor performance varies by movement orientation, direction, and device size during single-handed mobile phone use. Human Factors.

Trudeau, M., Young, J., Jindrich, D., \& Dennerlein, J. (2012). Thumb motor performance varies with thumb and wrist posture during single-handed mobile phone use. Journal of Biomechanics, 45(14), 2349-2354.

Xie, Y., Szeto, G., \& Dai, J. (2017). Prevalence and risk factors associated with musculoskeletal complaints among users of mobile handheld devices: A systematic review. Applied Ergonomics, 59(Pt A), 132-142. doi:10.1016/j.apergo.2016.08.020

Xie, Y., Szeto, G. P. Y., Dai, J., \& Madeleine, P. (2015). A comparison of muscle activity in using touchscreen smartphone among young people with and without chronic neckshoulder pain. Ergonomics, 59(1), 1-12. doi:10.1080/00140139.2015.1056237

Xiong, J., \& Muraki, S. (2014). An ergonomics study of thumb movements on smartphone touch screen. Ergonomics, 57(6), 1-13. doi:10.1080/00140139.2014.904007

Xiong, J., \& Muraki, S. (2016). Effects of age, thumb length and screen size on thumb movement coverage on smartphone touchscreens. International Journal of Industrial Ergonomics, 53, 140-148. doi:10.1016/j.ergon.2015.11.004

Young, J., Trudeau, M., Odell, D., Marinelli, K., \& Dennerlein, J. (2013). Wrist and shoulder posture and muscle activity during touch-screen tablet use: effects of usage configuration, tablet type, and interacting hand. Work.

Zhang, Y., Ou, B., Ding, Q., \& Yang, Y. (2015). Touch Behavior Analysis for Large Screen Smartphones. Proceedings of the Human Factors and Ergonomics Society Annual Meeting, 59(1), 1433-1437. doi:10.1177/1541931215591311 


\section{Chapter 3}

Sex/gender differences in upper extremity biomechanical exposures in office workers during an observational study 


\begin{abstract}
Women have higher rates of upper extremity musculoskeletal pain and disorders than men, but the reasons for the sex/gender difference are not well understood. One possible cause is the design of workstations are built for men and therefore expose women to larger biomechanical stresses. This observational study directly measured muscle activity, posture, joint movements, and applied forces in 84 women and 34 men during a two-hour period at their normal workstations. Significant differences were observed in forearm muscle activity and applied forces. These results support interventions in the design of input devices for women.
\end{abstract}




\section{Introduction}

Computer use and female sex/gender are both risk factors for upper extremity musculoskeletal disorders (MSDs) and pain (Messing, Stock, \& Tissot, 2009; Wahlstrm, 2005). Women have higher prevalence of hand, wrist, neck, and shoulder disorder (Nordander et al., $2009,2013,2016)$. Studies with office workers have reported up to twice rates of lost productivity from pain symptoms in women as compared to men (Hagberg, Vilhemsson, Tornqvist, \& Toomingas, 2007). The underlying causes of this sex/gender differential are poorly understood (Coté, 2011). A potential explanation for this difference is that the built environment is not designed for female workers, so a female worker will need to use more extreme postures and more of her total functional strength to complete the same task (Stellman, Lucas, \& Anderson, 2012).

Previous studies have observed self-reported computer-related pain and sex/gender differences. A prospective cohort study with 632 newly hired computer workers found that more than $50 \%$ of participants reported neck/shoulder or hand/arm symptoms in the first year (Gerr et al., 2002; Marcus et al., 2002). Risk factors reported were female sex/gender, prior history of symptoms, white ethnicity, children under 6 in the home, prior computer use, and some workstation related factors as measured at baseline. Similarly, Hagberg et al. (2007) observed twice the reduced productivity in women compared to men due to upper extremity symptoms over a 10 month period in a large prospective cohort study. They found that using a mouse more than half of the work day, working overtime, low exercise, high job demands, smoking, children under 6 in the home, and some workstation related factors were risk factors for reduced productivity due to pain. These studies included large cohorts over time, but they did not measure sex/gender exposure differences. 
Nordander and colleagues pooled cross-sectional data of exposure and MSD in workers in various occupations. They found an association between higher forearm and trapezius muscle activity, higher upper arm velocity, higher wrist flexion, and higher wrist velocity and neck and shoulder pain (2016). After controlling for physical and psychosocial factors, women had 10$15 \%$ higher neck and shoulder disorder prevalence. Similarly, higher wrist flexion and angular velocity, and higher forearm muscle activity were associated with hand and arm disorders, and there was a $10 \%$ higher symptom prevalence in women (2013). The authors did not test sex/gender differentials in the exposure measures.

Laboratory stories have shown sex/gender differences in upper extremity biomechanics during computer tasks (Coppola, Dixon, Hu, Lin, \& Dennerlein, 2019). Men have been shown to be more affected by monitor setup than women (Farias Zuniga \& Côté, 2017). Won et al. (2009) investigated sex/gender differences in a study of 15 women and 15 men in a repeated-measures study with five standardized computer tasks, with multiple mouse locations for one of the tasks. Women had higher relative applied forces to the keyboard and mouse, higher forearm muscle activity, and more degrees of wrist flexion, external rotation, and wrist extension.

Therefore, the purpose of this study was to determine if there were sex/gender differences observed during a field study. It examined sex/gender differences in upper extremity muscle activity, postures, joint velocities and applied forces during an observational study of office workers. The participants used their own desks during the study, which provides a more realistic exposure measure than laboratory experiments. 


\section{Methods}

To analyze upper extremity musculoskeletal differences between male and female computer workers in the field, data were obtained from the larger PRedicting Occupational biomechanics in OFfice workers (PROOF) study, which is aimed at investigating the effects of psychosocial stressors at work on biomechanical loading of office workers in the field (Bruno Garza et al., 2012). 120 (34 males and 86 females) healthy participants were recruited for this study at the VU University or the VU University Medical Center, in Amsterdam, the Netherlands (Table 3.1). All participants self-reported that they had a working contract between 20 and 40 hour/ week (61 participants reported working 36 hours or more per week) and held jobs that involved mainly computer work. Due to equipment error, only 118 (34 males and 84 females) participants were included in the final analyses.

All protocols and consent forms were approved by the Harvard T.H. Chan School of Public Health Human Subjects Committee, the Medical Ethics Committee of the VU University Medical Center Amsterdam and the Ethics Committee of the VU University Faculty of Human Movement Sciences.

Table 3.1: Participants' data

\begin{tabular}{|l|l|l|l|}
\hline & Male (SD) & Female & P-value \\
\hline $\mathbf{N}$ & 34 & 84 & $<\mathbf{0 . 0 0 1}$ \\
\hline Year of Birth (year) & $1966(12)$ & $1972(11)$ & $<\mathbf{0 . 0 0 1}$ \\
\hline Height (cm) & $183(17)$ & $171(7.7)$ & $<\mathbf{0 . 0 0 1}$ \\
\hline Weight (kg) & $83(11)$ & $70(14)$ & $<\mathbf{0 . 0 0 1}$ \\
\hline Body mass index & $26(12)$ & $24(4.4)$ & 0.0542 \\
\hline Arm length (cm) & $58(6.2)$ & $54.5(4.9)$ & $<\mathbf{0 . 0 0 1}$ \\
\hline Forearm length (cm) & $27(2.1)$ & $25(1.6)$ & $<\mathbf{0 . 0 0 1}$ \\
\hline Hand length (cm) & $9.3(5.1)$ & $7.5(0.49)$ & $<\mathbf{0 . 0 0 1}$ \\
\hline Shoulder breadth (cm) & $40(2.5)$ & $36(2.2)$ & $<\mathbf{0 . 0 0 1}$ \\
\hline Eye Height (cm) & $53(4.0)$ & $49(3.3)$ & $<\mathbf{0 . 0 0 1}$ \\
\hline Knee Height (cm) & $49(2.6)$ & $47(3.3)$ & $<\mathbf{0 . 0 0 1}$ \\
\hline Key Activation Force (N) & $0.33(0.03)$ & $0.37(.42)$ & 0.181 \\
\hline
\end{tabular}




\section{Data Collection}

To allow the participants to perform their regular work without interruption or restriction, the systems used to measure the biomechanical exposures were chosen to be unobtrusive and appropriate for field studies (Nordander et al., 2016). Participants were able to move freely at their workstation and to leave the workstation without restraint. Measurements were taken at participants' designated workstations on a day that participants reported to be representative of a regular workday, and balanced so that there were equal measurements on each weekday and in the morning/afternoon. Keyboard and mouse events were measured using custom-designed computer interaction monitoring software (Chang, Johnson, \& Dennerlein, 2008). The forces applied to the keyboard and sides of the mouse, muscle effort of the left and right trapezius and extensor carpi radialis, and postures of the left and right wrist and shoulder, the head, neck and trunk were simultaneously monitored.

Keyboard and mouse force was measured using a force platform similar to the one described in Asundi et al. (2009). Participants used their own keyboard during the measurement period, which was placed on the force plate. Mouse grip force was measured using a modified USB mouse with scroll wheel (Model 3902C693; Microsoft, Inc., Redmond, WA) modelled after the one designed by Johnson et al. (2000). The modified mouse had three compression load cells (ELW-D1-10L; Measurement Specialties, Hampton, VA) mounted inside and measured the thumb forces applied to the left side of the mouse. All participants were required to use the forcesensing mouse instead of their own mouse, and to use the mouse with their right hand during the measurement period. Keyboard and mouse grip force were recorded during all activities. The load cells in the keyboard and the mouse were connected to USB backplanes (NI cDAQ-9172; National Instruments, Austin, USA) that sampled the data at 10,000 samples per second using 
LabView (LabView v.8.5; National Instruments, Austin, USA). Data were low-pass filtered at $20 \mathrm{~Hz}$ (6th order Butterworth filter) and down-sampled to 40 samples per second before being saved on the personal computer. To avoid drift over time both forces signals were automatically zeroed whenever the standard deviation of the force signal over a one second window was close to zero. To normalize the force readings, three 5 -second maximal force contraction measurements were collected from each force-sensing device to determine the participant's maximum voluntary forces (MVFs). Separate, MVF-sensing devices with different compression load cells (Mouse Model LSB200 L2357, Range 0-875lb, Keyboard Model LSB200, Range 0100lbs, Futek Advanced Sensor Technology Inc., Irvine, CA) were used for the MVFs so that the MVFs did not overload the load cells of the force-sensing mouse and keyboard. A static, typing maximal force measurement was collected by having participants press down as hard as they could on the ' $J$ ' key of the MVF-sensing keyboard with their right index finger. A static, mousebased maximal force measurement was collected by having subjects squeeze the MVF-sensing mouse using the same hand and mousing posture that they used during their actual work. The MVF values were the highest one-second averages of the force signals collected from the three 5-second maximal force measurements for each force-sensing device. Subjects had approximately one minute of rest in between each contraction.

Muscle activity was collected for the right and left upper trapezius (TRAP) and extensor carpi radialis (ECR) using wireless surface electromyography (EMG) (Mega WBA; Mega Electronics LTD, Kupio, Finland). Due to technical error, only 102 subjects' left trap data were analyzed. After abrading the target areas of the skin and washing these areas with alcohol, 12mm diameter Ambu Bluesensor N-00-S surface electrodes containing highly conductive wet gel were mounted over the muscles of interest with $20 \mathrm{~mm}$ interelectrode spacing in accordance with 
published guidelines for the surface EMG of the ECR (Basmajian, 1989) and of the TRAP (Jensen et al. 1993). The wireless EMG pre-amplifier was attached to the two electrodes and a third ground electrode. While the sensors were being applied, participants sat in the postures that would be assumed during computer use. Data were recorded at 1000 samples per second after amplification (bandwidth of 10-500 Hz). The bipolar signal was converted to an EMG amplitude signal by smoothing its absolute value through a $3 \mathrm{~Hz}$ second-order, zero phase, low-pass Butterworth filter. The signals were then down-sampled to 40 samples per second using a mean filtering procedure. In order to normalize the EMG signal amplitude, prior to data collection three 5-second maximal muscle contraction measurements were collected from each muscle to determine each participant's maximum voluntary contractions (MVCs). Each muscle's MVC was the highest one-second average of the EMG amplitudes collected from the three measurements. Within each muscle, there was approximately one minute of rest in between each MVC.

Posture, wrist velocity and wrist acceleration were measured using twin axis electrogoniometers (Model SG65; Biometrics Ltd, Gwent, UK) that recorded wirelessly at 1000 samples per second via the same MegaWin WBA data logging system used for the muscle effort data collection. Data were digitally filtered through a $5 \mathrm{~Hz}$ second-order, zero phase, low-pass Butterworth filter and down-sampled to 40 samples per second. Wrist angles were the angle deviations in degrees, relative to the reference wrist posture angles defined as the position of approximately zero wrist flexion and wrist deviation determined by the experimenter while the participant's hand was open and relaxed. Wrist joint velocities and accelerations were calculated by digitally differentiating the posture data. The root mean squared (RMS) value was taken to represent each parameter. Shoulder flexion, shoulder abduction, torso, neck and head postures 
were measured using five data-loggers containing triaxial accelerometer data-loggers (G-Link Data Loggers; Microstrain, Inc; Williston, USA). The postural data loggers were placed on each participant's right and left arm as close to the shoulder as possible, on the torso centered above the acromial notch, on the neck centered above the $\mathrm{C} 7$ vertebrae, and centered on the participant's forehead. Due to the $2 \mathrm{Mb}$ onboard memory limitation of the data loggers, data were recorded at 25 samples per second. Once downloaded, data were passed through a $5 \mathrm{~Hz}$ second-order, zero phase, low-pass Butterworth filter and were converted from acceleration units to degrees. Angles were calculated with respect to the reference posture defined as the posture recorded while participants stood erect looking straight ahead with their arms resting at their sides. The accelerometer axes were aligned with flexion and extension by recording data during a pure bowing motion (flexion at the hips only).

To measure shoulder rotation, a custom video system calculated angles based on the projected position of black and white markers taped at the dorsal side of the wrist, the lower biceps brachii and on the acromion at the shoulder onto a video image (Bruno et al. 2011). Laboratory comparisons of this system with a 3D motion analysis system demonstrated good accuracy (average error of 1 degree for right rotation) for computer-related postures. Video images were collected at 30 frames per second. Position data from the images were filtered using a $5 \mathrm{~Hz}$ fourth-order, low-pass filter. To match recording rates of the other systems, all postural data were upsampled to 40 samples per second using a linear interpolation method.

Data were synchronized from the different systems and parsed to identify the data sections that corresponded to the different computer activities. To synchronize the force, muscle effort and postural data, after all of the instrumentation was mounted and before returning to their work participants performed a series of distinctive movements that would show in the 
datastream of multiple systems, including bowing, abducting their shoulders and tapping on the keyboard using flexion movements of their wrist. These movements were repeated at the end of the data collection period before instrumentation was removed. These synchronization events were readily identifiable via visual inspection and were used to align all force, muscle effort, posture and computer interaction data through cross-correlations calculated from the signals. Once synchronized, the force, muscle effort and postural data were parsed and grouped by keyboard activities, mouse activities and idle activities. For each force, muscle effort and postural measure within each computer activity, summary statistics were calculated including the 10th, 50th and 90th percentiles of the signal amplitude, which provided a measure of the distribution of the postural data and EMG data (Jonsson 1988). The difference between the 90th and 10th percentiles provided a measure of variability. For wrist velocity and acceleration, the root mean square values were calculated as described in Marras (1992).

\section{Statistical Analysis}

To test the hypothesis that forces, muscle activity, postures, velocities and accelerations differed by sex/gender for each computer activity, repeated measures ANOVA were fitted to find differences in the 50th percentile and variability (90th-10th) of each summary statistic (dependent parameters) with task (keyboard activity, mouse activity and idle activity) and sex/gender as fixed effects and subject as a random effect. Both unadjusted and adjusted models with anthropometry confounders were fitted. Hand length and shoulder breadth were controlled for as confounders based on examining correlations, univariate measures, and the literature. Year of birth was controlled for as a potential confounder in the model because this sample had statistically different mean ages between women and men (Nordander 2013). Significance was 
set at 0.05 . Statistical analysis was performed using JMP Pro 14 (SAS) linear mixed model software.

\section{Results}

Muscle Activity

There was a significant sex/gender difference $(\mathrm{p}=0.0134)$ for median left $\mathrm{ECR}$, but after controlling for YOB and anthropometry, this effect is not present (Table 3.2a). The median right ECR sex/gender difference approaches significance in both the adjusted and unadjusted models $(\mathrm{p}=0.0547, \mathrm{p}=0.0586)$. Both median ECR muscle activities showed a significant sex/gender by task interaction with a steeper slope in female participants (Figure 3.1). The median right trapezius muscle approached significance for a sex/gender main effect $(\mathrm{p}=0.0573)$ in the unadjusted model. No significant results were observed for the median left trap or the interaction effects in either shoulder.

There was a slightly significant sex/gender effect for the variability $\left(90^{\text {th }}-10^{\text {th }}\right)$ right ECR measure ( $\mathrm{p}=0.0183$ ) but this effect is not present after controlling for YOB and anthropometry (Table 3.3a). No sex/gender effect was observed for variability in the left ECR, but the sex/gender by task interaction was significant in both models $(\mathrm{p}=0.0111$ ) (figure 3.2). No significant sex/gender or interaction effects were observed for variability either trapezius muscle.

\section{Posture}

No significant sex/gender or interaction effects were observed for either wrists' median postures (Table 3.2b). Median right shoulder flexion $(p=0.0408)$ and left shoulder flexion $(\mathrm{p}=0.0110)$ had slightly significant effects in the adjusted model. Median right shoulder abduction had a significant sex/gender effect in both the adjusted and unadjusted models ( $\mathrm{p}=$ 
$0.0003, \mathrm{p}=0.0200$ ). No significant effects were observed for left shoulder abduction or the interaction between task and sex/gender for any of the shoulder postures. No significant results were observed for median head, neck, or torso postures (Table 3.2c).

There was a slightly significant sex/gender effect for the variability $\left(90^{\text {th }}-10^{\text {th }}\right)$ left wrist radial deviation $(\mathrm{p}=0.0235)$ but this effect is not present after controlling for YOB and anthropometry (Table 3.3b). No sex/gender effects were observed for the other wrist variability posture measures. After adjusting for YOB and anthropometry, a slightly significant sex/gender effect was observed for right shoulder flexion variability $(\mathrm{p}=0.0183)$ and the interaction between sex/gender and task $(\mathrm{p}=0.0135)$. No other significant results were observed for the other shoulder posture variability measures. No significant results were observed for head, neck, or torso posture variability, with the exception of torso flexion in the adjusted model $(\mathrm{p}=0.0032)$ (Table 3.3c).

\section{Joint movement}

There was a marginally significant difference $(\mathrm{p}=0.0206)$ in average right wrist radial velocity; however, after adjusting for YOB and anthropometry, this difference is no longer significant (Table 3.4). There were no other significant differences in right or left wrist velocity or acceleration in both the radial-ulnar and flexion-extension directions.

\section{Mouse and key forces}

Female participants used significantly more of their maximum mouse force during mousing tasks $(\mathrm{p}=0.0196)$ than male participants; however, after adjusting for YOB and anthropometry, this is no longer a significant result (Table 3.5). Female participants also used more of their maximum 
key force during keyboarding activities $(p=0.0186)$ than male participants, and this effect remains significant $(p=0.223)$ after controlling for YOB and anthropometry. 
Table 3.2a: Median Extensor Carpi Radialis and Trapezius Muscle Electromyography: Across participant marginal means (and standard errors) for $\% M V C$.

\begin{tabular}{|c|c|c|c|c|c|c|c|c|c|}
\hline $50^{\text {th }}$ & & $\begin{array}{l}\text { S/G } \\
p \text {-value }\end{array}$ & $\begin{array}{l}\text { Male mean } \\
\text { (SE) }\end{array}$ & $\begin{array}{l}\text { Female mean } \\
\text { (SE) }\end{array}$ & $\begin{array}{l}\text { Task } \\
\text { p-value }\end{array}$ & $\begin{array}{l}\text { Task x } \\
\text { S/G p- } \\
\text { value }\end{array}$ & $\begin{array}{l}\text { Year of } \\
\text { Birth } \\
\text { p-value }\end{array}$ & $\begin{array}{l}\text { Hand } \\
\text { Length p- } \\
\text { value }\end{array}$ & $\begin{array}{l}\text { Shoulder } \\
\text { Breadth p- } \\
\text { value }\end{array}$ \\
\hline \multirow[t]{2}{*}{ Right Extensor Carpi Radialis } & Unadjusted & 0.059 & $5.47(.52)$ & $6.64(.33)$ & $<0.001$ & $<0.001^{2}$ & & & \\
\hline & Adjusted & 0.055 & $5.30(.58)$ & $6.71(.33)$ & $<0.001$ & $<0.001$ & $<0.001$ & 0.858 & 0.367 \\
\hline Left Extensor Carpi Radialis & Unadjusted & 0.013 & $4.49(.37)$ & $5.58(.23)$ & $<0.001$ & 0.009 & & & \\
\hline Right Trapezius & Adjusted & 0.135 & $4.99(.65)$ & $6.22(.37)$ & $<0.001$ & 0.231 & 0.008 & 0.577 & 0.393 \\
\hline \multirow[t]{2}{*}{ Left Trapezius ${ }^{2}$} & Unadjusted & 0.249 & $6.74(.69)$ & $7.68(.44)$ & $<0.001$ & 0.682 & & & \\
\hline & Adjusted & 0.092 & $3.51(.71)$ & $5.02(.40)$ & $<0.001$ & 0.067 & $<0.001$ & 0.409 & 0.931 \\
\hline
\end{tabular}

${ }^{1}$ Repeated Measures ANOVA with participant as a random variable, sex/gender, task, sex/gender X task interaction, year of birth, hand length, and shoulder breadth. Bold values indicate a significant effect $(p<0.05)$.

${ }^{2}$ Interation means are shown in Figure 1

$$
{ }^{3} n=102 \text { for Left Trapezius }
$$


Table 3.2b: Median Wrist and Shoulder Posture: Across participant marginal means (and standard errors) for degrees.

\begin{tabular}{|c|c|c|c|c|c|c|c|c|c|}
\hline $50^{\text {th }}$ & & $\begin{array}{r}\mathrm{S} / \mathrm{G} \\
\mathrm{p} \text {-value }\end{array}$ & Male mean & Female mean & $\begin{array}{r}\text { Task } \\
\text { p-value }\end{array}$ & $\begin{array}{l}\text { Task x } \\
\text { S/G p- } \\
\text { value }\end{array}$ & $\begin{array}{r}\text { Year of } \\
\text { Birth } \\
\text { p-value }\end{array}$ & $\begin{array}{r}\text { Hand } \\
\text { Length p- } \\
\text { value } \\
\end{array}$ & $\begin{array}{r}\text { Shoulder } \\
\text { Breadth p- } \\
\text { value } \\
\end{array}$ \\
\hline \multirow[t]{2}{*}{ Right Wrist Extension } & Unadjusted & 0.738 & $26.66(1.9)$ & $25.90(1.2)$ & $<0.001$ & 0.843 & & & \\
\hline & Adjusted & 0.355 & $28.06(2.3)$ & $25.32(1.3)$ & $<0.001$ & 0.843 & 0.263 & 0.160 & 0.395 \\
\hline Left Wrist Extension & Adjusted & 0.833 & $18.81(2.4)$ & $19.45(1.4)$ & $<0.001$ & 0.466 & 0.280 & 0 & 0.316 \\
\hline \multirow[t]{2}{*}{ Right Wrist Radial Deviation } & Unadjusted & 0.2395 & $2.67(1.3)$ & $4.44(.80)$ & $<0.001$ & 0.573 & & & \\
\hline & Adjusted & 0.654 & $3.32(1.5)$ & $4.18(.86)$ & $<0.001$ & 0.573 & 0.039 & 0.913 & 0.908 \\
\hline \multirow[t]{2}{*}{ Right Shoulder Rotation } & Unadjusted & 0.428 & $3.89(1.7)$ & $2.30(1.1)$ & $<0.001$ & 0.207 & & & \\
\hline & Adjusted & 0.704 & $2.10(2.0)$ & $3.09(1.2)$ & $<0.001$ & 0.207 & 0.118 & 0.118 & 0.899 \\
\hline \multirow[t]{2}{*}{ Left Shoulder Rotation } & Unadjusted & 0.229 & $20.06(2.0)$ & $22.98(1.3)$ & 0.006 & 0.212 & & & \\
\hline & Adjusted & 0.070 & $18.15(2.4)$ & $23.82(1.5)$ & 0.006 & 0.212 & 0.303 & 0.678 & 0.070 \\
\hline \multirow[t]{2}{*}{ Right Shoulder Flexion } & Unadjusted & 0.150 & $15.07(2.3)$ & $11.13(1.47)$ & 0.798 & 0.517 & & & \\
\hline & Adjusted & 0.041 & $17.48(2.8)$ & $10.17(1.6)$ & 0.797 & 0.514 & 0.567 & 0.377 & 0.152 \\
\hline Left Shoulder Abduction & Adjusted & 0.217 & $9.40(1.9)$ & 6.38 & 0.871 & 0.363 & 0.599 & 0.981 & 0.222 \\
\hline
\end{tabular}

${ }^{1}$ Repeated Measures ANOVA with participant as a random variable, sex/gender, task, sex/gender X task interaction, year of birth, hand length, and shoulder breadth. Bold values indicate a significant effect $(p<0.05)$. 
Table 3.2c: Median Head, Neck, and Torso Posture: Across participant marginal means (and standard errors) for degrees.

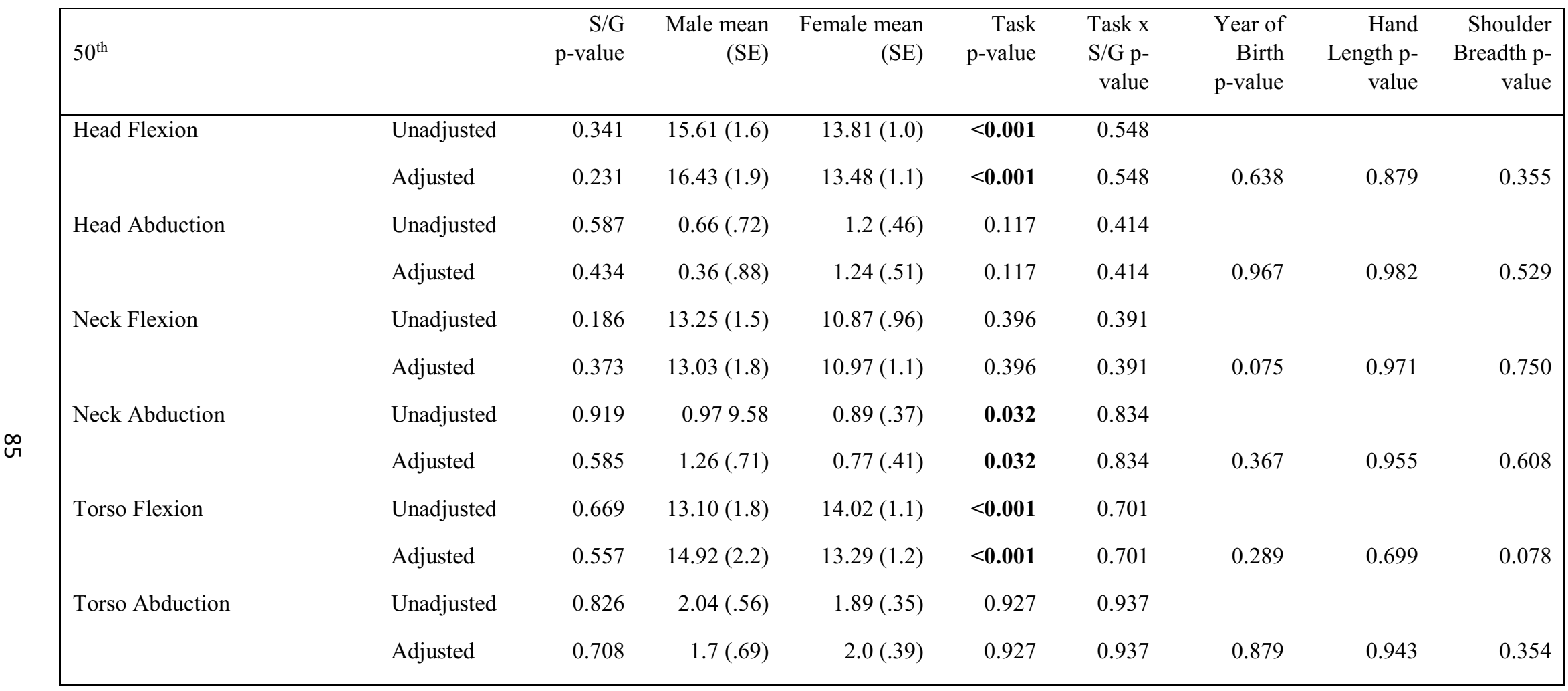

${ }^{1}$ Repeated Measures ANOVA with participant as a random variable, sex/gender, task, sex/gender X task interaction, year of birth, hand length, and shoulder breadth. Bold values indicate a significant effect $(p<0.05)$ 


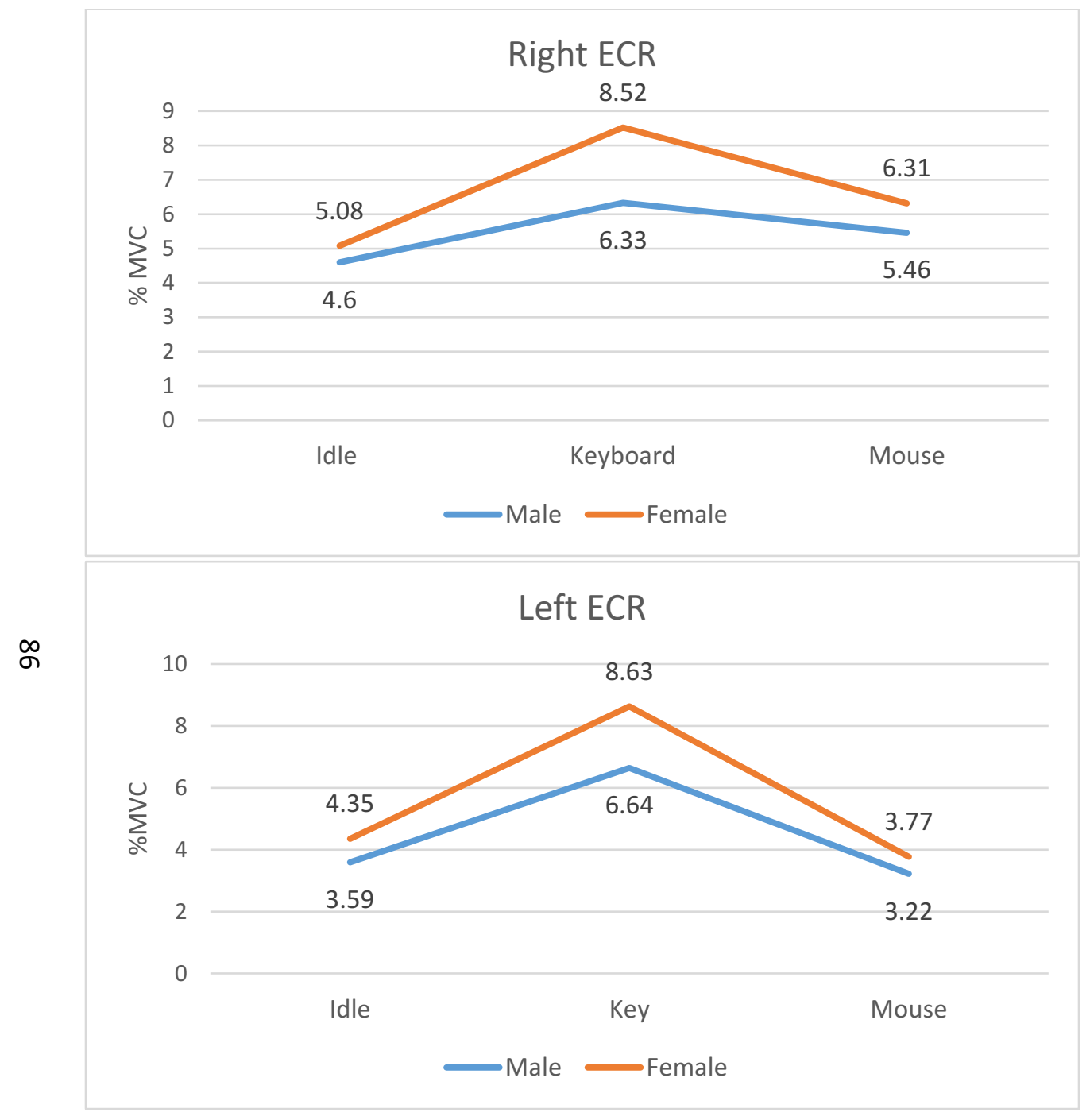

Figure 3.1: EMG plot for significant interactions $(p<0.05)$ between task and sex/gender for extensor carpi radialis (ECR). Marginal means for $\% M V C$. 
Table 3.3a: Variability Extensor Carpi Radialis and Trapezius Muscle Electromyography: Across participant marginal means (and standard errors) for $\% M V C$.

\begin{tabular}{|c|c|c|c|c|c|c|c|c|c|}
\hline $90^{\text {th }}-10^{\text {th }}$ & & $\begin{array}{l}\text { S/G } \\
p \text {-value }{ }^{1}\end{array}$ & $\begin{array}{l}\text { Male mean } \\
\text { (SE) }\end{array}$ & $\begin{array}{l}\text { Female mean } \\
\text { (SE) }\end{array}$ & $\begin{array}{l}\text { Task } \\
\text { p-value }\end{array}$ & $\begin{array}{l}\text { Task x } \\
\text { S/G p- } \\
\text { value }\end{array}$ & $\begin{array}{l}\text { Year of } \\
\text { Birth } \\
\text { p-value }\end{array}$ & $\begin{array}{l}\text { Hand } \\
\text { Length p- } \\
\text { value }\end{array}$ & $\begin{array}{l}\text { Shoulder } \\
\text { Breadth p- } \\
\text { value }\end{array}$ \\
\hline \multirow[t]{2}{*}{ Right Extensor Carpi Radialis } & Unadjusted & 0.018 & $5.42(.63)$ & $7.21(.40)$ & $<0.001$ & 0.489 & & & \\
\hline & Adjusted & 0.077 & $5.49(.75)$ & $7.18(.43)$ & $<0.001$ & 0.489 & 0.015 & 0.928 & 0.369 \\
\hline \multirow[t]{2}{*}{ Left Extensor Carpi Radialis } & Unadjusted & 0.273 & $7.22(.55)$ & $7.9(.35)$ & $<0.001$ & 0.011 & & & \\
\hline & Adjusted & 0.621 & $8.01(.62)$ & $7.62(.35)$ & $<0.001$ & 0.011 & 0.004 & 0.471 & 0.001 \\
\hline Right Trapezius & Adjusted & 0.499 & $7.88(.64)$ & $8.42(.36)$ & $<0.001$ & 0.738 & 0.032 & 0.671 & 0.316 \\
\hline \multirow[t]{2}{*}{ Left Trapezius ${ }^{2}$} & Unadjusted & 0.219 & $3.94(.62)$ & $4.85(.39)$ & $<0.001$ & 0.067 & & & \\
\hline & Adjusted & 0.194 & $6.46(.81)$ & $7.80(.46)$ & $<0.001$ & 0.682 & 0.006 & 0.994 & 0.800 \\
\hline
\end{tabular}

${ }^{1}$ Repeated Measures ANOVA with participant as a random variable, sex/gender, task, sex/gender X task interaction, year of birth, hand length, and shoulder breadth. Bold values indicate a significant effect $(p<0.05)$.

${ }^{2} \mathrm{n}=102$ for Left Trapezius 
Table 3.3b: Variability Wrist and Shoulder Posture: Across participant marginal means (and standard errors) for degrees.

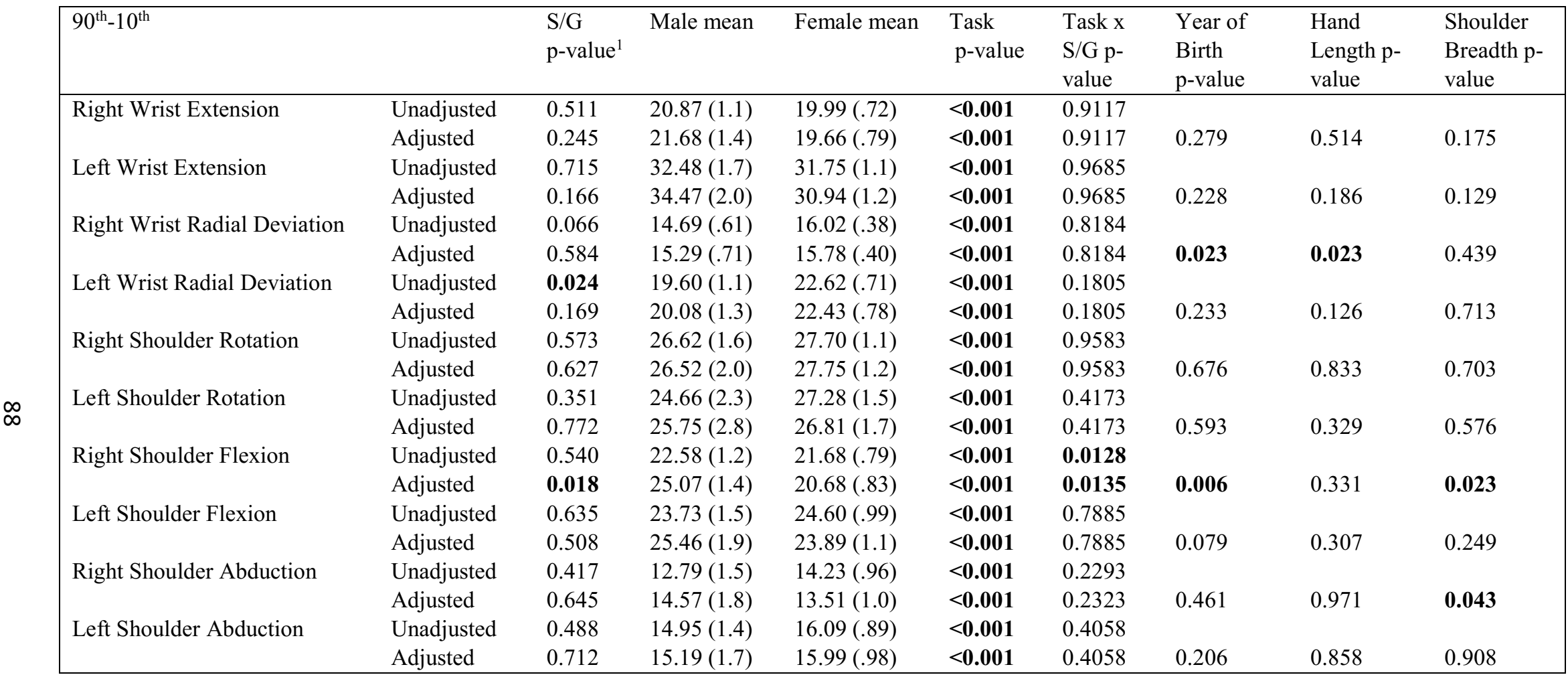

${ }^{1}$ Repeated Measures ANOVA with participant as a random variable, sex/gender, task, sex/gender X task interaction, year of birth, hand length, and shoulder breadth. Bold values indicate a significant effect $(p<0.05)$. 

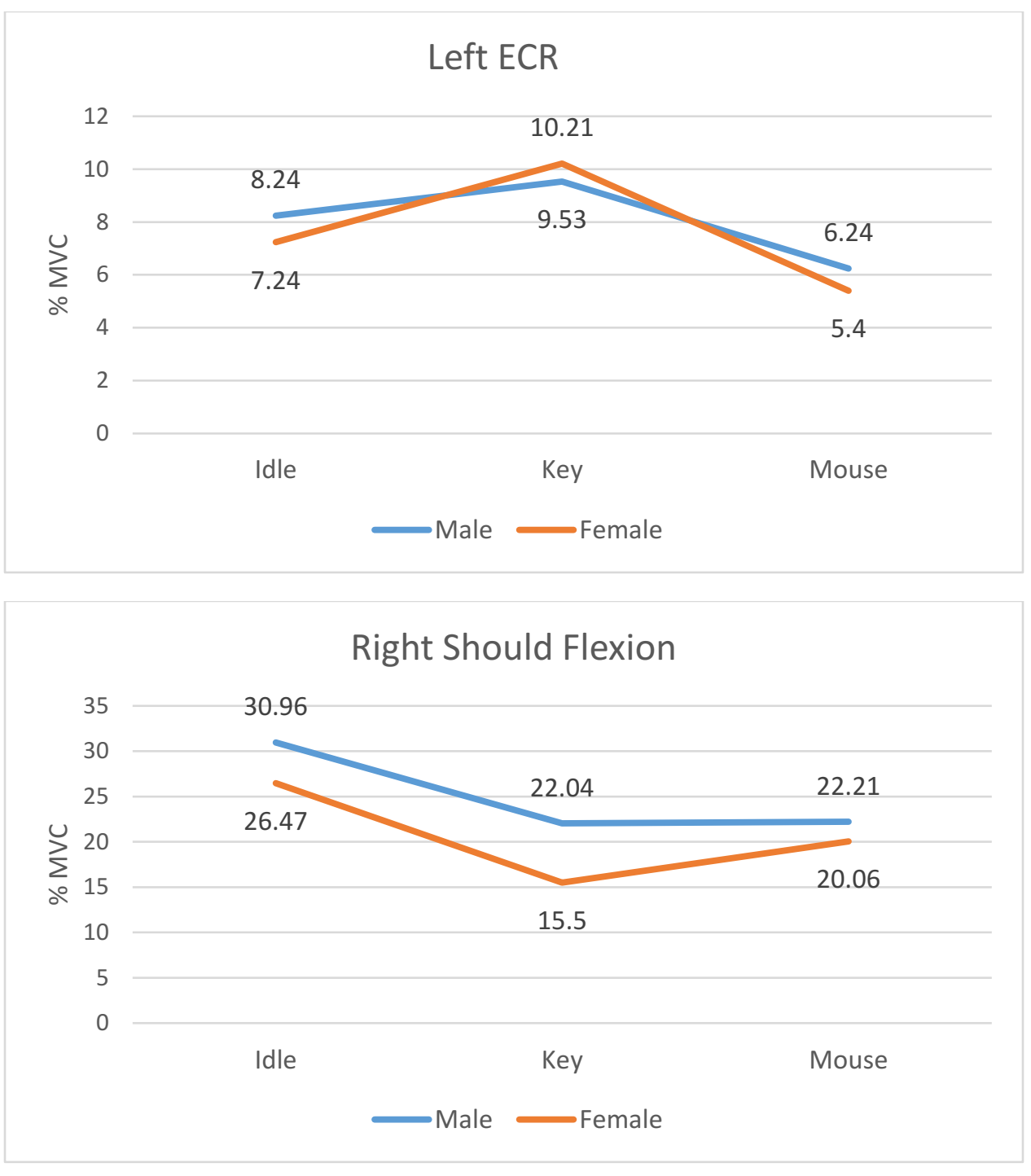

Figure 3.2: Plot for significant interactions $(p<0.05)$ between task and sex/gender for left extensor carpi radialis $(E C R)$ EMG and Right Shoulder Flexion Posture. Marginal means for variation $\left(90^{\text {th }}-10^{\text {th }}\right) \% M V C$. 
Table 3.3c: Variability Head, Neck, and Torso Posture: Across participant marginal means (and standard errors) for degrees.

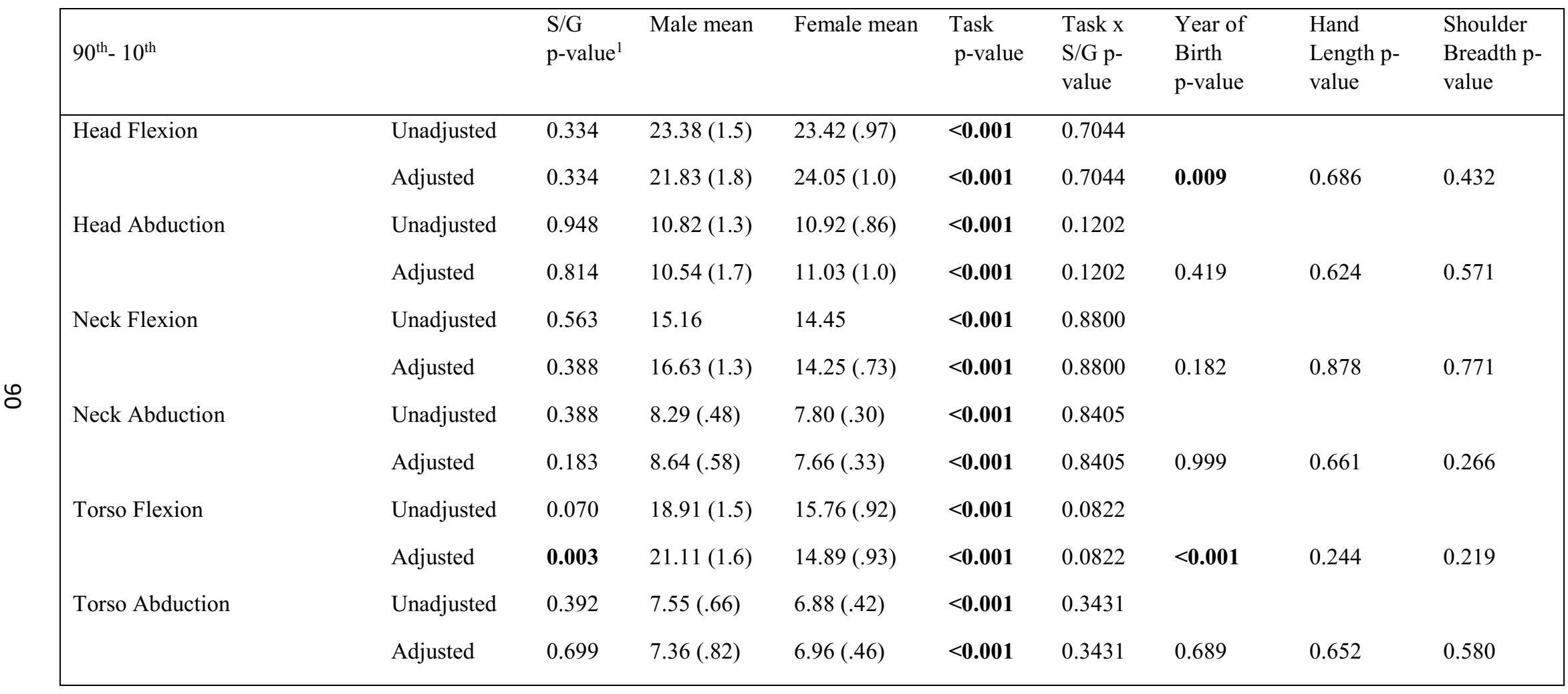

${ }^{1}$ Repeated Measures ANOVA with participant as a random variable, sex/gender, task, sex/gender $\mathrm{X}$ task interaction, year of birth, hand length, and shoulder breadth. Bold values indicate a significant effect $(p<0.05)$. 
Table 3.4: Mean Wrist Velocity and Acceleration: Across participant marginal means (and standard errors).

\begin{tabular}{|c|c|c|c|c|c|c|c|c|c|}
\hline RMS & & $\begin{array}{l}\text { S/G p- } \\
\text { value }^{1}\end{array}$ & Male mean & Female mean & $\begin{array}{l}\text { Task } \\
\text { p-value }\end{array}$ & $\begin{array}{l}\text { Task x S/G } \\
\text { p-value }\end{array}$ & $\begin{array}{l}\text { Year of } \\
\text { Birth } \\
\text { p-value }\end{array}$ & $\begin{array}{l}\text { Hand } \\
\text { Length } \\
\text { p-value }\end{array}$ & $\begin{array}{l}\text { Shoulder } \\
\text { Breadth } \\
\text { p-value }\end{array}$ \\
\hline \multirow[t]{2}{*}{ Right Wrist Flex Velocity } & Unadjusted & 0.292 & $26.55(1.4)$ & $24.83(.89)$ & $<0.001$ & 0.559 & & & \\
\hline & Adjusted & 0.236 & $27.17(1.7)$ & $24.57(.99)$ & $<0.001$ & 0.559 & 0.582 & 0.733 & 0.634 \\
\hline \multirow[t]{2}{*}{ Left Wrist Flex Vel } & Unadjusted & 0.643 & $22.17(.90)$ & $21.68(.58)$ & $<0.001$ & 0.979 & & & \\
\hline & Adjusted & 0.472 & $22.56(1.1)$ & $21.52(.65)$ & $<0.001$ & 0.979 & 0.775 & 0.864 & 0.598 \\
\hline \multirow[t]{2}{*}{ Right Wrist Radial Velocity } & Unadjusted & 0.021 & $14.40(.65)$ & $16.22(.42)$ & $<0.001$ & 0.630 & & & \\
\hline & Adjusted & 0.252 & $14.87(.79)$ & $16.02(.45)$ & $<0.001$ & 0.630 & 0.039 & 0.083 & 0.732 \\
\hline \multirow[t]{2}{*}{ Left Wrist Radial Velocity } & Unadjusted & 0.159 & $12.57(.52)$ & $13.45(.34)$ & $<0.001$ & 0.924 & & & \\
\hline & Adjusted & 0.603 & $12.88(.65)$ & $13.31(.38)$ & $<0.001$ & 0.924 & 0.616 & 0.956 & 0.473 \\
\hline \multirow[t]{2}{*}{ Right Wrist Flex Acceleration } & Unadjusted & 0.079 & $383(21)$ & $337(14)$ & $<0.001$ & 0.121 & & & \\
\hline & Adjusted & 0.144 & $386(27)$ & $336(16)$ & $<0.001$ & 0.121 & 0.849 & 0.943 & 0.761 \\
\hline \multirow[t]{2}{*}{ Left Wrist Flex Acceleration } & Unadjusted & 0.212 & $286(13)$ & $267(8.2)$ & $<0.001$ & 0.672 & & & \\
\hline & Adjusted & 0.328 & $287(16)$ & $267(9.2)$ & $<0.001$ & 0.672 & 0.798 & 0.855 & 0.869 \\
\hline \multirow[t]{2}{*}{ Right Wrist Radial Acceleration } & Unadjusted & 0.210 & $191(9.8)$ & $206(6.3)$ & $<0.001$ & 0.988 & & & \\
\hline & Adjusted & 0.596 & $196(12)$ & $204(6.9)$ & $<0.001$ & 0.988 & 0.243 & 0.322 & 0.788 \\
\hline \multirow[t]{2}{*}{ Left Wrist Radial Acceleration } & Unadjusted & 0.558 & $151.6(6.2)$ & $155.9(4.1)$ & $<0.001$ & 0.989 & & & \\
\hline & Adjusted & 0.998 & $155(7.7)$ & $155(4.6)$ & $<0.001$ & 0.989 & 0.838 & 0.621 & 0.529 \\
\hline \multirow[t]{2}{*}{ Right Wrist Flex Velocity } & Unadjusted & 0.292 & $26.55(1.4)$ & $24.83(.89)$ & $<0.001$ & 0.559 & & & \\
\hline & Adjusted & 0.236 & $27.17(1.7)$ & $24.57(.99)$ & $<0.001$ & 0.559 & 0.582 & 0.733 & 0.634 \\
\hline \multirow[t]{2}{*}{ Left Wrist Flex Velocity } & Unadjusted & 0.643 & $22.17(.90)$ & $21.68(.58)$ & $<0.001$ & 0.979 & & & \\
\hline & Adjusted & 0.472 & $22.56(1.1)$ & $21.52(.65)$ & $<0.001$ & 0.979 & 0.775 & 0.864 & 0.598 \\
\hline
\end{tabular}

${ }^{1}$ Repeated Measures ANOVA with participant as a random variable, sex/gender, task, sex/gender X task interaction, year of birth, hand length, and shoulder breadth. Bold values indicate a significant effect $(p<0.05)$. 
Table 3.5: Applied Mouse and Keyboard Forces: Across participant marginal means (and standard errors) for \%maximum voluntary force. Mouse forces measured only during mousing tasks and keyboard forces measured only during keyboarding tasks.

\begin{tabular}{|c|c|c|c|c|c|c|c|}
\hline & & $\mathrm{S} / \mathrm{G}$ p-value & Male mean (SE) & $\begin{array}{l}\text { Female mean } \\
\text { (SE) }\end{array}$ & $\begin{array}{l}\text { Year of Birth } \\
\text { p-value }\end{array}$ & $\begin{array}{l}\text { Hand } \\
\text { Length p- } \\
\text { value }\end{array}$ & $\begin{array}{l}\text { Shoulder } \\
\text { Breadth p- } \\
\text { value }\end{array}$ \\
\hline \multirow[t]{2}{*}{ Mouse } & Unadjusted & 0.019 & $1.10(.20)$ & $1.66(.13)$ & & & \\
\hline & Adjusted & 0.499 & $1.36(.24)$ & $1.56(.14)$ & 0.280 & 0.925 & 0.019 \\
\hline \multirow[t]{2}{*}{ Keyboard } & Unadjusted & 0.019 & $0.52(.22)$ & $1.14(.14)$ & & & \\
\hline & Adjusted & 0.022 & $0.61(.17)$ & $1.10(.10)$ & 0.099 & $<0.001$ & 0.923 \\
\hline
\end{tabular}

${ }^{1}$ Repeated Measures ANOVA with participant as a random variable, sex/gender, year of birth, hand length, and shoulder breadth. Bold values indicate a significant effect $(p<0.05)$. 


\section{Discussion}

In response to observed increased prevalence of upper extremity computer related pain and disorders in women compared to men, the goal of this study was to examine the sex/gender differences in upper extremity muscle activity, postures, joint movements, and applied mouse and typing forces in office workers who used their assigned workstations during typical work tasks. Female participants used more of their maximum voluntary muscle activity and applied more of their maximum force when mousing and typing. Few significant differences were observed in joint postures or movements.

The results suggest there is a sex/gender difference in forearm muscle activity and typing force during computer usage, especially typing. There was a significant interaction in median muscle activity between sex/gender and task, and female participants' wrist extensors are more affected by keyboarding tasks. In addition, female participants used significantly more of their maximum voluntary typing forces. This result is similar to Coppola et al. (2019) which found that female participants were more affected by differences in keyboard designs. These higher muscle activities and typing forces over time could lead to forearm symptom development (Feuerstein, Armstrong, Hickey, \& Lincoln, 1997; Marcus et al., 2002; Pascarelli \& Kella, 1993). High wrist muscle activity is also associated with neck and shoulder disorders (Nordander et al., 2016).

This study did not find sex/gender differences in most joint postures and movements. While posture and movement have been associated with MSDs (Nordander et al., 2016; Nordander et al., 2013) these results suggest that male and female participants were not affected differently. Interestingly, male participants had higher right shoulder flexion, right shoulder abduction, and left shoulder flexion than female participants, suggesting they were more affected 
by input device location. This is different from the results found in laboratory experiments where devices were placed in relation to participants' anthropometry (Won et al., 2009).

Motor control patterns and muscle/posture variability have been postulated as causes for the sex/gender difference in MSDs and pain symptoms(Cote, 2011; Madeleine, Mathiassen, \& Arendt-Nielsen, 2008; Nordander et al., 2016); however, this study did not find many sex/gender differences in the variability measures $\left(90^{\text {th }}-10^{\text {th }}\right)$ for muscle activity or posture. This is different from Federowich et al. (2012) and Farias Zuniga and Coté (2017) which found more shoulder variability over time in male participants compared to female participants.

These results support intervention at the device design to reduce the exertion load and exposure for women. Lower activation force input devices and smaller keyboards would reduce the forearm muscle activity required and reduce injury risk over time (Asundi and Odell, 2011). While participants all used the same study mouse, participants used their own keyboards, so it is unclear how keyboard design factors are related to the study outcomes.

This study's results should be understood within its limitations. Data were collected over a two-hour period of computer usage that was self-reported to be representative work, but this may not accurately reflect participants normal work experiences. Participants used a study mouse, which was reported to be larger and heavier than the devices they were used to. This may have affected exposure, though a benefit of this approach is that each participant was exposed to the same device over the study period. Participants were recruited among office workers in an educational setting and these results are likely attenuated by the healthy worker bias. While we expect these results to be generalizable to many office workers, they may not be generalizable to specialized workers in computer-intensive roles such as data entry or computer aided design. 
Sex/gender is a proxy for multiple biological and psycho-social characteristics, and controlling for a male/female binary may not explain the root cause of the differences observed.

This study found sex/gender differences in forearm muscle activity and applied typing forces during an observational study with office workers. The results support the importance of input design features such as activation force.

\section{Acknowledgements}

This study was supported in part by National Institute for Occupational Safety and Health (T42 OH008416). Jennifer Bruno Garza was a collaborator on this manuscript. 


\section{References}

Asundi, K., Johnson, P. W., \& Dennerlein, J. T. (2009). Inertia artefacts and their effect on the parameterisation of keyboard reaction forces. Ergonomics, 1259-1264.

Asundi, K., Odell, D. (2011) Effects of keyboard keyswitch design: a review of the current literature. Work.

Basmajian, J. V. 1989. Biofeedback; principles and practice for clinicians, Baltimore: Willams \& Wilkins.

Bruno Garza, J., Eijckelhof, B., Johnson, P., Raina, S., Rynell, P., Huysmans, M., . . .

Dennerlein, J. (2012). Observed differences in upper extremity forces, muscle efforts, postures, velocities and accelerations across computer activities in a field study of office workers. Ergonomics.

Chang, C.-H., Johnson, P. W., \& Dennerlein, J. T. (2008). A Wide Range of Activity Duration Cutoffs Provided Unbiased Estimates of Exposure to Computer Use. Journal of Occupational and Environmental Hygiene, 5(12), 790-796. doi:10.1080/15459620802491158

Coppola, S. M., Dixon, P. C., Hu, B., Lin, M. Y. C., \& Dennerlein, J. T. (2019). Going Short: The Effects of Short-Travel Key Switches on Typing Performance, Typing Force, Forearm Muscle Activity, and User Experience. Journal of Applied Biomechanics, 1-8. doi:10.1123/jab.2018-0167

Cote, J. N. (2011). A critical review on physical factors and functional characteristics that explain a sex/gender difference in work-relatedneck/shoulder disorders. Ergonomics, $55: 2,173-182$.

Farias Zuniga, A. M., \& Côté, J. N. (2017). Effects of Dual Monitor Computer Work Versus Laptop Work on Cervical Muscular and Proprioceptive Characteristics of Males and Females. Human Factors: The Journal of Human Factors and Ergonomics Society, 59(4), 546-563. doi:10.1177/0018720816684690

Fedorowich, L., Emery, K., Gervasi, B., \& Cote, J. N. (2012). Gender differences in neck/shoulder muscular patterns in response to repetitive motion induced fatigue. Journal of Electromyography and Kinesiology, 1183-1189.

Feuerstein, M., Armstrong, T., Hickey, P., \& Lincoln, A. (1997). Computer keyboard force and upper extremity symptoms. JOEM, 39(12), 1144-1153.

Gerr, F., Marcus, M., Ensor, C., Kleinbaum, D., Cohen, S., Edwards, A., \& Monteilh, C. (2002). A prospective study of computer users: I. Study design and incidence of musculoskeletal symptoms in disorders. American Journal of Industrial Medicine, 41(4), 221-235.

Hagberg, M., Vilhemsson, R., Tornqvist, E. W., \& Toomingas, A. (2007). Incidence of selfreported reduced productivity owing to musculoskeletal symptoms: association with workplace and individual factors among computer users. Ergonomics, 1820-1834.

Jensen, C., Vasseljen, O. and Westgaard, R. H. 1993. The influence of electrode position on bipolar surface electromyogram recordings of the upper trapezius muscle. European Journal of Applied Physiology and Occupational Physiology, 67(3): 266-273.

Johnson, P. W.,, Hagberg, M., Hjelm, E.W. and Rempel, D. 2000. Measuring and characterizing force exposures during computer mouse use. Scandinavian Journal of Work and Environmental Health, 26(5): 398-405.

Jonsson, B. 1988. The static load component in muscle work. European Journal of Applied Physiology and Occupational Physiology, 57: 305-310. 
Madeleine, P., Mathiassen, S., \& Arendt-Nielsen, L. (2008). Changes in the degree of motor variability associated with experimental and chronic neck-shoulder pain during a standardised repetitive arm movement. Experimental Brain Research, 185(4), 689-698. doi:10.1007/s00221-007-1199-2

Marras, W. S. 1992. Toward an understanding of dynamic variables in ergonomics. Journal of Occupational Medicine, 7(4): 655-677.

Marcus, M., Gerr, F., Monteilh, C., Ortiz, D. J., Gentry, E., Cohen, S., . . Kleinbaum, D. (2002). A prospective study of computer users: II. Postural risk factors for musculoskeletal sympotms and disorders. American Journal of Industrial Medicine, 236-249.

Messing, K., Stock, S. R., \& Tissot, F. (2009). Should studies of risk factors for musculoskeletal disorders be stratified by gender? Lessons from the 1998 Quebec health and social survey. Scandinavian Journal of Work and Environmental Health, 96-112.

Nordander, C., Hansson, G., Ohlsson, K., Arvidsson, I., Balogh, I., Stromberg, U., . . Skerfving, S. (2016). Exposure-response relationship for work-related neck and shoulder musculoskeletal disorders- analyses of pooled uniform data sets. Applied Ergonomics.

Nordander, C., Hansson, G.-Å., Ohlsson, K., Arvidsson, I., Balogh, I., Strömberg, U., . . . Skerfving, S. (2016). Exposure-response relationships for work-related neck and shoulder musculoskeletal disorders - Analyses of pooled uniform data sets. Applied Ergonomics, 55, 70-84. doi:10.1016/j.apergo.2016.01.010

Nordander, C., Ohlsson, K., Åkesson, I., Arvidsson, I., Balogh, I., Hansson, G.-Å., . . . Skerfving, S. (2009). Risk of musculoskeletal disorders among females and males in repetitive/constrained work. Ergonomics, 52(10), 1226-1239. doi:10.1080/00140130903056071

Nordander, C., Ohlsson, K., Åkesson, I., Arvidsson, I., Balogh, I., Hansson, G.-Å., . . . Skerfving, S. (2013). Exposure-response relationships in work-related musculoskeletal disorders in elbows and hands - A synthesis of group-level data on exposure and response obtained using uniform methods of data collection. Applied Ergonomics, 44(2), 241-253. doi:10.1016/j.apergo.2012.07.009

Pascarelli, E. F., \& Kella, J. J. (1993). Soft-tissue injuries related to use of the computer keyboard. A clinical study of 53 severely injured persons. Journal of Occupational Medicine, 35(5), 522-532.

Stellman, J. M., Lucas, A., \& Anderson, L. M. (2012). International Perspectives: Women's Occupational Health. In M. B. Goldman, K. M. Rexrode, \& R. Troisi (Eds.): Elsevier Science \& Technology.

Wahlstrm, J. (2005). Ergonomics, musculoskeletal disorders and computer work. Occupational Medicine, 55(3), 168-176. doi:10.1093/occmed/kqi083

Won, E. J., Johnson, P. W., Punnett, L., \& Dennerlein, J. T. (2009). Upper extremity biomechanics in computer tasks differ by gender. Journal of Electromyography and Kinesiology, 19(3), 428-436. 
Conclusion 
The objective of this dissertation was to determine whether there is a sex/gender bias in the design of modern computing technologies that leads to different upper extremity exposures in women and men. Chapter 1 described a laboratory study of four commercially available microtravel keyboards. Chapter 2 described a laboratory story that tested different tablet and software factors. Chapter 3 described an observational study of office workers.

In Chapter 1, participants experienced different forearm muscle activity, typing force, typing performance, and self-reported experience across 4 micro-travel keyboards. The results also indicated that the effect of device was different between female and male participants, and that female participants were more affected by changes in keyboard design. Overall, given similar activation force, larger key travel distances were associated with better performance and experience. Key travel alone did not predict muscle activity or typing force as the two devices with the same short travel were associated with the largest differences in outcomes. These results indicated that activation force and keyswitch mechanism are important design considerations as manufacturers continue to introduce thinner devices.

In Chapter 2, tablet software and form factors were associated with different muscle activity, performance, and self-reported experience. Female participants used significantly more muscle activity, and were affected differently by tablet orientation and swipe location compared to male participants. The study's results demonstrated the importance of including both women and men in usability testing. In addition, user interface design can be an important factor for mitigating upper extremity MSD risk.

Finally, in Chapter 3, office workers were observed in their normal workstations over two hours and tested for upper extremity muscle activity, posture, joint movement, and applied device forces. Female participants used significantly more of their maximum effort for muscle 
activity and applied forces. These results further affirm the importance of designing input devices with specific people's capabilities in mind.

These results provide an important contribution towards better understanding the different exposures of women and men when using modern computing technologies. Chapters 1 and 2 quantified differences when using the same devices in a controlled laboratory experiment. These were the first studies to measure sex/gender biomechanical differences in micro-travel keyboards and touchscreen tablets. Chapter 3 adds to the sex/gender and occupational musculoskeletal pain and disorder literature. It is one of the first to quantify the different exposures in a real work environment where devices (other than the mouse) and workstation set up were not controlled by the researchers.

These results should inform future work to design and implement better technologies that are optimized for human capabilities. Women, people with disabilities, and older adults should be included from the earliest stages of user testing. More input devices such as keyboards, mice, and touchscreens should come in different sizes and with different activation forces. Instead of designing these devices for men and calling them one-size-fits-all, they should be designed specifically with women's capabilities in mind. In addition, more studies are necessary to quantify and validate exposures. In addition to controlled laboratory experiments with new technology, we need longitudinal randomized control trials with different devices that measure both the direct biomechanical exposures and health outcomes.

In conclusion, this dissertation provides original contributions to the field of ergonomics and understanding of sex/gender and new technology. Specifically, it examined biomechanical exposures in mobile computers, desktop computers, and tablet devices in both laboratory and field settings. Understanding the sex/gender difference in upper extremity exposures will help to 
better explain the observed increased upper extremity injury and pain in women as compared to men. These results will inform better design and usage guidelines as well as increase occupational equity. 